\title{
A BIOLOGICAL AND CYTOLOGICAL STUDY OF SEX DETERMINATION IN PHYLLOXERANS AND APHIDS
}

BY

T. H. MORGAN

With One Piate and Twenty-threx Figures in Text

PART I

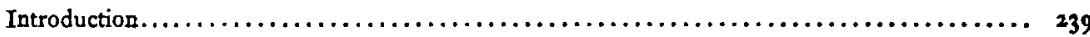

The life cycle of Phyllorerans. . . . . . . . . . . . . . . . .

Sex determination in Phylloxera fallax................................... 244

Sex determination in Phyllorera caryæcaulis. . . . . . . . . . . . . . .

Precocious sexual differences correlated with male and fernale eggs $\ldots \ldots \ldots \ldots \ldots \ldots \ldots \ldots \ldots$ 270

Is the elimination of the sex chromosomes fortuitive or determinative..$\ldots \ldots \ldots \ldots \ldots \ldots \ldots 273$

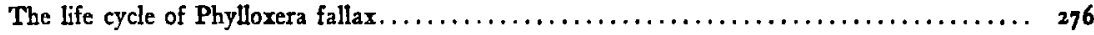

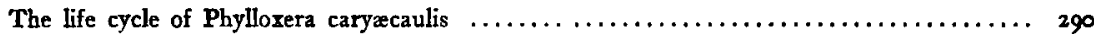

The serual (?) forms of other species................................. 293

Spermatogenesis in aphids........................................ 298

Cytological parallel between P. caryæcaulis and Syromastes marginatus ............. 305

PART II

Critical review of the recent literature.

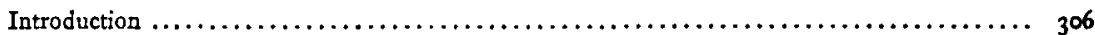

The cytological evidence......................................... 307

The influence of environment on parthenogenetic development.................. 314

The problem of the three chromosomes................................. 322

The botanical experimental evidence................................ 326

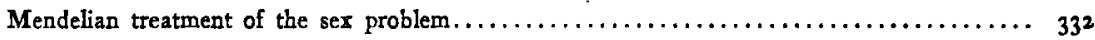

Sex determination as the result of a quantitative relation $\ldots \ldots \ldots \ldots \ldots \ldots \ldots \ldots \ldots \ldots \ldots 3^{6}$

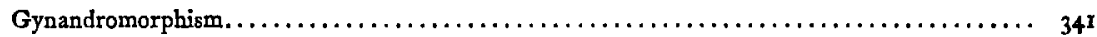

Theoretical Discussion. $\ldots \ldots \ldots \ldots \ldots \ldots \ldots \ldots \ldots \ldots \ldots \ldots \ldots \ldots \ldots \ldots \ldots \ldots \ldots \ldots \ldots \ldots \ldots \ldots, 344$

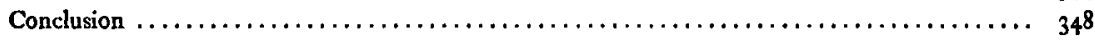

PART I

INTRODUCTION

The results described in the following pages are the outcome of sevelal years' work. In I903, when I first began to study the aphids, the possibility that sex is determined by external conditions was the general opinion of zoölogists. The observations of Dageer and Kyber in particular on the aphids seemed to show

The Journal of Experimental. Zoölogr, vol. vir, No. 2. 
that either temperature or food is the sex-determining factor in this group. On this interpretation it might seem possible to regulate sex by controlling the conditions under which the aphids were kept. In the autumn of I903 Miss. N. M. Stevens and I began our work on the group with these ideas in mind. Miss Stevens undertook the histological examination, while the experimental work was to be done conjointly. The former yielded the results that Miss Stevens published in 1905 , but the experimental work gave only negative results. None of the external conditions to which we subjected the rose aphid produced the change from the parthenogenetic to the sexual forms. Later I tried a long series of other experiments in which twigs of the rose with aphids on them were kept in solutions of various salts, magnesium, calcium, potassium, lithium. The solutions, drawn up into the stem by the evaporation from the leaves should be imbibed by the aphids which procure their food by sucking the juices of the plant. These it was hoped might cause a change in the mode of reproduction. The results were negative.

Observations made during the course of the experiments soon convinced us that temperature, at least, is not the cause of the change in the cycle in the rose aphid; for we found that the sexual forms may appear in the late summer before the cool weather has begun. Furthermore late in the autumn parthenogenetic individuals can always be found on the ends of the young twigs of the rose. In one case I kept a potted rose outside of a window and aphids remained on it until December, even after a freezing temperature outside. If brought into the green-house, these terminal aphids may continue to multiply throughout the winter without reproducing sexually. The facts show that temperature need take no direct part in the change in mode of reproduction; they also show that the conclusions that have been drawn from Kyber's experiments are doubtful. The continued parthenogenesis of aphids brought into the greenhouse need not mean that the result is due to removal from the effects of cold, but that those individuals having escaped, so to speak, the influences, whether internal or external, that cause the cyclical change, continue to reproduce by parthenogenesis. Whether, having escaped at the critical period 
they could ever subsequently be caused to produce the sexual forms, is not known, but there is nothing that we know opposed to such a view.

Through the courtesy of Prof. W. J. Gies, an analysis was made by Dr. W. Berg of the leaves of the rose and of the maple. The first analysis was made in June when the young aphids had just emerged; the second late in the autumn when the leaves were old and the sexual forms had appeared. There is no very great difference between the two sets of leaves as the accompanying table shows. There is more water in June and more starch in October. The ash is also greater in October. These are the only clues that the analyses furnish as to differences in the food plants. Of course there may be many other substances present that differ in amount not brought out by an analysis of this kind.

\begin{tabular}{|c|c|c|c|c|c|c|c|c|}
\hline & \multicolumn{4}{|c|}{ ROSE LIAF } & \multicolumn{4}{|c|}{ KAPLE IEAF } \\
\hline & \multicolumn{2}{|c|}{ October, 1905.} & \multicolumn{2}{|c|}{ June, 1906.} & \multicolumn{2}{|c|}{ October, 1905.} & \multirow{2}{*}{\begin{tabular}{|c|} 
June, \\
fresh
\end{tabular}} & \multirow{2}{*}{$\frac{1906 .}{d r y}$} \\
\hline & fresh & $d r y$ & fresh & $d r y$ & fresh & $d r y$ & & \\
\hline Water................. & 60.25 & & 63.39 & - & $63 \cdot 37$ & - & 72.79 & - \\
\hline Total nitrogen........... & $0.79 \pi$ & 2.004 & 0.971 & 2.645 & 0.914 & 2.495 & 0.86 & 3.16 \\
\hline Ether extract.......... & 3.09 & $7 \cdot 78$ & $2.23^{8}$ & 6.114 & 2.15 & 5.86 & 2.10 & 7.719 \\
\hline $\begin{array}{c}\text { Water soluble reducin } \\
\text { substances, calculated } \\
\text { as dextrose........... }\end{array}$ & 2.12 & $5 \cdot 33$ & 2.754 & $7 \cdot 503$ & $2.3^{64}$ & 6.453 & 1.102 & 4.050 \\
\hline $\begin{array}{l}\text { Starch (total reducing } \\
\text { sugars calculated a }\end{array}$ & & & & & & & & \\
\hline dextrose, $x \quad 0.9 \ldots \ldots$ & 6.42 & 16.15 & $6.63^{*}$ & $18.06 *$ & $4.08 \mathrm{I}$ & II.I4 & 3.648 & 13.40 \\
\hline Ash $\ldots \ldots \ldots \ldots \ldots \ldots$ & $3.6 \mathrm{x}$ & 9.085 & 3.069 & 8.215 & 4.775 & 13.10 & 2.064 & 7.586 \\
\hline
\end{tabular}

The foregoing discussion is not intended to imply that external conditions are not potent factors in the life cycles of species with alternating sexual and parthenogenetic reproduction. On the contrary, I am prepared to accept such a view despite the negative result of the experiments; but one fact of capital importance has been, I think, overlooked in the interpretation that has been applied to the facts. The results show that whatever the conditions are that bring about the transformation, the change involves the pro- 
duction of both sexual forms, the male and the sexual female; hence the conditions do not determine sex in the sense of producing either males or sexual females, but bring to an end parthenogenetic and introduce sexual reproduction. It follows, I think, with probability that we are dealing with two different things here, and that confusion has resulted from supposing them to be the same.

These ideas led me to abandon the hope of finding the clue to sex determination in the external conditions, however important these factors may be in cyclical changes in sex production. In recent years the repetition, by several zoölogists, of the older experiments on tadpoles, caterpillars, etc., that had been accepted as demonstrating the influence of external conditions, has shown with great probability that those experiments did not establish their claim. The discovery at the same time of an internal mechanism associated with sex determination has gradually brought conviction that internal and not external factors determine sex.

In the group of insects, and especially in the group of Hemiptera to which the aphids belong, sex determination has been shown to be associated with an internal factor with which the number or the kind of chromosomes is closely linked. Therefore we should expect, a priori, to find in the aphids some similar factor, if we are to ascribe to it any profound significance.

The most hopeful field for investigation seemed to be in cases where eggs of different sizes exist associated with male and female development. In the phylloxerans, near relatives of the aphids, these conditions are found. The presence in America of many species of Phylloxerans on the hickories gave me the opportunity I sought, and a fortunate discovery of two species, in which the sexual eggs could be obtained in vast numbers, has made the working out of the problem possible, although extremely laborious. My first results were published in I906; since then I have continued to study the group, but only during the spring and summer of 1907 did I obtain the material that has made it possible to work out, not only the spermatogenesis, but the entire cycle of cytological phenomena. The main facts in regard to the spermatogenesis were made out in October and November, 1907, and the briefest possible statement of the main facts was given before the Society 
of Experimental Biology and Medicine, 1908, reserving the complete account until the whole story could be told. The results there published on Phylloxera have been confirmed by von Baehr, I 908 , and by Stevens on aphids, I909. I had also studied the aphids and convinced myself of the identity of the main processes with those of Phylloxerans.

\section{THE LIFE CYCLE OF THE PHYLLOXERANS}

A definite and limited number of generations is passed through by the Phylloxerans of the hickory. In the spring the stem-mother hatches from the winter egg. When the leaves first burst from the bud she attaches herself to the under surface, and piercing the leaf with her proboscis causes the gall-like growth that gradually surrounds her. She soon begins to lay eggs that develop parthenogenetically. These eggs I shall call the stem-mother's eggs. In most species they produce winged individuals, all alike externally, but some carry male eggs only, others female eggs only. This generation I shall refer to as the winged forms, or the second generation. Their eggs I shall call male and female eggs. The male egg is considerably smaller than the female egg, and more of them are present in the adult animal. In most species the winged forms leave the galls to deposit their eggs on the twigs, trunks or leaves of hickory trees. The eggs hatch in about a week. The small eggs produce the minute acrive males (Plate I, Fig. I), ready to fertilize the females as soon as they hatch; the large eggs produce the sexual females (Plate I, Fig. 3), each containing a single egg, relatively enormous as compared with the size of the female, but in reality no larger than the parthenogenetic eggs of the preceding generations. The female is also sexually ripe very soon after hatching. She is fertilized by a male and deposits her egg on a branch of the tree. From this egg-the winter egg-the stemmother emerges the following spring.

There are certain deviations from this typical cycle which will be referred to in their proper place. 


\section{SEX DETERMINATION IN PHYLLOXERA FALLAX}

This species is found abundantly in the vicinity of New York on young hickories, or on the lower leaves of older trees. When well infected the leaves are covered thickly with the conical galls. There is some question as to the identification of the species owing to differences of observation as to its life cycle. A discussion of this matter is relegated to another section. Here it will suffice to say that in many galls the winged generation is replaced by wingless individuals (Fig. XVIII, $A$ ), and these lay the male and female eggs within the gall itself, where they hatch. Owing to this unusual habit it is possible to collect quantities of the sexual eggs and embryos. The formation of the spermatozoon takes place within the male embryo before it hatches. Abundant material for the study of spermatogenesis is therefore readily obtained.

The stem-mother begins to deposit her eggs, one at a time, before the gall reaches full size. The number of eggs is variable, and since the first may hatch, and grow up into an adult which begins to lay, before the stem-mother has completed her series, there may be some overlapping of the two sets of eggs. The number of eggs

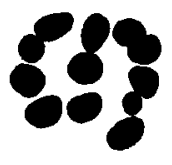

$A$

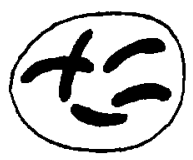

$D$

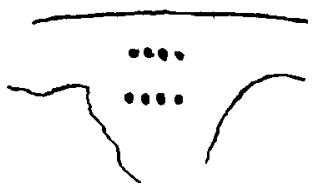

$B$

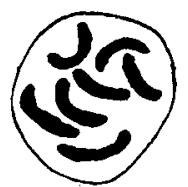

E

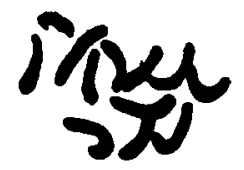

C

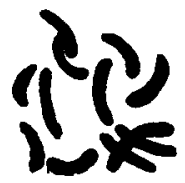

F

Fig. I P. fallax. $A$, Equatorial plate of a polar spindle of egg of stem-mother; $B$, side view of polar spindle; $C$, chromosomes of somatic cell of embryo from egg of stem-mother; $D-E$, two sections of nucleus of same; $F$, another nucleus of same. 
laid by the stem-mother varies from one to 60 or more, Different stem-mothers produce different numbers; sometimes sterile individuals are found, sometimes the death of the stem-mother occurs after the gall has begun, in which case its further growth stops.

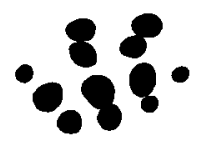

$A$

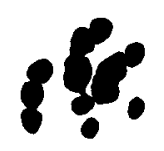

$D$

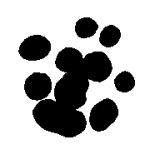

$B$

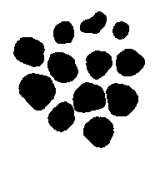

$E$

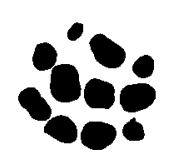

C

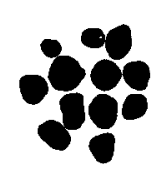

$\boldsymbol{F}$

Fig. II $A-F$, equatorial plates of polar spindle of eggs of winged individuals.

Before the egg is laid the polar spindle is formed. As shown in Fig. I, $A$, twelve chromosomes of unequal sizes are present. After the egg is laid a single polar body is formed. The nucleus, remaining in the egg, to judge from the chromosomes in its later divisions, contains also twelve chromosomes. This number seems to be characteristic of all the embryos derived from the stem-mother's egg, despite the fact that an important change has probably been initiated already, for some of the embryos produce adults that are male layers; others, female layers. In Fig. I, $C-F$, the chromosomes of embryos from the stem-mother's eggs are shown. The number seems to be twelve in all cases.

As stated, there are two kinds of individuals of the second generation in $\mathrm{P}$. fallax-the winged and the wingless. Comparison with other species makes probable the view that the wingless forms have been secondarily derived, and replace the winged. 


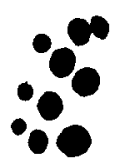

G

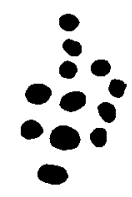

K

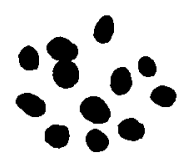

0

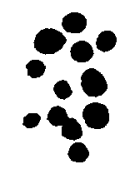

H

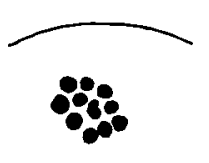

$L$

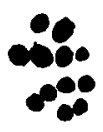

I

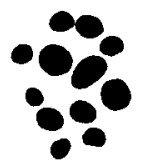

M

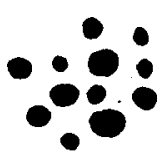

J

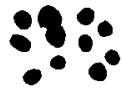

N

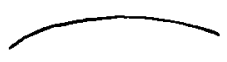

1000

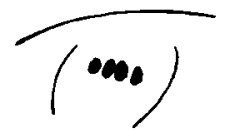

2

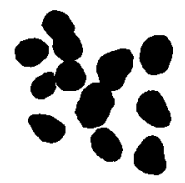

$R$

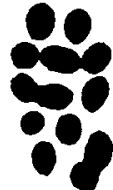

$S$

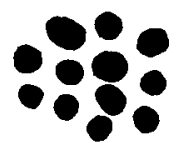

$\mathcal{T}$

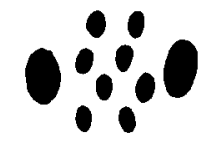

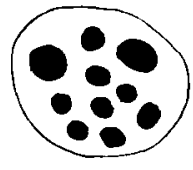

$U$

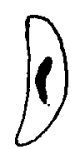

0.

V

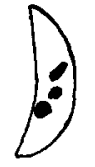

W

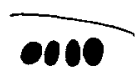

$X$

Fig. IIa $G-0, R-T$, equatorial plates of polar spindle of egg of winged individuals; $P-Q$, side views of same; $U, V, W$, polar spindles of eggs of wingless individuals; $X$ side view of same. 
It is curious to note that the wingless generation bring to maturity one egg (seldom more) at a time, as does the stem-mother, whom, in fact, the wingless forms resemble externally. It has been difficult to get flat views of the polar spindle of the eggs of these wingless individuals. The only two clear cases found are shown in Fig. II $a, U$ and $W$. Each shows ten chromosomes of which two are noticeably larger than the others and beyond doubt represent a pair of fused chromosomes. I have found eight plates $(K-O$, $R-T$ ) with 12 chromosomes each, and nine plates with 12 chromosomes (Figs. II, and II $a-I$ ) in two winged individuals. All of the winged individuals that I have found-some 300 in number-contained only small eggs and are therefore male-producers.

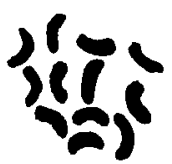

$A$

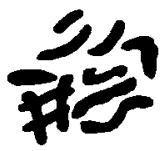

$B$

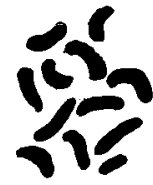

C

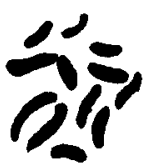

$D$

Fig. III $A-D$, chromosomes of somatic cells of female embryos.

As soon as the eggs are laid-male or female-a single polar body is given off. It has not been possible to count definitely in this species the number of chromosomes eliminated in the polar body, but the subsequent results show that the outcome must be the same as in P. caryæcaulis where the chromosomes in the polar body can be counted.

After the polar body is given off the female egg still contains twelve chromosomes, as the count of those in the embryonic cells shows (Fig. III, $A-D$ ). On the other hand only ten chromosomes are found in the embryonic cells of the male (Fig. IV, $A-D$ ). Two have disappeared. In the light of our general knowledge of chromosome behavior two possible explanations of their disappearance may be offered; either in two cases two have fused into 
one, so that eight single and two double chromosomes are present, or two entire chromosomes are given off into the male polar body. On the former alternative we should expect to find two chromo-

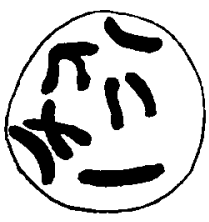

$A$

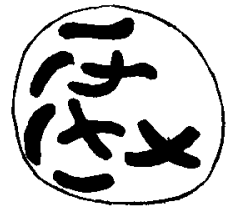

$B$

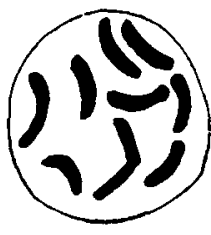

C

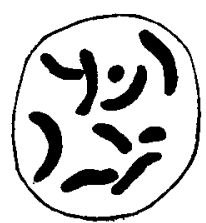

D

Fig. IV Chromosomes of somatic cells of male embryos.

somes twice as large as the rest if the larger rather than the smaller chromosomes are involved, but such is not the case. In the other species I shall bring forward evidence to show that two whole

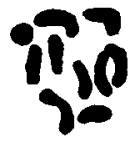

$A$

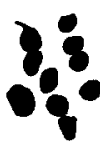

E

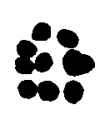

$I$

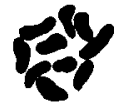

$B$

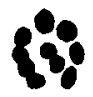

F

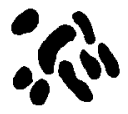

于

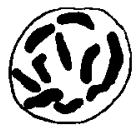

C

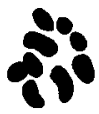

$\boldsymbol{G}$

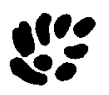

$K$

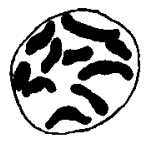

$D$

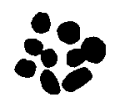

$\boldsymbol{H}$

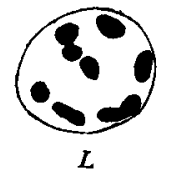

Fig. V Chromosomes of spermatogonial cells of male.

chromosomes are in fact sent out into the polar body at the time when all the others divide. 
The ten chromosomes of the male embryo (Fig. IV, $A-D$ ) are shown to be of nearly equal size. We should expect two to be much larger than the rest if they have not divided at the polar body stage when other pairs were thrown out unless these were the smaller chromosomes. It is difficult to determine the size relations in the somatic cells with sufficient precision to settle this point. In the spermatogonia the chromosomes may sometimes be counted, and the number counted was nine or ten (Fig. V, $A-L$ ). Ten is undoubtedly the full number.

We come now to the two spermatocyte divisions in one of which the behavior of the chromosomes is of great interest. The synapsis stage has not been especially studied. As the chromosomes emerge from synapsis their number is found to be reduced to six equal or nearly equal chromosomes (Fig. VI, $A-C$ ). These six chromosomes represent four double chromosomes produced by the pairing of eight of the spermatogonial chromosomes, and two unpaired chromosomes.

This stage is found in such abundance that we must suppose it to be a temporary halting-place. Each of the four double chromosomes divides-separating into its elements, according to current interpretation. As they move apart it is seen that two of the chromosomes draw out, but show no line of division, as do the other paired chromosomes (Fig. VI, $D-G$ ). The process continuing, the four pairs become widely separated, while the two lagging become slightly elongated (Fig. VI, $H$ ). It is also important to note that these two chromosomes often unite into a single body by lateral fusion, more or less complete. Of course the appearance of fusion is produced when one chromosome lies slightly above the other, but excluding all such cases, there still remains abundant evidence to show that these chromosomes are sometimes apposed at this stage so closely as to present the appearance of fusion.

The behavior of these two shows unmistakably that they represent the accessory, lagging, odd, or sex chromosomes of other hemiptera.

As the chromosomes separate further the protoplasm shows a constriction at first near the middle of the cell, but as the separation continues it slips more and more towards one end (Fig. VI, 
$H-K)$. The accessory chromosomes now begin to contract and clearly move towards one pole, always to that lying in the larger cell. At the same time the chromosomes at the opposite pole fuse or stick together, and the surrounding cytoplasm, retreating to the

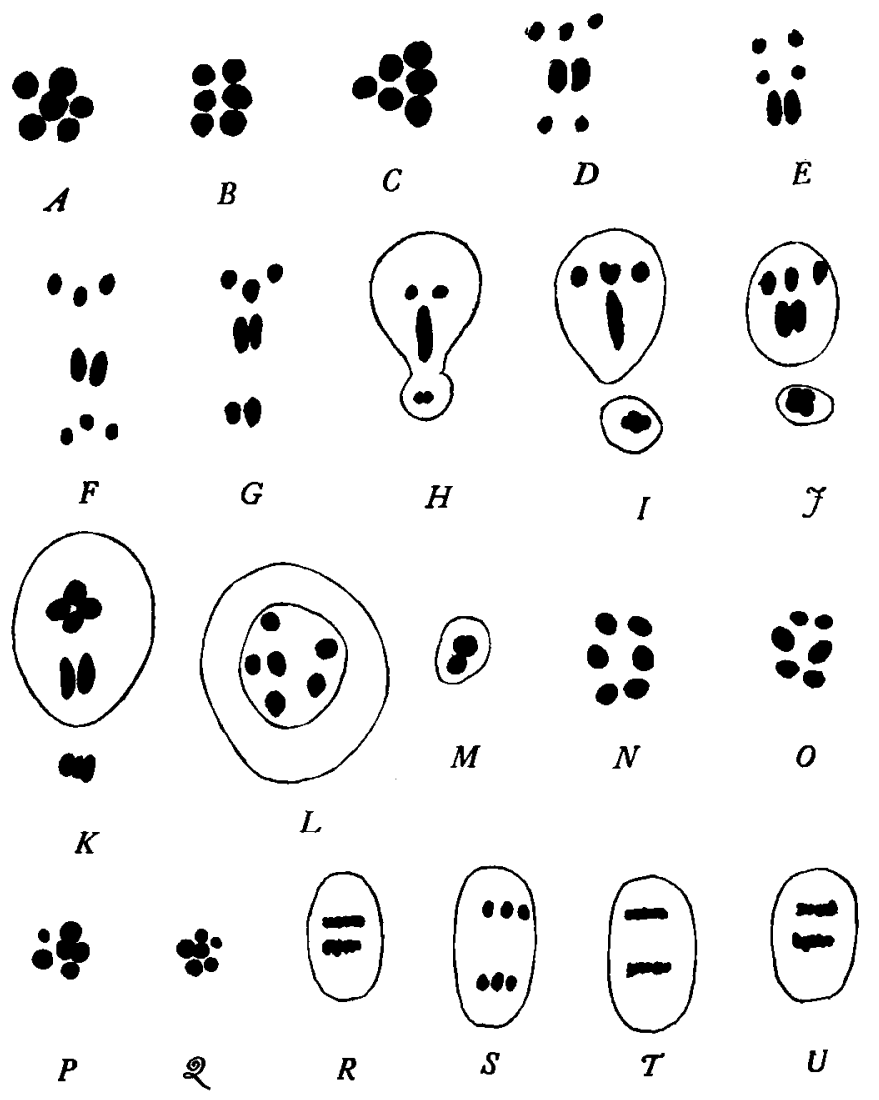

Fig. VI Spermatogenesis: $A-C$, equatorial plates of first spermatocytes; $D-I$, dividing first spermatocytes; $K-M$, after division; $N-2$, equatorial plates of second spermatocytes; $2-U$, dividing second spermatocytes.

larger cell (as the constriction passes down), there is produced a small cell containing four fused chromosomes, and a large cell containing six, i. e., four separate chromosomes and the two accessories. A nuclear space has appeared around the four chromosomes in the 
larger cell even before the accessories have quite approached that region. As they move in, they, with the rest, become enclosed in a common nuclear wall.

This first spermatocyte division is of unusual significance. Hundreds of nuclear stages have been examined, and they all tell clearly the same story. It is certain that the accessories do not divide, but pass entire to one of the two cells formed at the first spermatocyte division. It is true that they are somewhat elongated at one stage, and sometimes give an impression that they are about to divide; but later they contract and pass over entire into the larger cell.

The resting stage following the first division is shown in Fig. VI, $L-M$. In many cases all six chromosomes can be counted in the larger cells. The small cells come to lie in the corners between the larger cells, or often at the outer wall of the follicle. The chromosomes form a dense mass, staining deeply in iron hæmatoxylin. Their presence in a follicle shows that the cells have passed through the first division-a point not easily made out from the size of the larger cells alone since these, from their mode of origin, necessarily approach closely the size of the prespermatocyte cells.

Equatorial plates of the second spermatocyte are relatively less abundant. Some of them are represented in Fig. VI, $N-Q$. Four of the chromosomes are sometimes seen to be smaller than the other two-owing to the non-division of the latter. The chromosome plate is more compact, and it is difficult to obtain cases where the chromosomes are distinct.

At the second spermatocyte division all the chromosomes of the larger cells divide equally. There are none that lag behind the rest (Fig. VI, $R-U$ ). Two equal cells result, and these become spermatozoa, each carrying six chromosomes.

The small rudimentary cells, present after the first spermatocyte division, do not divide, as far as I have observed, at the time when the large second spermatocyte cells divide. They remain in the follicles as dark bodies which can be identified for some time later when they disappear without producing spermatozoa.

Let us return to the female line. We have seen that the polar 
spindle of the female egg contained twelve equal chromosomes. The somatic cells of the female also contain twelve chromosomes. These embryos become sexual females (Plate I, Fig. I); each carrying a single egg. Before the sexual or winter egg is laid its polar spindle is produced. One clear case that I found showed six chromosomes. Evidently the expected reduction has occurred which from analogy must lead to the extrusion of two polar bodies. In the aphids, in fact, two polar bodies have been found by Blochman and later by Stevens, to be extruded from the winter egg. After the polar body formation, the egg should contain six univalent elements - the same number contributed by the male. Hence the fertilized winter egg will contain twelve chromosomes, corresponding to the number found in the parthenogenetic eggs.

With the preceding facts as a basis, we can sum up the chromosomal history of P. fallax as follows, beginning with the spermatozoon.

The functional spermatozoon contains two accessory or sex chromosomes and four others. The unfertilized sexual egg contains likewise two chromosomes, the homologues of the accessory chromosomes, and four others. The fertilized eggs contain, therefore, four accessory chromosomes and eight others. Consequently the stem-mother contains these twelve chromosomes, all of which appear in the polar spindle of her egg. One polar body is extruded, all twelve chromosomes dividing, twelve go out and twelve remain in the eggs. The eggs are destined to become female-producing and male-producing individuals; both sets of individuals, as well as their ripe eggs containing twelve chromosomes. The female eggs are larger than the male eggs. Each gives off a single polar body. In the female all twelve chromosomes presumably divide equally - twelve going out, twelve remaining in the egg. In the male egg, on the contrary, two of the accessories are presumably given off with the polar body, ten chromosomes remaining in the egg. The two entire chromosomes given off at this time must be the partners of the accessories; hence we can understand how in the male two of the chromosomes have no partners, and therefore cannot pair during synapsis. They pass over in the first division to one pole at the time when the other paired chromosomes separate. 
This occurs at the first spermatocyte division. In the second spermatocyte division the larger cell containing six chromosomes divides, each chromosome dividing. Two spermatids result.

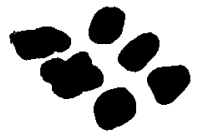

A

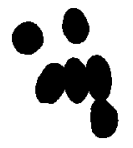

E

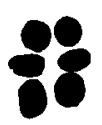

I

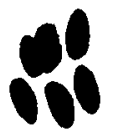

M

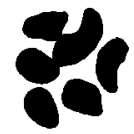

B

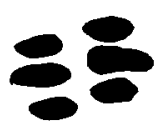

F

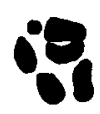

F

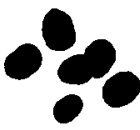

N

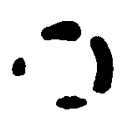

C

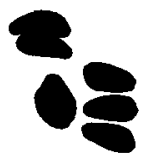

G

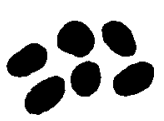

K

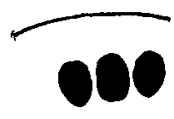

o

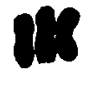

D

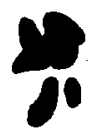

H

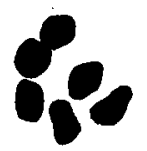

$L$

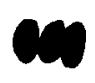

2

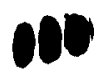

$R$

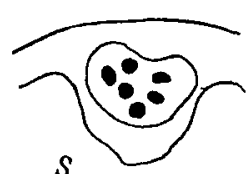

$S$

Fig. VII Phylloxera caryæcaulis. $A, B, E-N, P, S$, equatorial plate of eggs of stem-mother; $C$, polar body of same egg; $D, O, 2, R$, side views of polar spindle.

The small cells, containing only four chromosomes, do not divide, and later degenerate.

In the sexual female there is presumably a synapsis period, the twelve chromosomes pairing to give six bivalents. Two polar 
bodies are given off, one chromosomal division being equatorial, the other reductional, in the ordinary sense, i. e., the reduced number of chromosomes appears; so that two of the sex chromosomes pass into one of the polar bodies; their partners remaining in the egg. The egg having two accessories gets two more accessories from the functional spermatozoon which accounts for the four accessories that our analysis calls for.

\section{SEX DETERMINATION IN PHYLLOXERA CARYACAULIS}

'The life cycle in this species is typical of the group. The chromosomal history is as follows: The polar spindle of the stem-

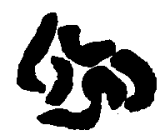

$A$

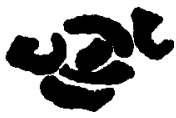

$D$

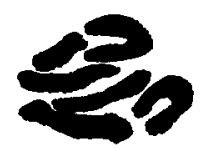

$B$

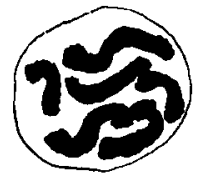

E

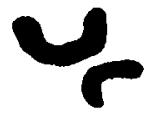

$H$

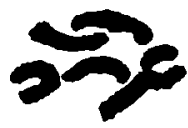

C

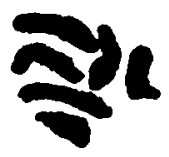

I

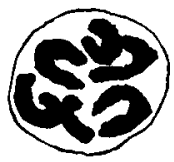

C

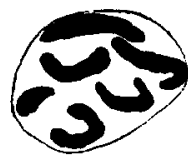

$F$

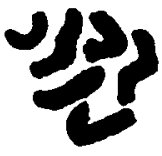

F

Fig. VIII $A-\mathcal{F}$, chromosomes of embryo from stem-mother's egg. $H$, shows only two chromomomes, for size relations.

mother's egg contains six chromosomes of nearly equal size (Fig. VII, $A, B, E-N, P, S$ ). These eggs give off a single polar body (Fig. VII, $C$ ).

The cells of the embryos contain six chromosomes, as shown in Fig. VIII, $A-\mathcal{f}$. It is a point of some importance to know 
whether the chromosome group is the same for the female-producing and for the male-producing embryo. The observations leave the point in doubt since no differences were found, but the number of cases was not large.
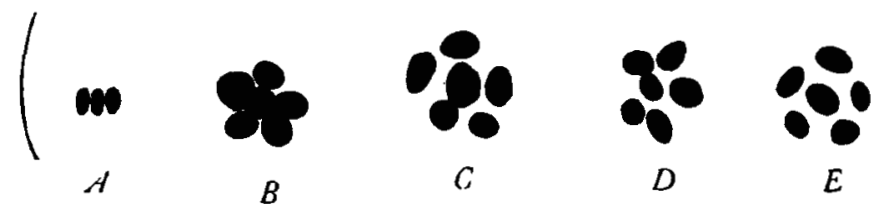

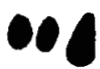

F

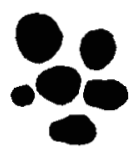

l

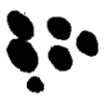

$N$

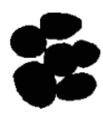

$S$

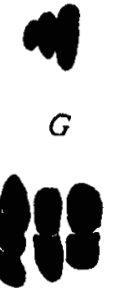

$K$

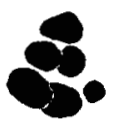

$P$

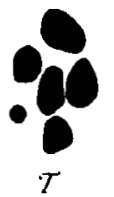

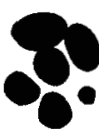

0

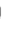

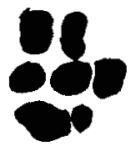

f

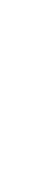

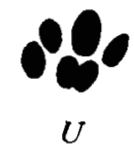

000

$H$

Fig. IX $B-E$, equatorial plates of polar spindle of female egg; $A$, side view of same; $I-W$, equatorial plates of polar spindle of male eggs; $F-H$, side views of same.

The female-producing winged form of the next generation contains a few large female eggs. The polar spindle in these eggs contains a group of six nearly equal chromosomes as seen in Fig. IX, $A-E$. In the polar spindle of the male egg of other winged individuals there are also six chromosomes, but of very unequal sizes (Fig. IX, $I-W$ ). There is one largest chromosome, almost twice 
as big as the medium-sized ones, and one smallest, much smaller than the medium ones. Evidently some change has occurred which, without altering the number of the chromosomes, has given them different sizes. The meaning of this change will be apparent later.

A single polar body is given off from the female and from the male eggs. I have studied the polar body formation in this species with great care and have tried for a long time to obtain demonstrative telophase stages. The accumulative evidence is convincing, I think, although despite the long labor that the search has involved I have not yet found a case in which in the telophase both daughter plates could be counted except for one female egg.

In this female egg, as shown in Fig. $X, \mathcal{F}$, the chromosomes divided equally, six going into the polar body and six remaining in the egg.

In the male egg I have found no case in which both daughter plates can be counted, but in one case the outer plate showed six distinct chromosomes. Polar bodies show in the best cases at least six chromosomes as seen in Fig. X, $C-I$.

The number of chromosomes left in the egg can be determined by the number found in the embryonic cells. Here a curious fact comes to light. In some male embryos all the cells contain five chromosomes of nearly equal sizes-one can often be seen to be larger than the rest-and the others can be sorted into two pairs (Fig. XI). In other male eggs there are six chromosomes - one of them being much smaller than the others, and generally, though not always, connected with one end of another chromosome (Fig. XII). A comparison of size-relations shows that the smallest chromosome here corresponds to the smallest in the polar spindle of the male egg. It would seem to be absent in the other-the fivetype-but facts to be developed later show beyond doubt that it is not absent, but united to one of the other chromosomes. Thus in the cells of the male embryo the chromosomal number is six, the same number counted in the females. The result seems at first incompatible with that for the other species in which the male contains two less chromosomes than the female. In reality the results agree; for, here the true female number will be shown to be eight, 

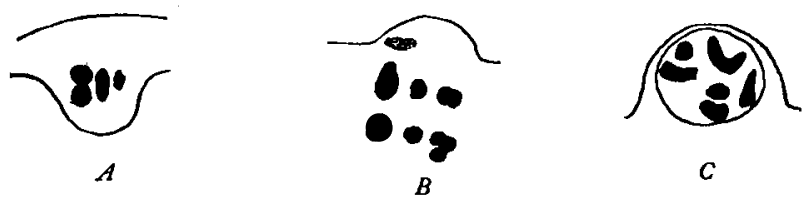

c
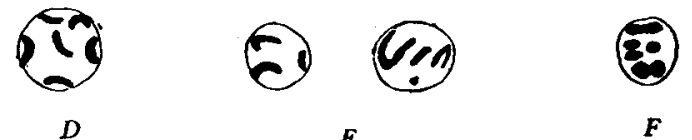

D

$\boldsymbol{E}$

F
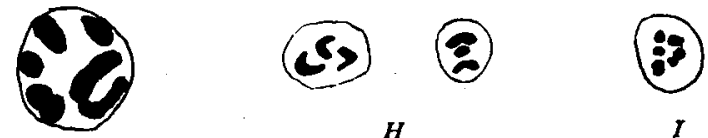

H

I

G
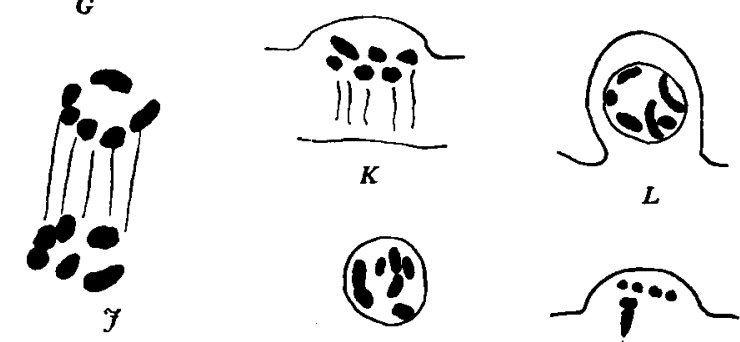

$\boldsymbol{L}$

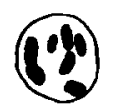

$\boldsymbol{M}$
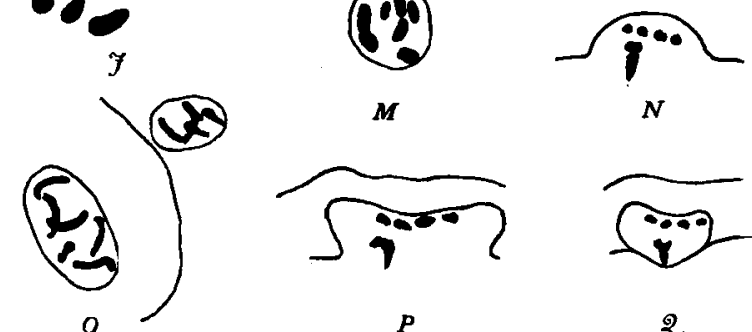

o

$\boldsymbol{P}$

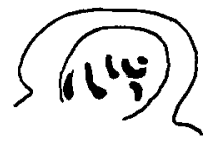

$\boldsymbol{R}$

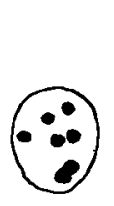

$s$

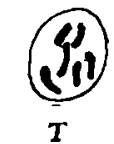

$T$

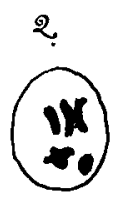

$\boldsymbol{U}$

Fig. $\mathrm{X} A-I$, polar spindle and polar body of male egg; $A$, polar spindle; $B$, dividing polar plate; $C-I$, polar body; $\mathcal{F} O$, polar spindle and polar body female egg; $\mathcal{F}$, telophase; $K$, outer pole of another telophase, inner pole lost; $L-N$, polar body; $O$, polar body and female pronucleus with six chromosomes; $P-U$, polar bodies of eggs, sex of egg not determined. 


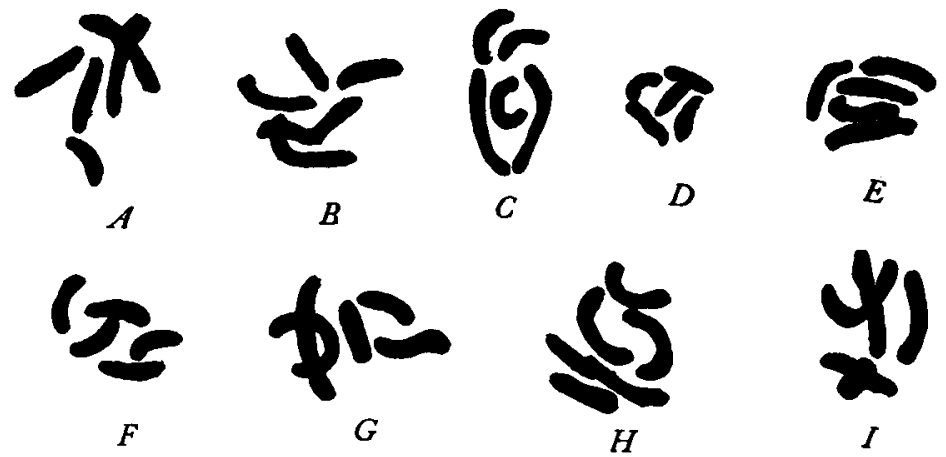

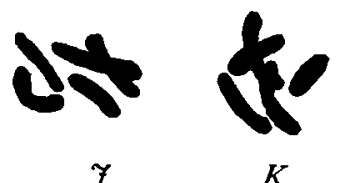

III

$O$
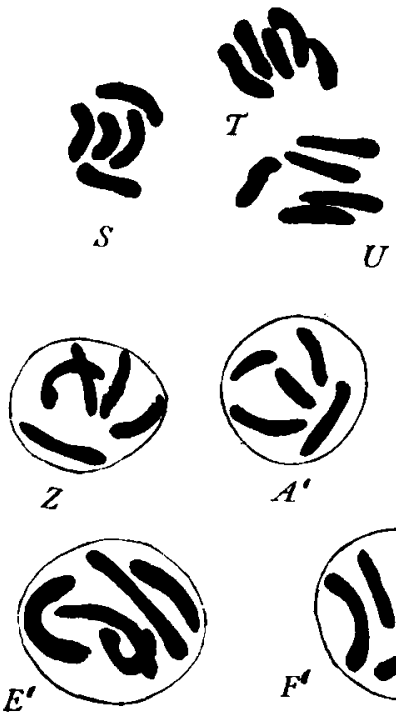

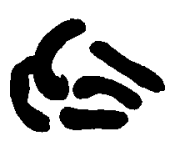

L
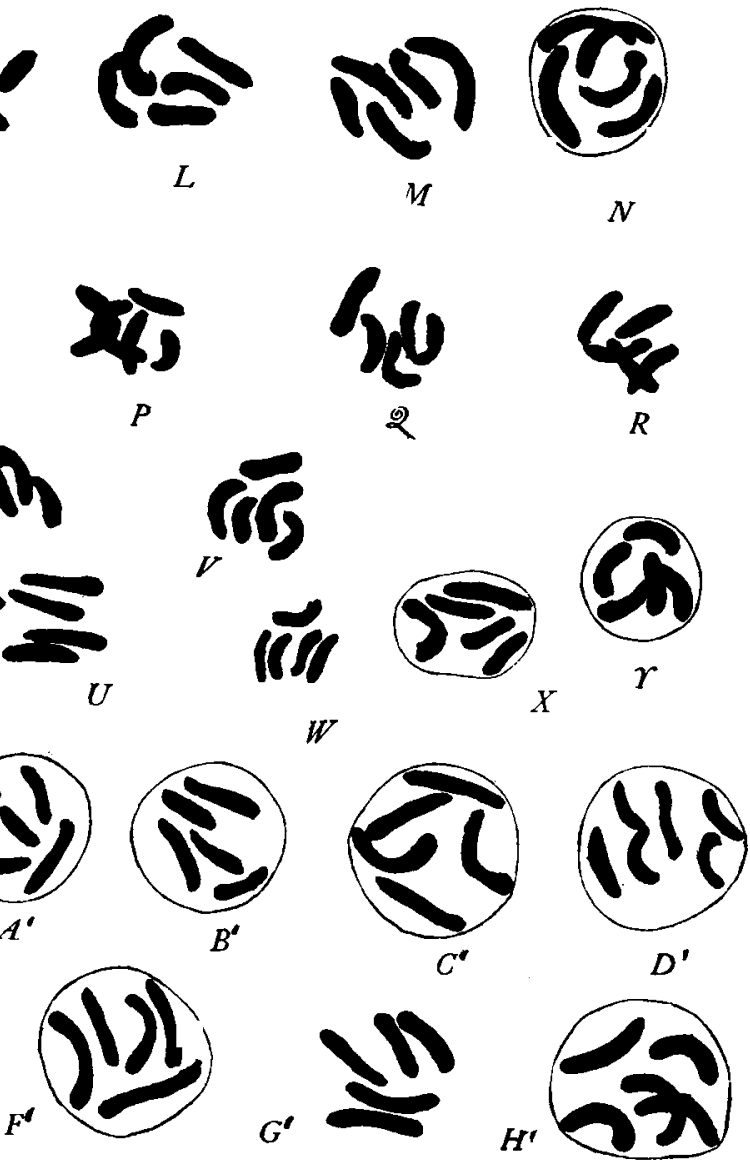

Fig. XI Chromosomes of somatic cells of male embryo-five chromosome type. In many cases the cells are from the same embryo. 
not six as stated, although in the embryos from female eggs the number of chromosomes counted is six (Figs. XIII and XIII, $A$ ).

The spermatogonia of $P$. caryæcaulis also show either five nearly

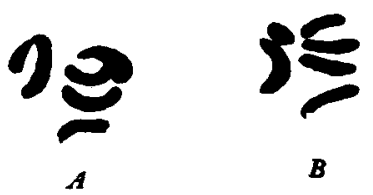

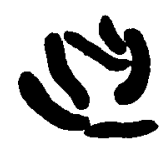

$\boldsymbol{C}$

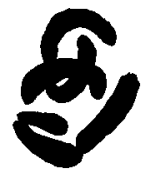

D

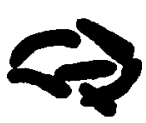

E

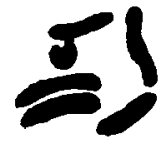

F

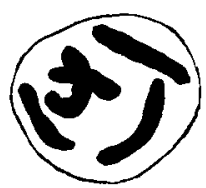

$\boldsymbol{G}$

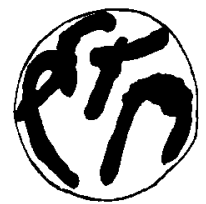

$\boldsymbol{H}$

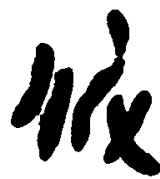

$\boldsymbol{L}$

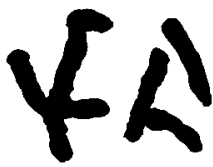

$\boldsymbol{P}$

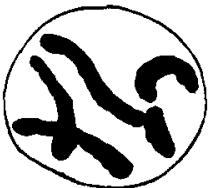

$\boldsymbol{I}$

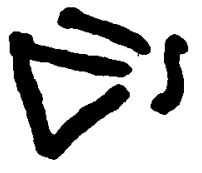

$\boldsymbol{M}$

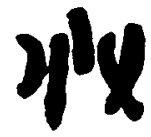

2.

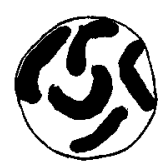

$\boldsymbol{f}$

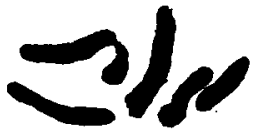

$\boldsymbol{N}$

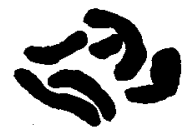

$\boldsymbol{R}$

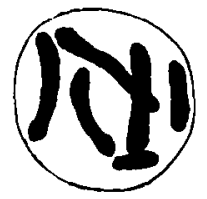

$\boldsymbol{K}$

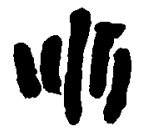

o

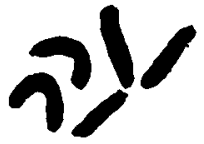

$s$

Fig. XII Chromosomes of somatic cells of male embryos; six chromosome type.

equal chromosomes, or five such and one very small one. The spermatocytes show an equatorial plate made up of three equal or nearly equal-sized chromosomes (Fig. XIV, $C$ ), or else of three 
equal or nearly equal-sized chromosomes and one small one (Figs. $\mathrm{XV}, N-R ; \mathrm{XVI}, S, \mathcal{T})$. These two types obviously correspond to the two somatic types, and here, as there, all the cells of one embryo are alike in that they fall into one group or the other.

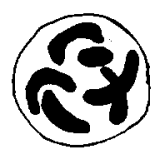

A

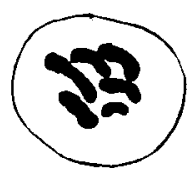

E

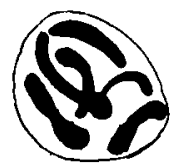

I

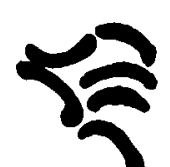

$M$

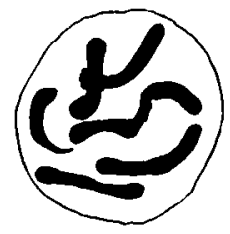

$P$

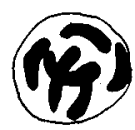

$B$

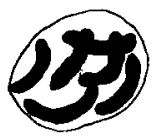

F

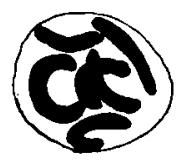

$\mathcal{F}$

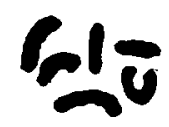

N

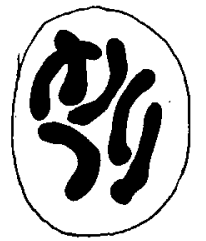

$\bar{Q}$

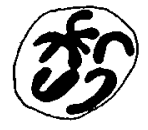

c
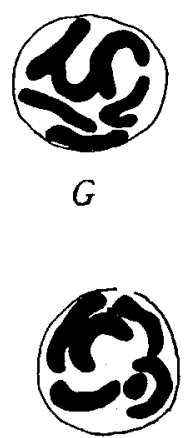

$K$

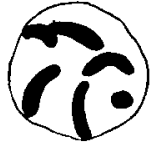

$D$
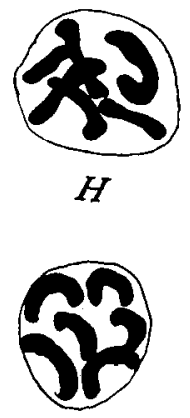

$L$

Fig. XIII Chromosomes of somatic cells of female embryos.

At the beginning of the division two of the chromosomes show a clear line in the middle where the halves will subsequently sepa- 
rate (Fig. XIV, $F$ ). The other large chromosome shows no division at this time (Fig. XIV, $F$ ), nor does the smallest one, if it can be detected (Fig. XV, $S$ ). As the two pairs separate the

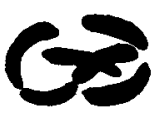

$A$

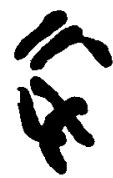

$\boldsymbol{E}$

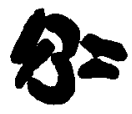

f

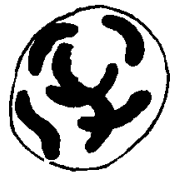

0

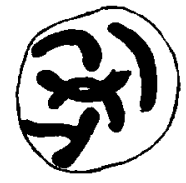

$\boldsymbol{F}$

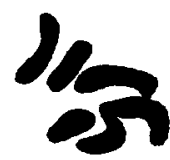

C

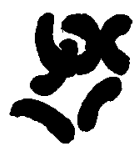

D

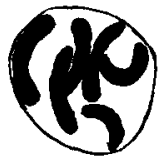

G

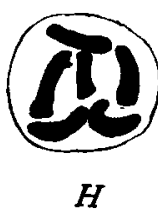

$H$

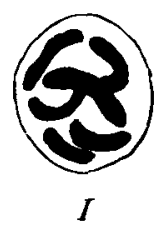

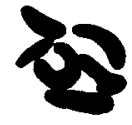

$K$

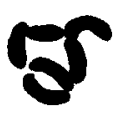

$\boldsymbol{P}$

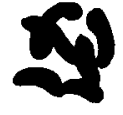

2

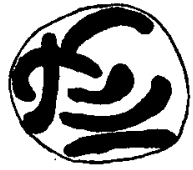

$\boldsymbol{V}$
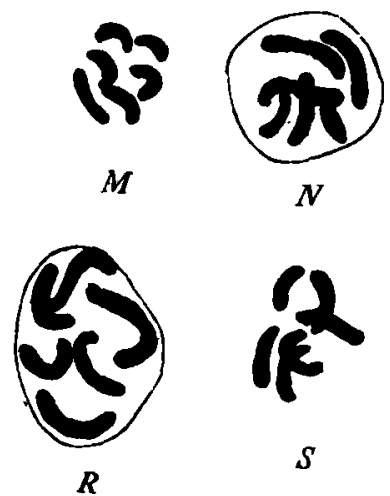

$S$

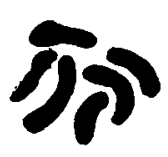

W

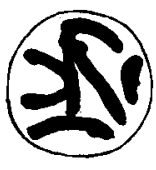

$X$

Fig. XIII Chromosomes of somatic cells of female embryos.

larger chromosome becomes drawn out into a somewhat dumbbell shaped mass. (Fig. XIV, D). At this stage it is very noticeable 


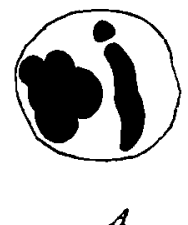

$A$

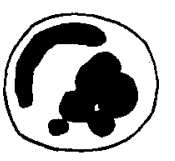

$B$

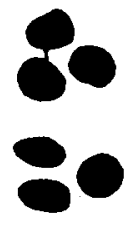

C

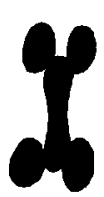

D

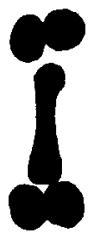

E
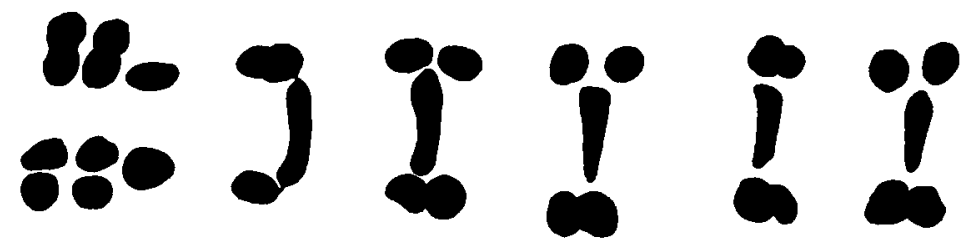

F

$G$

$H$

I

$K$
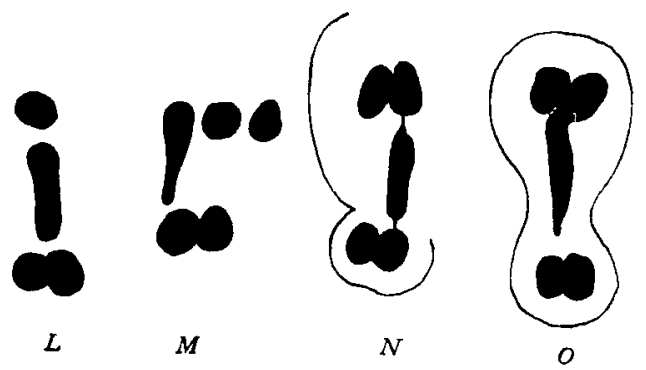

0
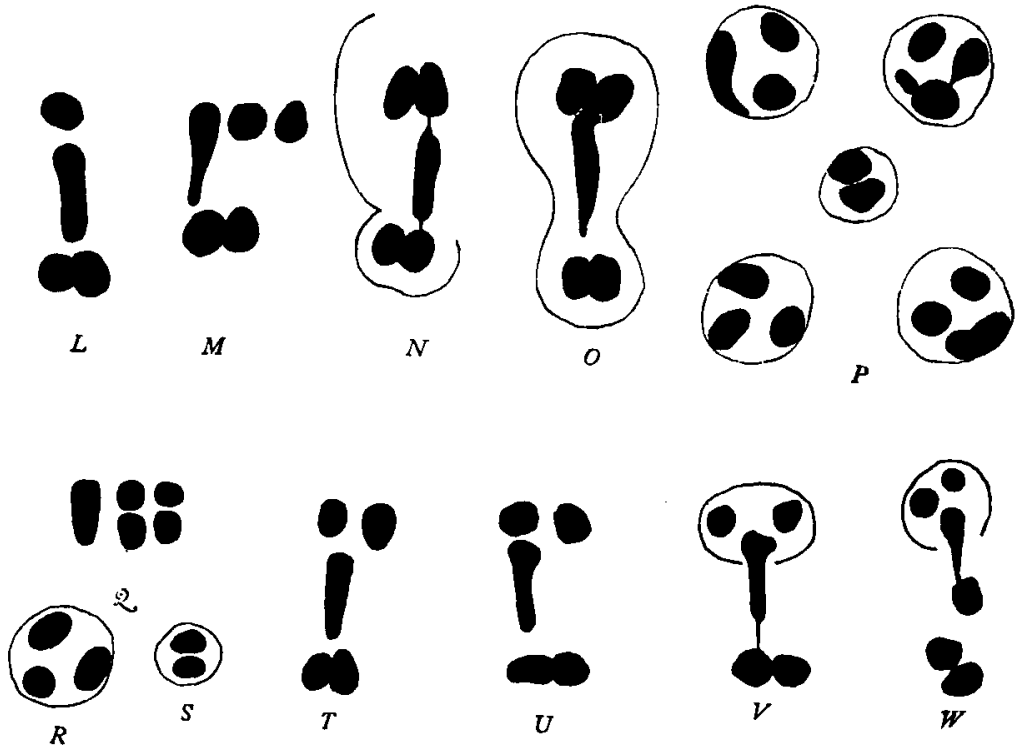

Fig. XIV $A, B$, nuclei just prior to the formation of the first spermatocyte, several chromosomes bunched together, two separate-late synapsis; $C$, two equatorial plates; $D-W$, first spermatocyte divisions. 
that the two chromosomes that have not divided-the lagging or sex chromosomes-almost invariably fuse into a single chromosome; or if they do not fuse, become so closely apposed that no line of separation is visible (Fig. XIV, $G-M$ ). Moreover this union is not due to the optical effect of superposition but to actual contact. ${ }^{1}$ When I first studied the spermatogenesis of this species I believed for some time that there was but a single lagging chromosome.

As the cytoplasm begins to constrict it soon shows that one cell is to become larger than the other (Fig. XIV, O; Fig. XV, G; Fig. XVI, $C$ ). The lagging chromosome - the larger visible onebecomes greatly elongated extending to each daughter plate. It is often enlarged at both ends and narrower in the middle, as though it would divide into two (Figs. XIV, $D ; \mathrm{XVI}, D, F$ ); yet such is not the case, for a little later it shortens, thickens, and retreats towards the larger cell. In its behavior it resembles, on the one hand, the aphids as closely as it does P. fallax on the other.

During the final stages of division the smaller cell loses nearly all of its cytoplasm (Figs. XV, $L, X ; \mathrm{XVI}, X . Y, Z$ ); and when finally separated consists of two closely apposed chromosomes with only a thin covering of cytoplasm (Fig. XV, $L$; Fig. XVI, $Z, A^{\prime}$ ). The larger cell shows a nuclear space around the two chromosomes before the lagging chromosome has reached the same level (Fig. XIV, $V$; Fig. XV, $G$; Fig. XVI, $P, Q R$ ); but a little later its end becomes included in the clear area. At this time, in some cases, one may detect the smaller lagging chromosome budding out, as it were, from the end of the other lagging chromosome in the larger cell (Fig. XV, G; Fig. XVI, $F-\mathcal{f}$ ). Its free end becomes round, and it now assumes in such cases an independent position in the new nucleus (Fig. XV, $L, N, O$; Fig. XVI, $C-I$ ). Very often it remains attached by a thread or band to the other accessory. In some cases the two remain closely united, the smaller like a knot on the side of the larger.

In the second type, the small lagging chromosome does not emerge from the other at this time, and only three nearly equal

\footnotetext{
${ }^{1}$ In a few cases, perhaps abnormal, I have detected the smallest chromosome lying nert to the other accessory, Fig. XVIIa.
} 
264

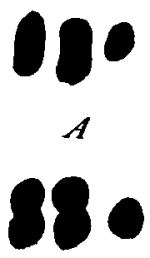

B

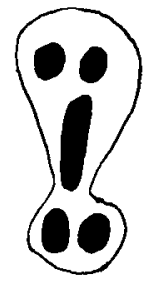

C

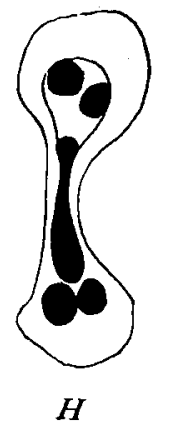

G

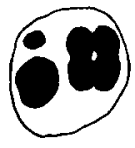

N
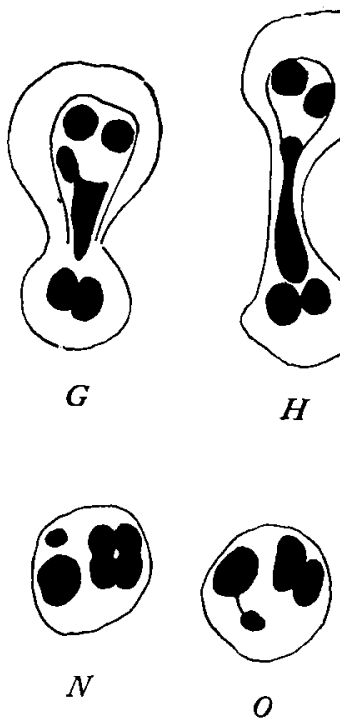

T. H. Morgan
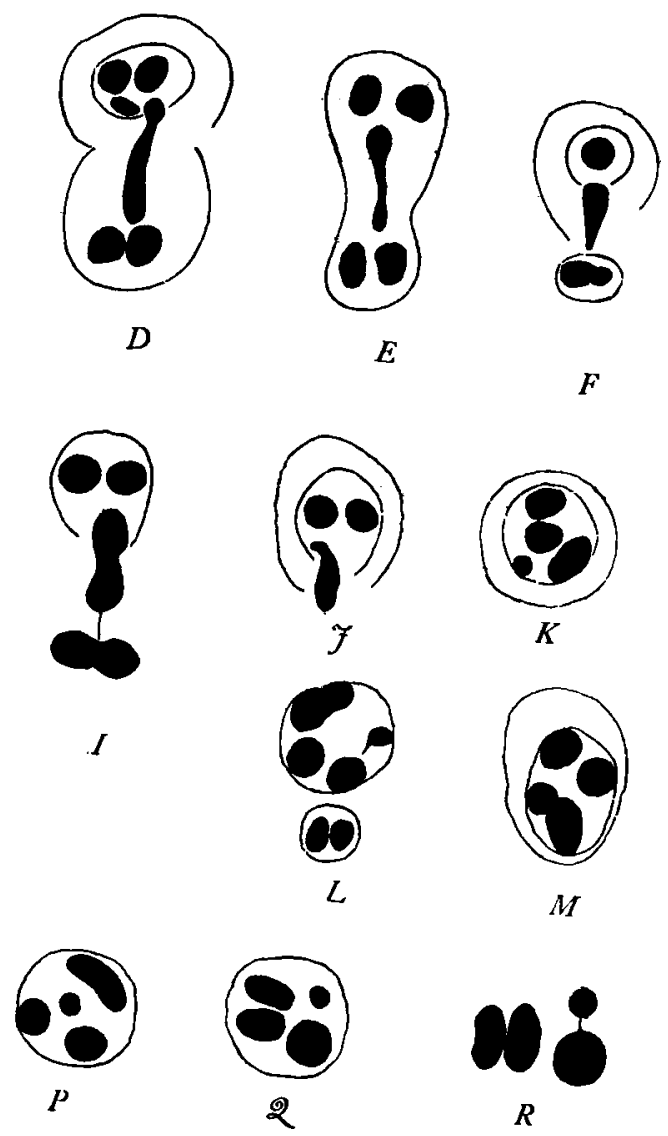

88:

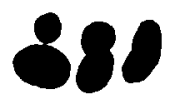

$S$

$\tau$
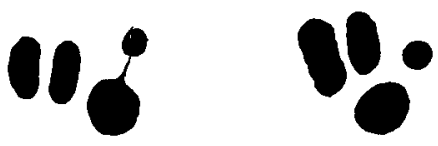

88

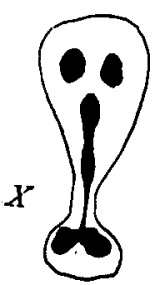

U

V

$\checkmark$
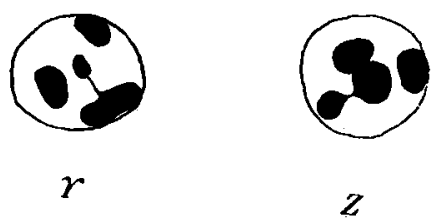

Fig. XV First spermatocyte division stages. 
Sex Determination in Phylloxerans and Aphids $\quad 265$
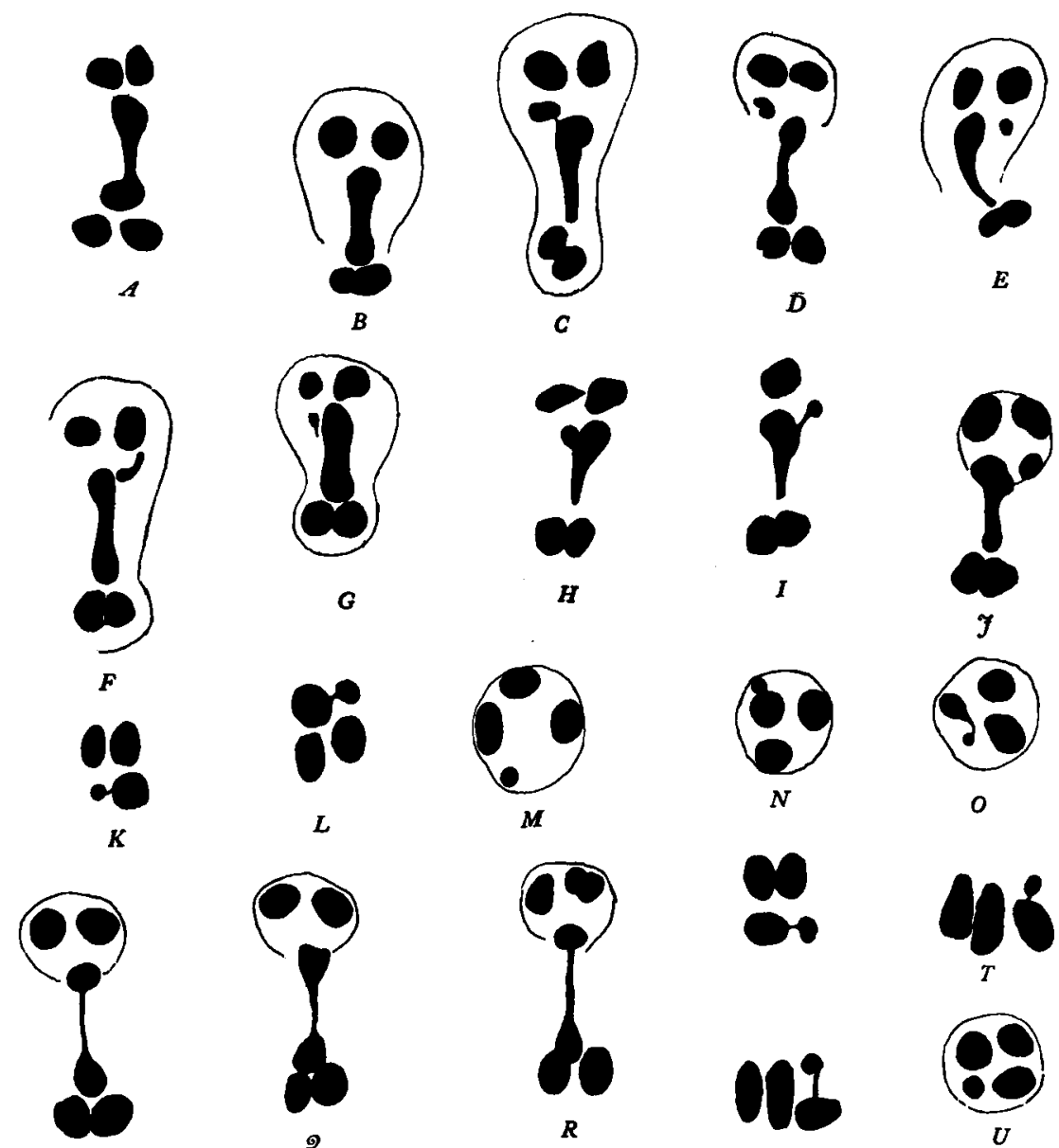

2.
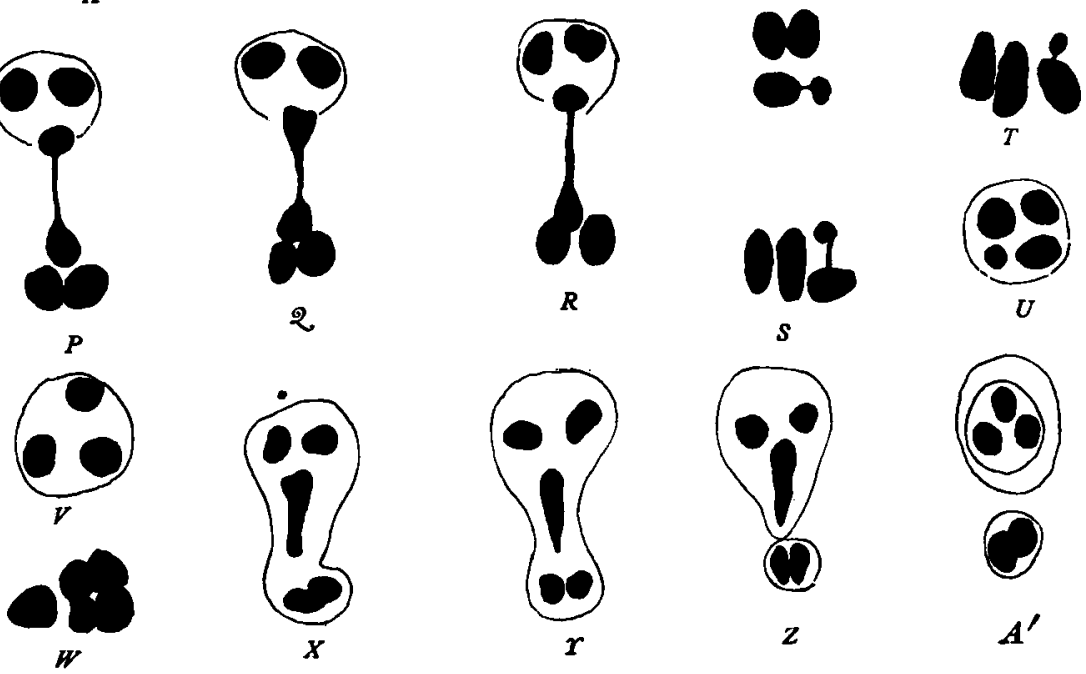

Fig. XVI First spermatocyte division stages. 
chromosomes are present-the largest one being therefore the double accessory (Fig. XIV, $U-W$; Fig. XVI, $P, Q$ ). This difference in the behavior of the small accessory has made the study of this species very perplexing. It might appear that we are dealing here with two species, one with three and the other with four chromosomes, but this view is negatived by a number of facts. A close examination of the sexual males fails to reveal two types, and since the sexual individuals of different species are readily determined, the evidence is strongly in favor of one species. On the tree, at New Bedford, Mass., on which this species was found swarming out of the galls only one kind of gall was present, and since $I$ have studied the sexual forms of the commoner galls in this region it is improbable that two species here exist. The fact that all intermediate types between union and separation of the chromosomes are found also indicates that they all belong to the same species; in some individuals the two chromosomes are always separate, in others united by a connecting thread; in others the smaller is stuck to the side of the larger, and others show only a single larger chromosome. On the assumption that there are four chromosomes in the male, the results can be brought into harmony with the facts found for the stem-mother's egg, and for the number of chromosomes present in the spindle of the male egg. This conclusion also harmonizes with the results on the other species, P. fallax.

In the resting stage following the first division, the nuclei of the larger cells contain three or four chromosomes each, and it is interesting to note that the type that prevails in each individual corresponds with the type found in the stage preceding division as is shown when both stages coexist in the same testis.

The equatorial plates of the second spermatocytes also show one or the other type (Fig. XVII, $L, N, O$ ); but the chromosomes are crowded and these stages are difficult to find. I have not studied them extensively. As the chromosomes divide it is apparent that there is no lagging chromosome (Fig. XVII, $D^{\prime}, E^{\prime}, F$ ) and a few successful cases show clearly that the three or four chromosomes, according to the type, divide and pass to the poles. These are the two cells from which the spermatozoa develop. 


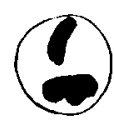

A

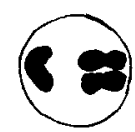

B

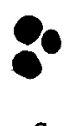

C

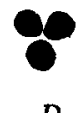

D

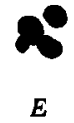

$E$
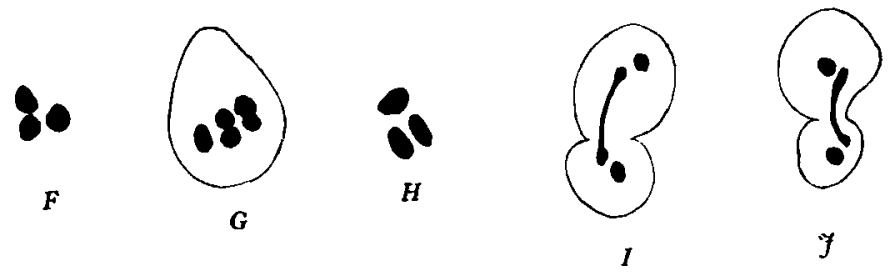

f
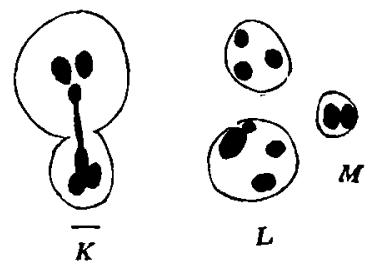

L

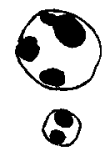

N

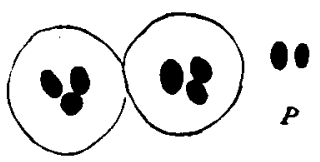

$o$
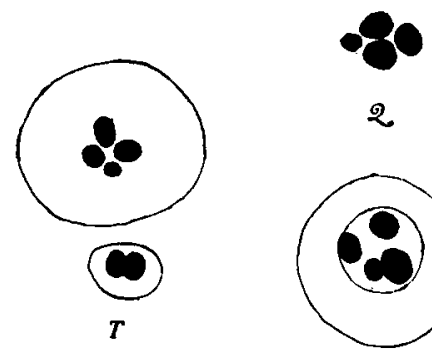

2
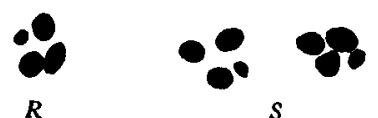

$s$
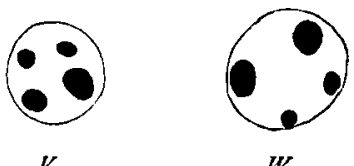
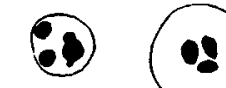

$X$

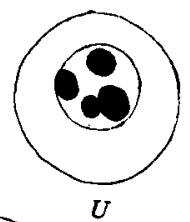

r

w
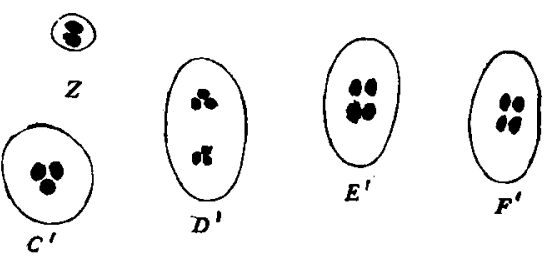

Fig. XVII $A-B$, nuclei just prior to the formation of the first spermatocyte; $C-H$, equatorial plates of first spermatocytes; $I-O$, division of same; $P$, rudimentary cell; $2-W W$, nuclei prior to second spermatocyte; $X, r, B^{\prime}, C^{\prime}$, equatorial plates of second spermatocytes; $Z, A^{\prime}$, rudimentary cells; $D^{\prime}$, $E^{\prime}, F^{\prime}$, division of second spermatocytes. 

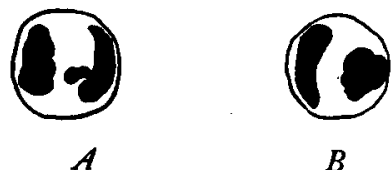

$B$
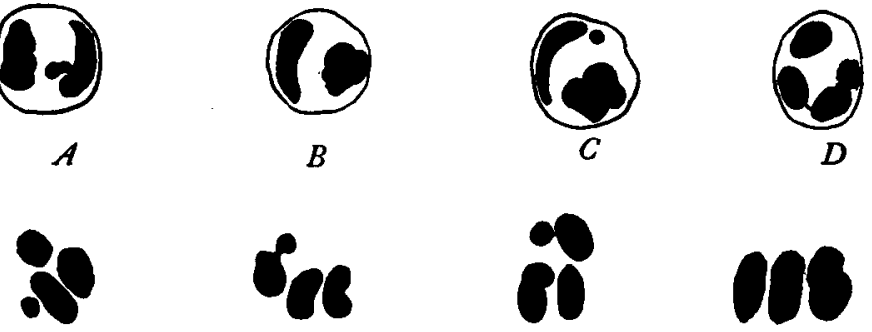

E

F

G

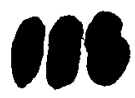

$H$
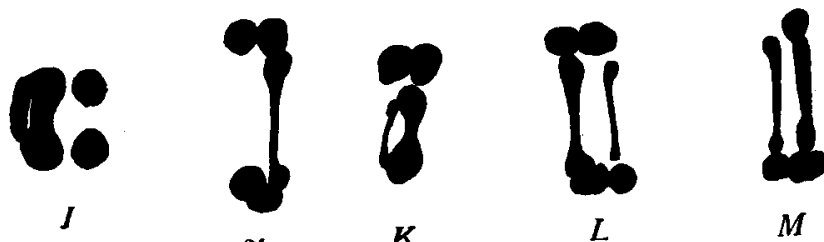

于

K

$L$
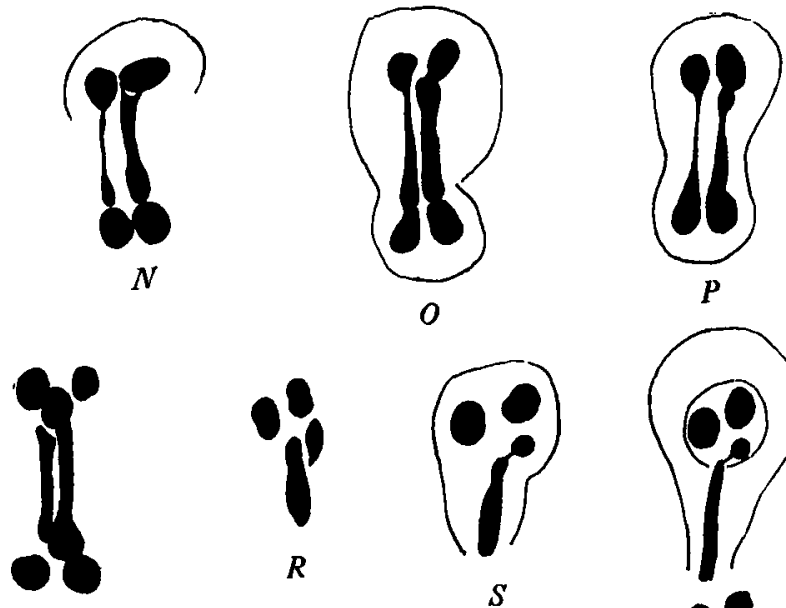

2

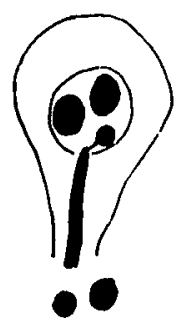

$\tau$

Fig. XVIIa $A-D$, nuclei prior to first spermatocytes; $E-G$, equatorial plate of first spermatocytes; $H-T$, side views of dividing first spermatocytes. In $K, L, M, N, O, P, 2$, the second lagging chromosome is separate from the first. 
The rudimentary cells of the first spermatocytes, containing two chromosomes (Fig. XVII, $M, P$ ), can be found wedged in between the other cells, or lying at the periphery of the follicle. They do not appear to divide and disappear later.

In a few individuals; apparently somewhat abnormal the two accessories are distinctly separated. Several cases of this sort are brought together in Fig. XVII $a$.

Returning to the female egg, where six nearly equal chromosomes were counted, it was shown that the six divide so that six pass out and six remain in the egg. The somatic cells of the female embryo also contain six equal or nearly equal chromosomes, differing from the six-type of the male in that one chromosome in the latter is much smaller than the rest. Each female produces a single egg. I have been unable as yet to obtain the polar spindle of the egg, but just before it develops the chromosomes appear in the nucleus as a group of deeply staining bodies in a less deeply staining plasmasome. In these cases I have counted four chromosomes, including one small one. The evidence from this source is not entirely convincing, but, if corroborated, it adds further evidence in favor of the view that eight, not six is the diploid number.

My interpretation of the chromosomal history of this species is, then, as follows:

The functional spermatozoon contains four chromosomes, two ordinary ones and two lagging chromosomes of which one is large and one very small. The two lagging chromosomes show a tendency in many individuals to form a single body producing the appearance of only three chromosomes for the reduced number. The sexual egg contains the same number of chromosomes as the sepermatocyte, i. e., two ordinary and two sex chromosomes, the two latter possibly united. After fertilization eight chromosomes are present but only six appear since the two pairs of sex chromosomes unite. These six chromosomes are nearly the same size. Hence each smallest must be fused with its larger partner (accessory). This same number, and in the same combinations, persists in the polar spindle of the stem-mother's egg. Here all must be divided equally since the same number, six, is found in the 
embryos. These embryos become female- and male-producersthe winged migrants - whose eggs are large or small. The former contain six chromosomes in the polar spindle of nearly equal size which seem to represent the same combinations existing in the preceding generation. In the male spindle a difference appears, there being one largest, four intermediate and one smallest chromosome. The only way in which such a combination can be accounted for, on the assumption that here too the original number is still retained-as in P. fallax-is that the two smallest of the eight have shifted over from their larger partners and have united with each other; the larger partners have also combined to produce the very large chromosome. The "purpose" of the shifting is a preparation for the polar division in which one of the larger chromosomes and one of the smallest passes entirely out of the male egg to leavesix chromosomes in the egg. ${ }^{2}$ These six often appear as five, owing to the subsequent union of the largest and the smallest sex chromosomes. Hence we find in the spermatogenesis two pairs of ordinary chromosomes that unite during synapsis and two sex chromosomes that have no pairs. These, in consequence, pass over to one pole at the first spermatocyte division that represents the "reduction division." The theoretical questions connected with these results will be discussed later.

PRECOCIOUS SEXUAL DIFFERENCES CORRELATED WITH MALE AND FEMALE EGGS

The relations described in the preceding section throw an important light on the differences in size of the male and female eggs. It is obvious that the difference is connected with the precocious development of the sexual individuals and not with the condition of maleness or femaleness of the egg, as such. In other animals size differences may also exist, the female being much larger than the male, yet the eggs are all of the same size. The differences in adult size in the latter case result from differences in the rate or time of growth after hatching. It is therefore of unusual interest

\footnotetext{
2 In P. fallax the same result is probably shown when ten chromosomes appear in the polar spindle, two being of greater size.
} 
to note that in two other species of animals in which a difference in size exists between the male and the female egg, the males are practically sexually mature when they emerge from the egg. I refer to Hydatina senta and Dinophilus apatris. In both of these the males are sexually mature a few hours after emerging from the egg, and without growing larger to any extent they become sexually potent. The relation has, I believe, heretofore entirely escaped the attention of zoölogists. ${ }^{3}$ Does it give us any clue to sex-determination?

The first point to settle is whether the male egg is smaller than the female because the young are sexually mature at the time of hatching, or whether the relation is the reverse, the male being smaller because it comes from the small egg.

The female emerging from the egg is as near sexual maturity as the male, hence it is not apparent why the difference in size should depend on the maturity of either sex; yet comparison with other animals shows that only where early sexual maturity exists are the eggs of two sizes. All of the materials that make the sexually mature female must exist in the egg, since there is neither time nor opportunity to get them after hatching. The female body is larger than that of the male, and the egg is larger. The difference in size therefore of the male and female is owing to the fulfillment of those conditions necessary for producing the sexually mature female directly from the egg and the same holds for the male. In other animals, sexually dimorphic, the conditions that determine sex may also exist in the fertilized eggs, but while the factor that determines the size differences must also be present in potentia, it need not be one that makes a difference in the egg size. It follows, I think, with great probability that the difference in the size of the male and female eggs in Phylloxerans can be referred to the difference in the sizes of the males and females that these eggs produce. In other words the two kinds of individuals and their sex is already determined before the egg is laid and before its polar spindle has developed. Therefore sex is determined in the presence of all of the chromosomes.

${ }^{3}$ See Morgan, T. H., for a brief statement of this relation. Exp. Zoöl. 
There can be no doubt that the two kinds of eggs are not simply the result of the accidental amount of material contained in them. If this were the case, there would be no sharp line of demarcation but a gradual series of sizes, and if the result were purely chance, there would be more eggs of intermediate sizes than of large and small. The facts are the reverse. There are two sharply separated groups of eggs and while, of course, there are fluctuating size differences, these center around two widely separated modes.

Two alternative views offer themselves at this point. Either there is a sex-determining factor in the eggs of the stem-mother that separates female-producing from male-producing individuals, or in the life of the winged individuals some factor external or internal turns the scale in one or in the other direction. Let us dwell for a moment on these possibilities.

If a sex-determining factor is present we have found no clue to such in our study of the chromosomes. The eggs of the stemmother are all of a size. If events subsequent to the egg formation of the stem-mother determine whether the individual produces male or female eggs, the following considerations should receive attention. Foremost is the observed fact that the male producers contain small eggs, but more of them, and the sum total of egg-material may be actually greater in some male producers than in other female producers. If then some condition should bring about the setting free of a larger number of eggs from the ovary the presence of so many developing at once might turn the scale so that the alternative of the smaller egg is followed. If this view seems too improbable it might be imagined that the food conditions are less favorable at first than later on, or vice versa, and in consequence the first individuals that mature would be male producers, the later ones female producers. I find no facts to support this view. One argument far outweighs these possibilities. The male egg shows from its very earliest embryonic development that it is characteristically a male and I do not think, in the light of other facts regarding the influence of the chromosomes on the early development of the egg, that the results here can be safely

4 I refer to the early differences in the cytoplasmic relations of male and female embryos. 
ascribed to the absence of two chromosomes. For these and for other reasons I am inclined to think that the determination of the male and female producers is not the result of chance or of some external factor but that a mechanism, perhaps, or something definite at least, within the stem-mother's egg determines the characters of the result.

If one were inclined to make fine distinctions it might be said that we are dealing here with two independent, yet correlated phenomena. The size differences in the egg are connected with the production of small individuals and of large individuals. The sex of these individuals is determined by other factors; the two events are so correlated that they coincide, but I doubt the advantages of such an explanation.

\section{IS THE ELIMINATION OF THE SEX CHROMOSOMES FORTUITOUS OR DETERMINATIVE?}

Are the two chromosomes thrown out of the male egg different from their partners that remain behind? Are the homologous chromosomes of both of these pairs in the female line identical or qualitatively different? Are the two left in the sexual egg identical with the two in the male, or are they so to speak complementary in their relation to sex determination? An answer to these questions involves several assumptions concerning the rôle, qualitative or quantitative, of the chromosomes in sex determination.

If we assume that the chromosomes thrown out of the male egg are female-producing (and we are forced to this view if we assume that there are two kinds of sex chromosomes) it follows that the functional spermatozoon is the bearer of the male determinant, yet it clearly corresponds to the "female producing" spermatozoon of other insects. Following the same line of thought, the sexual egg should eliminate its male-producing chromosomes-otherwise after fertilization the egg would contain only "male-producing" chromosomes. Fertilization would bring together the male-producing chromosomes of the spermatozoon and the femaleproducing chromosomes of the egg; the result being a female whose sex on the hypothesis is due to the egg and not to the "female 
producing" sperm. Here we meet with one of the many paradoxes to which the view, that the sex chromosomes are sexually different, leads.

On the contrary assumption that the male egg eliminates the male chromosomes we leave unexplained the essential point of what then determines that that egg is to become a male. Other combinations of the sex chromosomes are conceivable, but all lead alike to contradiction or difficulties on the assumption that the chromosomes are really differentials and that their elimination from the egg and sperm is discriminative.

The opposite point of view looks upon the two pairs of chromosomes of the female and the single pair remaining in the male egg as strictly equivalent, pair for pair. As long as either member of a pair is eliminated from the male egg the essential conditions for male production are fulfilled. The union of the homologous members of the pair in Phylloxera caryæcaulis would mean that this is a step preparatory to their separation at the next division. The pairs might be turned either way on the spindle since it would be a matter of indifference which member of the pair was eliminated and which remained in the egg. The separation would be fortuitous. The difference between male and sexual female would be a quantitative difference so far as the chromosomes are concerned. But since the total number of chromosomes is the same in the parthenogenetic and the sexual females some other condition must determine the transition from the one to the other. What that other condition could be unless synapsis we do not know any more than why in the body the cells are differentiated in many directions without any chromosomal differences to distinguish them.

If the transition from a parthenogenetic female to a sexual female can occur without chromosomal diminution-and the transition involves as vast a number of differences as those that distinguish male from female-may not the same sort of change take place in the case of the transition from the parthenogenetic to the male form? We have seen, in fact, that a change has taken place a generation before the male egg appears that is prophetic of the change that comes later. May not this change be the real condi- 
tion that determines sex? The chromosomal elimination being the consequence and not the cause of sex. Such interpretation would involve a profound alteration in our views of the relation of sex and chromosomes. It would mean, for one thing, that in ordinary forms there are other differences in the two kinds of sperm that are male and female producing than that of the number of chromosomes. The female spermatozoon would not be female producing only because it contains one or two more chromosomes than the male, but, conversely, it contains these chromosomes because other changes have already been initiated that cause the accessory chromosome to move into that cell. Just as in the male egg the behavior of the sex chromosomes is discriminative-two entire chromosomes going into the polar body, so in the sperm two entire chromosomes go into the "female-producing" sperm. It seems to me the evidence may mean that there is a mechanism in the cell that is determinative in regard to sex factors; and that this mechanism has come to have associated with it particular chromosomes.

The chromosomal relations, however, remain still a fact and a very extraordinary fact. It is hard to conceive that these relations have no connection with sex determination, even if we grant that changes take place before the differences in the number of the chromosomes occur that foreshadow the later sex differences. Why this extraordinary behavior in regard to the chromosomes if it is not concerned with the sex relation? It may be as injudicious to ignore the hehavior of the chromosomes, as to deny that antecedent events also connected with sex determination are operative. The evidence that we have at present seems to point to the conclusion that in the insects at least, the chromosomes are involved in the series of changes that determine sex; but may not the chromosomes be only a part of the process that leads to sex determination? The visibility of the chromosomal changes has caught our eye; the obscurity of the antecedent changes has caused them to be ignored; but in such a case as this one where a parthenogenetic cycle is introduced, the analysis shows that conditions antecede the chromosomal elimination-conditions also essential to sex determination. 
Such considerations show at least that there are questions connected with sex determination that may be as important as the visible differences relating to the quantitative factor alone. At present however our evidence is largely confined to the recognizable quantitative changes in the chromosomes. A problem of exceptional interest arises in connection with the oögenesis of the parthenogenetic eggs that produce parthenogenetic individuals (the stem-mother's oögenesis for example) and of the parthenogenetic eggs that produce the male and sexual female individuals. Is there a synapsis of the chromosomes? Even though the full number of chromosomes is retained, this fact does not preclude the possibility of synapsis. I have studied this problem with some care but the decision is so fraught with difficulties that I have decided for the present to withhold any attempt to answer the question until I can give the matter fuller consideration.

\section{THE LIFE-CYCLE OF PHYLLOXERA FALLAX}

The doubts that have arisen in regard to the identification of this species (see Pergande) are due to an incomplete knowledge of its life-cycle. Only a series of consecutive observations made at short intervals could reveal the relations of the successive generations. During two years I have made such observations and at the critical periods have preserved quantities of material every three or four days. The facts discovered in the course of these observations show how difficult it would be to unravel the lifecycle without a very complete series of stages; for, the inhabitants of galls first formed may pass through certain phases before the inhabitants of later formed galls reach those stages. There is thus an overlapping of stages. Second, the number of individuals of a phase in the cycle is closely connected with the size of the gall, which in turn is generally dependent on the time at which the gall is produced. Third, the production of winged and wingless forms by the stem-mother is not the same for all galls.

The following data give the results of observations made during the spring of 1908 on material collected on the Palisades north of Fort Lee, New Jersey. 
On May 23 young galls, many not yet closed in, were found. Each contained one stem-mother and from I to 83 eggs. The number of eggs is almost directly proportional to the size of the gall. Thus in small galls the number of eggs was 3, I, 4, 3, 3, $6,4.5,0,0,0,0,4,9,1,0,2,2$, Somewhat larger galls contained I I, I3, 16, 6, 6, 8, Medium-sized galls contained I4, 18, 39, 29, $23,35,27,33,38,30,37,21,47,32,45,37,36,29,15,43,39,44$, $27,3^{6}, 19,23$. Big galls contained $25,30,30,54,36,47,42,67$, $62,74,31,83,36,46,22$. In the largest galls a few of the eggs had hatched.

Several days later (June 4) a considerable advance had beenmade. The chief events may be here summarized. Many of the eggs laid by the stem-mother had hatched. She was still present, however, and continued to lay eggs. The young that first hatched had become either wingless or winged individuals, or both in the same gall. The relation of these two kinds of individuals to each other is interesting and will be referred to later. The most important fact brought out by a study of the galls of this date ( $\mathrm{I} 66$ galls in all) is that there is a sudden break in the series of offspring; the eggs first laid producing individuals that grow to full-sized winged or wingless individuals, while those laid later produce a different kind of individual that never grows larger and remains throughout life the same size as when first hatched. These individuals I have named the supernumerary or dwarf females. Equally interesting is the discovery, that in the larger galls as many as 46 eggs may produce the large individuals, and then the smaller series abruptly begins; while in the smallest galls only one to three or four or more large individuals are produced when the small series begins. There seems to be here not a predetermined number of large and dwarf females, but the conditions of life determine when the one kind ceases to be produced and the other kind begins. The two types of individuals must, however, be predetermined by alternative possibilities possessed by each egg.

The supernumerary or dwarf females differ from their large wingless sister-forms, and from the young of the latter in a number of points (Fig. XVIII). The shape of the body is entirely different and resembles that of the sexual male; but it differs from 


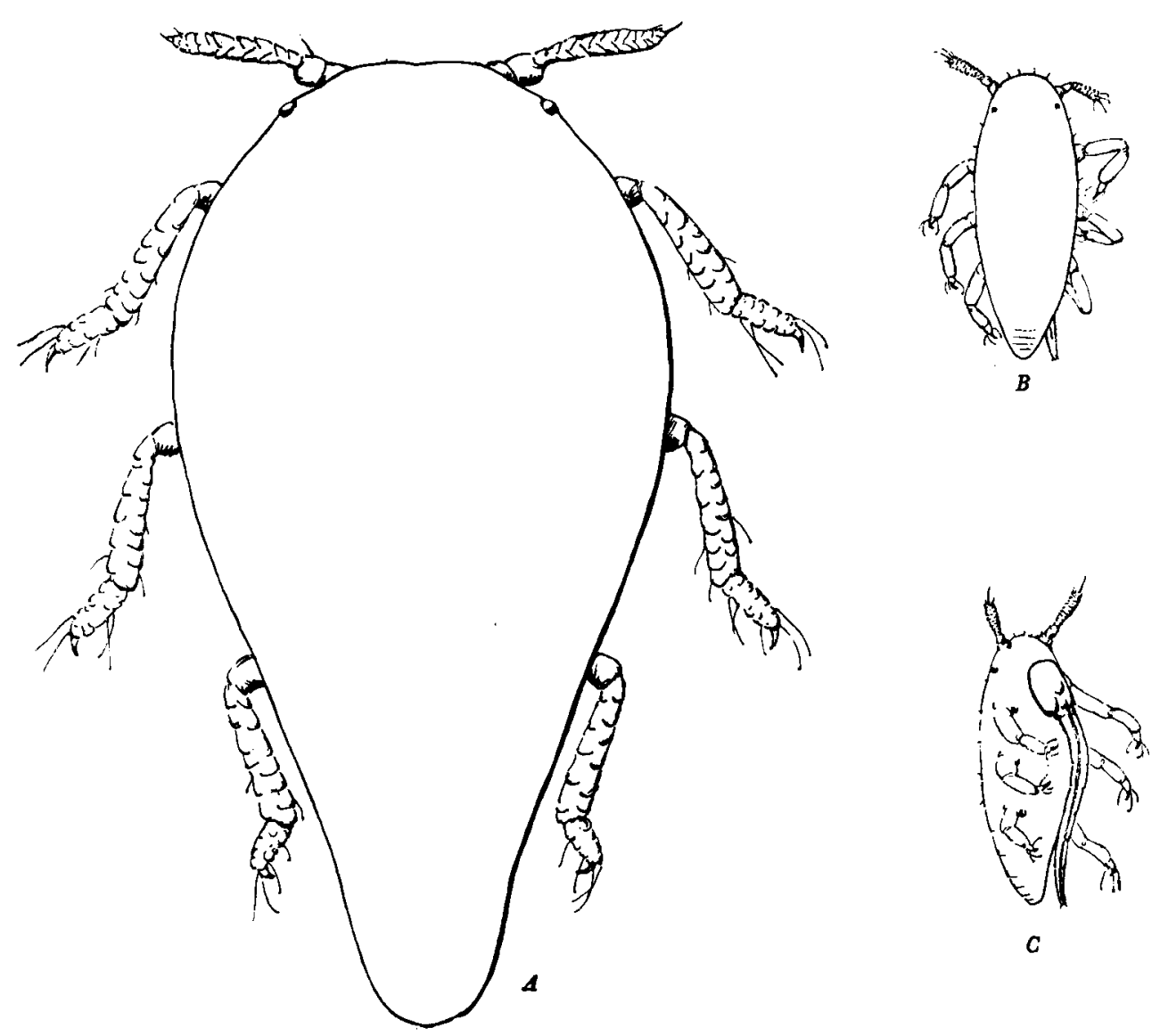

Fig. XVIII P. fallax. $A$, wingless individual of second generation; $B-C$, rudimentary females; $B$, dorsal; $C$, ventral view. 
the male in two important respects; first, the dwarf individuals have a very long proboscis which in this species is absent in the male; second, there are no testes within the abdomen as in the males, where they form a relatively enormous mass. Otherwise the dwarfs are so similar in external form to the sexual males that their. true nature was uncertain until they were studied in serial sections. These showed the absence of the testes and the presence of rudimentary ovaries and ducts resembling those of immature parthenogenetic females. There was nothing to indicate that the dwarfs could become sexual females. In fact the latter contain each an enormous egg when they hatch.

The dwarfs can at once be distinguished from the young of the same generation by the length of the proboscis. In the dwarfs the proboscis is as long as the body, while in the young it is not more than two-thirds as long. The presence of the well-developed proboscis might lead one to infer an exceptional ability for prolonged life, and this might readily suggest that these minute individuals are predestined to short circuit the life-cycle by remaining on the tree to produce the sexual forms of the following year. While I cannot positively deny to them such an existence, the facts that I have indicate on the contrary that these dwarfs are destined to a brief existence, and die without progeny.

In the following table, I, (June 4) I give the results of an examination of the contents of I 66 galls. In the first column is given the number of the gall; in the second, the size of the gall; in the third, the total number of individuals; in the fourth, the number of large wingless or winged individuals. For very young stages it is not easy to detect the wings, but for older stages the presence of rudimentary (or of complete) wings is readily seen. When the wings are spread, i. e., when the insect is an imago, I have underscored the figures indicating the number of individuals. The other columns include the number of eggs and the number of dwarfs or supernumerary females. 
TABLE I

\begin{tabular}{|c|c|c|c|c|c|c|c|c|c|c|c|}
\hline $\begin{array}{l}\text { no. } \\
\text { or } \\
\text { calr }\end{array}$ & size & 莣 & 总总 & 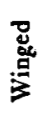 & 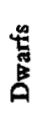 & $\begin{array}{c}\text { No. } \\
\text { Or } \\
\text { GALL }\end{array}$ & size & 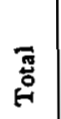 & 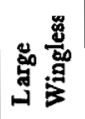 & $\begin{array}{l}\stackrel{8}{8} \\
\stackrel{g}{0}\end{array}$ & 莺 \\
\hline$I$ & medium + & 25 & 12 & & & 44 & small + & 15 & 5 & & \\
\hline 2 & medium + & 53 & 4 & & & 45 & small + & 9 & & & \\
\hline 3 & medium & 28 & 4 & & & $4^{6}$ & small + & 2 & & & \\
\hline 4 & medium & 15 & & & & 47 & small + & 9 & 2 & & \\
\hline 5 & medium & 16 & 2 & & & $4^{8}$ & small + & 19 & & & \\
\hline 6 & medium & $3^{2}$ & 8 & & & 49 & small + & 15 & 7 & & \\
\hline 7 & medium & 118 & 4 & 19 & & 50 & small + & 13 & 9 & & \\
\hline 8 & medium & 21 & & & & $5 I$ & small & 4 & & & \\
\hline 9 & medium & 23 & ro & & & $5^{2}$ & medium- & 12 & & & \\
\hline 10 & small & 10 & & & & 53 & medium - & 19 & & & \\
\hline II & small & I3 & I & & & 54 & & II & 4 & & ' \\
\hline 12 & small & 49 & 4 & & & 55 & & 13 & 4 & & . \\
\hline 13 & medium & 22 & 13 & & & $5^{6}$ & small & 10 & 4 & & \\
\hline 14 & medium & 27 & 8 & & & 57 & & 3 & & & \\
\hline 15 & medium & 4I & & & & 58 & & I I & & & \\
\hline 16 & medium & 35 & & & & 59 & small & 6 & & & \\
\hline 17 & medium & 12 & 7 & & & 60 & small & 6 & & & \\
\hline 18 & medium & II & & & & 65 & small & 4 & & & \\
\hline 19 & medium & 13 & & & & 62 & very smal & 2 & & & \\
\hline 20 & medium & 8 & I & & & 63 & very smal & 7 & & & \\
\hline 21 & medium & 59 & 2 & 11 & & 64 & small & 12 & & & \\
\hline 22 & medium & 49 & 4 & & & 65 & small & 5 & & & \\
\hline 23 & medium & 17 & 4 & & & 66 & small & 7 & & & \\
\hline 24 & medium & $5^{1}$ & 6 & & & 67 & small & 32 & IO & & \\
\hline 25 & medium & 17 & 3 & & & 68 & small & 16 & 6 & & \\
\hline 26 & medium & 18 & 4 & & & 69 & small & 15 & 6 & & \\
\hline 27 & medium & 10 & 2 & & & 70 & small & 23 & 8 & & \\
\hline 28 & & 10 & 4 & & & 71 & large & 208 & 34 & ! & \\
\hline 29 & medium - & 25 & 8 & & & 72 & large & 63 & - & & 3 \\
\hline $3^{\circ}$ & medium - & 9 & 4 & & & 73 & large & 64 & 11 & & 4 \\
\hline $3^{1}$ & medium - & 24 & 6 & & & 74 & large & II & 5 & & $\mathbf{I}$ \\
\hline $3^{2}$ & medium - & 17 & 5 & & & 75 & large & $3^{6}$ & - & & 3 \\
\hline 33 & medium - & I3 & 6 & & & $7^{6}$ & large & 40 & 14 & & $\mathbf{I}$ \\
\hline 34 & sinall & 4 & 2 & & & 77 & large & $5^{2}$ & I4 & & \\
\hline 35 & small & 8 & 6 & & & $7^{8}$ & large & 49 & 25 & & 2 \\
\hline $3^{6}$ & small & 7 & & & & 79 & large & 67 & 18 & & I \\
\hline 37 & small & 6 & & & & 80 & large & 49 & & & \\
\hline $3^{8}$ & & 26 & & & & 81 & large & 25 & & & 2 \\
\hline 39 & small & 12 & & & & 82 & small & 13 & & & 2 \\
\hline 40 & small & $4 I$ & & & & 83 & small & 10 & & & \\
\hline 41 & small + & 20 & & & & 84 & small & 13 & & & 2 \\
\hline 42 & small + & 29 & & & & 85 & small & 13 & - & & \\
\hline 43 & small + & 12 & & & & 86 & small & 14 & - & & 1 \\
\hline
\end{tabular}


Sex Determination in Phylloxerans and Aphids

TABLE I-Continued.

\begin{tabular}{|c|c|c|c|c|c|c|c|c|c|c|c|}
\hline $\begin{array}{c}\text { No. } \\
\text { or } \\
\text { GALL }\end{array}$ & size & है & 题 & $\begin{array}{l}\text { 总 } \\
\text { 恶 }\end{array}$ & 莺 & $\begin{array}{l}\text { No. } \\
\text { OF } \\
\text { iAIL }\end{array}$ & size & 焉 & 总总 & $\begin{array}{l}\text { g. } \\
\text { g }\end{array}$ & 葛 \\
\hline 87 & small & I & - & & $\mathbf{I}$ & 128 & small & 5 & & & \\
\hline 88 & & & & & 2 & 129 & small & 4 & & & \\
\hline 89 & tery sma & & & & & 130 & small & 3 & & & \\
\hline go & very sma: & 3 & & & 3 & IRI & small & 29 & & & I \\
\hline 91 & big & 3 & - & & 2 & $13^{2}$ & medium & 14 & & & \\
\hline 92 & big & 5 & & & & 133 & medium & 34 & & & \\
\hline 93 & big & 3 & 10 & & & 134 & medium & 21 & & & \\
\hline 94 & & 7 & - & & & 135 & small & 9 & & & \\
\hline 96 & & 4 & - & & & 136 & small & 7 & & & \\
\hline 97 & medium & I & 3 & & $\mathbf{I}$ & 137 & medium & 22 & & & \\
\hline 98 & mediun & 2 & & & 2 & 138 & medium & 27 & & & \\
\hline 99 & medium & $!$ & & & I & 139 & medium & 26 & r & & 2 \\
\hline 100 & small & 1 & & & & 140 & medium & 33 & & & \\
\hline 101 & small &. & & & & 141 & medium & 16 & & & \\
\hline 102 & small & : & & & & 142 & medium & 25 & & & \\
\hline 103 & small & : & & & & 143 & medium & 13 & & & \\
\hline 104 & small & 4 & & & & 144 & medium & 87 & $i$ & & \\
\hline 105 & small & 7 & & & & 145 & small & 5 & & & \\
\hline 106 & small & $?$ & & & I & 146 & small & 8 & & & \\
\hline 107 & medium & $3 i$ & 7 & & $I$ & 147 & small & 24 & & & \\
\hline 108 & medium & 26 & 5 & & $\mathbf{I}$ & 148 & small & 28 & & & \\
\hline 109 & medium & 12 & 3 & & 2 & 149 & big & 75 & 1 & & \\
\hline 110 & medium & 12 & 4 & & I & $\frac{1}{150}$ & small & 9 & & & \\
\hline$I I I$ & medium & IC & & & & $\overline{151}$ & medium & 79 & . & & \\
\hline 112 & medium - & 39 & - & & 2 & 152 & medium & 83 & $i$ & & \\
\hline 113 & medium- & 14 & 6 & & $\mathbf{I}$ & 153 & medium & 74 & . & & \\
\hline 114 & medium - & IC & 0 & & $\mathbf{I}$ & 154 & medium & 72 & i & & 3 \\
\hline 115 & nedium -1 & 60 & & 7 & & 155 & medium & 44 & & & \\
\hline 116 & ned um $\dashv$ & 116 & 8 & & & 156 & medium & 79 & . & & \\
\hline 117 & nedium - & 126 & 7 & & 3 & 157 & mall (?) & 28 & $i$ & & \\
\hline I 18 & small & 6 & & & I & 158 & mall (?) & $4^{2}$ & r & & \\
\hline II9 & medium & 72 & 7 & & & r 59 & mall (?) & 165 & , & & 3 \\
\hline 120 & & 28 & 3 & & 2 & 160 & mall (?) & $5^{6}$ & ; & & \\
\hline 121 & small & 9 & 2 & & & 161 & imall (?) & 44 & t & & \\
\hline 122 & small & 14 & 3 & & 1 & 162 & imall (?) & $6 I$ & $p$ & & 4 \\
\hline 123 & small & 2 & & & & 163 & imall (?) & 40 & ; & & 2 \\
\hline 124 & small & 5 & & & $\mathbf{I}$ & 164 & size (?) & 52 & ; & & 4 \\
\hline 125 & small & 11 & & & & 165 & size (?) & 62 & 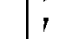 & & 6 \\
\hline 126 & small & 3 & & & & 166 & size (?) & 44 & 3 & & $\mathbf{I}$ \\
\hline 127 & small & 13 & & & & & & & & & \\
\hline
\end{tabular}

* In No. $13^{8}$ two stem-mothers were present. 
The table shows a number of important details not mentioned above. The minimum and maximum number of eggs laid by the stem-mother can be approximately estimated from the data. The extremes vary between I (in No. 20) and 60 (in No. I15). ${ }^{5}$ It is true that still larger numbers are found in some other cases, but in most of these the wingless individuals of the second generation were already full sized and may have begun to layeggs. In fact in some cases, especially in the last ones given, this is certainly true, since large and small eggs were present. ${ }^{\circ}$ The smallest numbers also may not represent the entire output, since many of these galls were still small and later would no doubt contain more eggs of the stem-mother. Nevertheless since in some of these cases the second generation, consisting of a few individuals, contained fully grown insects, it is probable that the complete number of eggs had been laid. This conclusion is confirmed when we find, as in No. I06, a dwarf female was present and only two other individuals.

Another interesting point is also brought out. In No. 165 there were i7 large individuals (or young ones that would have become larger) and $6 \mathrm{dwarfs}$. This means approximately that the first 17 eggs developed into large individuals, and the 18 th was a dwarf. It follows that there is no fixed number of large productive individuals but the conditions determine the result.

The conclusion is of some general importance since it shows that external conditions may be responsible for producing not a graded series of differences, but a sudden change, in other words, a mutation. The eggs have therefore a dual capacity, external conditions determining which alternative is realized.

The largest number of large individuals, including wingless and

${ }^{5}$ As many as 83 were recorded in another count: (See ante).

'Several measurements were made of the three kinds of parthenogenetic eggs. These gave the relative sizes of the eggs.

$\begin{array}{ccc}\text { STEM-MOTH ER EgGS } & \text { MALE EgGS } & \text { FEMALE EGGS } \\ 16 \times 9 & 16 \times 9 & 20 \times 10 \\ 17 \times 9 & 18 \times 9 & 20 \times 11 \\ 14 \times 8 & 17 \times 8 & 20 \times 9 \frac{1}{2} \\ 15 \times 8 & & \\ 15 \times 8 & & \end{array}$


winged, is found in No. 71 , where 46 individuals are present. It is probable that even this number does not represent the maximum, as all those capable of growth may not have been at this time full grown; but this number is probably near the upper limit, and there can be no doubt that the lower limit is far below this.

In the tables, cross lines in the first columns separate galls from different leaves. There is, in a general way, a resemblance between the contents of galls from the same leaf, indicating that similar conditions give similar results. While this holds in general there can be no doubt that the later arriving stem-mothers producing small galls are differently affected. In this connection the occurrence of winged individuals presents some curious results. They occur most frequently on the same leaf, i. e., some leaves contain them, others are nearly free from them. Two interpretations are possible; either special conditions call forth this form or else in certain strains the production of winged individuals is more potent (still possibly subject to external conditions). The method of breeding in this species may appear to lend some probability to the latter interpretation. All the males and females from a single gall and from the same or from neighboring leaves will remain on those branches from which the leaves arise, except for the few winged migrants, and even these seem at times to deposit within the gall. In the following year their offspring will be likely to crawl out to the new leaves on that branch, hence at least we might expect them to appear in groups. The production of winged forms occurs also in aphids where in some species in almost every generation a certain number of winged migrants appear. Whether here also they owe their presence to special external conditions or to an internal mechanism has not as yet been definitely determined. ${ }^{7}$

A few minor observations may be here noted. In only two cases have I ever found more than one stem-mother in the same gall. In both of these cases two stem-mothers occurred. Such cases are probably due to two stem-mothers occurpying exactly the same position-possibly to a late mother entering a still open gall. When one recalls that the entire leaf may be completely

\footnotetext{
${ }^{7}$ See Morgan, "Experimental Zoölogy," pages 322-334.
} 
covered with galls - converted into a mass of galls in some cases it is surprising that two stem-mothers do not oftener produce a common gall. When the galls are near together they crowd each other and flatten at the contact planes, but I have never found any communication between them.

The size of the gall does not appear to depend on the presence of the second generation; for, in one case I found a large gall occupied by a single stem-mother without progeny. She must have been enfeebled or parasitized, yet the gall was fully developed. On the other hand if the stem-mother dies after the gall has begun and before she lays her first eggs, the gall ceases to grow. Experiments should be made to see if the gall will develop after the stemmother is killed and only her early progeny left in the gall. The transfer of stem-mothers of different galls would also be profitable and might give interesting "hybrid galls."

The data indicate, if they do not prove, that the fertility of the stem-mother is intimately connected with the growth of the gall, and the growth of the gall in turn seems to depend on the condition of the leaf when it first begins to develop. The earliest galls develop rapidly and the stem-mothers in them lay the maximum number of eggs. Later galls remain small and the stem-mothers produce very few eggs. That the result is due to the condition of the leaf when the gall is first formed and not to the time of year is shown by an observation I made on this species in 1906. The buds on a certain branch were delayed as much as two weeks behind the others. When they did develop they became infested with $P$. fallax. The stem-mothers must therefore have waited two weeks for the bud to unfold yet the gall became full size. The converse point of view, that small galls are produced by weak mothers that will lay few eggs, may hold for some cases, but in general the facts indicate that it is the condition of the plant rather than that of the animals that determines the fertility of the latter.

Contrary to the behavior of other species of phylloxerans, the winged individuals of $P$. fallax may deposit their eggs within the gall. This is indicated by the empty abdomen of some of the winged individuals. That others may emerge and deposit outside seems also not improbable. This in fact would be the only 
means of dispersal for the species at present. ${ }^{8}$ The depositing within the gall may be connected with the condition of the gall that fails to open soon enough to let the migrant escape. In fact the galls do not become well opened until the sexual males and females are ready to crawl out. This divergence from the traditions of the genus might seem to throw some light on the occurrence of the apterous females of the second generation in P. fallax. The late opening of the gall may have led to the depositing of eggs within it by some of the winged generation. The presence of wings became therefore superfluous, at least except for colonization on other plants; hence the opportunity was given for the appearance of apterous females that would better insure the continuation of the race, since they are not exposed to the great dangers of failure to find a suitable plant, etc. Teleological argument of this kind, is, I think, of no special value. It is shot through and through by the kind of anthropomorphism that exposes much of our zoölogical work to reproach. For, to go no. further, it is equally manifest that the same advantage would accrue to other species even if they early opened their galls.

That the appearance of the apterous forms was due to a sudden change-a mutation - is more than probable, since both winged and wingless exist at present without intermediates and since the wingless condition is obviously an innovation. But the wingless individual is not simply a curtailed winged individual-lacking the wing-factor, in the latest phraseology-is shown by her egg-laying habits. In the winged forms all the eggs ripen at the same time; at least they all become fully formed before any are laid. In the wingless forms, on the contrary, the eggs ripen one (or two) at a time in rapid succession and are at once deposited-an apparent adaptation since the place of deposit is at hand and taken advantage of, while the winged forms must retain their egg for deposition in a different location.

A point of unusual biological significance is found in the fate of the supernumerary eggs of the stem-mother. She may lay, as we have seen, as many as fifty or more; yet the maximum number

\footnotetext{
${ }^{8}$ In the present case, however, the winged migrants contained only male eggs. This would lead to crossing but not to dispersal in any other sense.
} 
of those that become full size is not more than half this number. Although, potentially, of course, each egg must be looked upon as having the possibility, its fate is determined by the condition of nourishment of the stem-mother. A few of the later laid eggs produce the dwarfs, the rest begin to develop but do not hatch; they may be found in older galls, turned black and on the road to decay, an astonishing fact, in itself, possibly connected with the enormous productivity of their sisters that mature-a point discussed later.

There is an interval of four days between the observations recorded in the last table and those given in the next table, II, (June 8). In this interval a large number of sexual eggs have been laid in the large galls. It is noticeable that the number of supernumerary females has increased very little, indicating that the later laid eggs of the stem-mother do not hatch.

It will be seen that only eight winged individuals were found in these thirty-two galls. The galls were still closed so that there can be no question of their escape. The wingless individuals must be very prolific, as shown by the number of sexual eggs found in some of the galls where few wingless forms are recorded. Some deduction must be made, however, for small eggs recorded as male eggs, since these are mixed with stem-mother eggs still present. The size of the male eggs and of the stem-mother eggs is so nearly the same that their record is here combined. ${ }^{\circ}$

Even at this time the very small galls produced by late arrivals contain very few eggs or immature individuals (in addition to the stem-mother, not recorded in the count). In one case (No. 200) there was present in a very small gall only an immature stemmother. In another case (No. 174) there was present one immature apterous form, three eggs and one dwarf, showing that the latter must have developed from a stem-mother's egg, since the second generation was not yet mature. Other similar cases have been found.

\footnotetext{
'In the table "total," third column includes immature individuals and stem-mother eggs. Male and female eggs, seventh and eighth columns, also include whatever stem-mother eggs have not yet hatched. Such eggs would fall into the "male" column which is therefore too great. The stem-mother is not counted in with the total.
} 
It is not without interest to note the proportion of male and female eggs at this time, but it would be unsafe to make any deductions, since the numbers are as yet too small and the records confused owing to the presence of stem-mother eggs. It is nevertheless worth observing that even in the small and very small galls, where conditions have been extremely adverse, female eggs occur without any relative diminution in their number.

TABLE II.

\begin{tabular}{|c|c|c|c|c|c|c|c|}
\hline $\begin{array}{l}\text { NO. OF } \\
\text { GALL }\end{array}$ & SIZE & TOTAL & $\begin{array}{l}\text { LARGE } \\
\text { WING- } \\
\text { IESS }\end{array}$ & WINGEI & WARFS & $\begin{array}{l}\text { MALE } \\
\text { EGGS }\end{array}$ & $\begin{array}{l}\text { FEMALE } \\
\text { EGGB }\end{array}$ \\
\hline 167 & large $\ldots \ldots \ldots \ldots \ldots \ldots \ldots \ldots \ldots \ldots$ & 5 & 13 & 1 & & & \\
\hline 168 & medium...$\ldots \ldots \ldots \ldots \ldots \ldots$ & 193 & $\mathbf{2}$ & & 5 & 135 & $5^{I}$ \\
\hline 169 & $\operatorname{medium} . . \ldots \ldots \ldots \ldots \ldots \ldots \ldots$ & 112 & 5 & & 5 & 67 & 35 \\
\hline 170 & medium..$\ldots \ldots \ldots \ldots \ldots \ldots \ldots$ & 114 & 4 & & 2 & 73 & 35 \\
\hline 171 & médium $\ldots \ldots \ldots \ldots \ldots \ldots \ldots \ldots$ & 81 & 3 & & 3 & 50 & 24 \\
\hline 172 & medium- $\ldots \ldots \ldots \ldots \ldots \ldots \ldots$ & 52 & 4 & 5 & & $3^{8}$ & 5 \\
\hline 173 & small $\ldots \ldots \ldots \ldots \ldots \ldots \ldots \ldots \ldots$ & 14 & 3 & & & & \\
\hline 174 & small. $\ldots \ldots \ldots \ldots \ldots \ldots \ldots \ldots \ldots$ & 5 & & & $\mathbf{I}$ & & \\
\hline 175 & 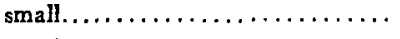 & 20 & 4 & $\mathbf{I}$ & $\mathbf{2}$ & & \\
\hline 176 & small. $\ldots \ldots \ldots \ldots \ldots \ldots \ldots \ldots \ldots \ldots$ & & 3 & & 2 & 9 & 2 \\
\hline 177 & small. $\ldots \ldots \ldots \ldots \ldots \ldots \ldots \ldots \ldots$ & 20 & 2 & & 2 & 15 & 2 \\
\hline 178 & 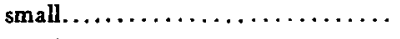 & 26 & 4 & $\boldsymbol{I}$ & 2 & 16 & 3 \\
\hline 179 & small $\ldots \ldots \ldots \ldots \ldots \ldots \ldots \ldots \ldots$ & 17 & 3 & & 2 & I I & $\mathbf{I}$ \\
\hline 180 & 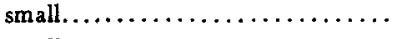 & 9 & 2 & & I & 6 & \\
\hline 181 & small $\ldots \ldots \ldots \ldots \ldots \ldots \ldots \ldots \ldots$ & 25 & 3 & & $\mathbf{I}$ & 16 & 5 \\
\hline 182 & very small...................... & 8 & $\mathbf{I}$ & & 2 & 4 & $\mathbf{I}$ \\
\hline 183 & very small $\ldots \ldots \ldots \ldots \ldots \ldots \ldots$ & 4 & & & $\mathbf{I}$ & & \\
\hline 184 & 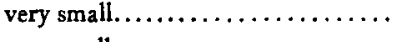 & 16 & 2 & & I & II & $\mathbf{I}$ \\
\hline 185 & very small $\ldots \ldots \ldots \ldots \ldots \ldots \ldots \ldots$ & 5 & & & $\mathbf{I}$ & & \\
\hline 186 & small $\ldots \ldots \ldots \ldots \ldots \ldots \ldots \ldots \ldots$ & 14 & 2 & & & 7 & 5 \\
\hline 187 & 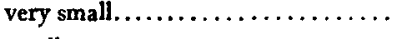 & 5 & & & I? & & \\
\hline I88 & 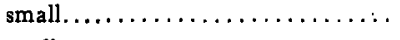 & 23 & 2 & & 2 & 12 & 7 \\
\hline 189 & medium..$\ldots \ldots \ldots \ldots \ldots \ldots \ldots$ & 59 & 5 & & 3 & 39 & 12 \\
\hline 190 & 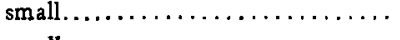 & 4 & & & & & \\
\hline 191 & 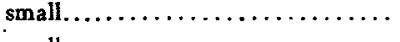 & 15 & 2 & & 2 & 8 & 3 \\
\hline 192 & small $\ldots \ldots \ldots \ldots \ldots \ldots \ldots \ldots \ldots \ldots$ & 15 & 3 & & & 4 & 8 \\
\hline 193 & 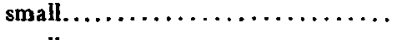 & 16 & 2 & & $\mathbf{I}$ & 9 & 4 \\
\hline 194 & 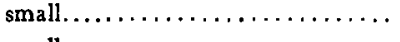 & 7 & I & & $\mathbf{I}$ & 4 & $\mathbf{I}$ \\
\hline 195 & small $\ldots \ldots \ldots \ldots \ldots \ldots \ldots \ldots \ldots \ldots$ & 12 & $\mathbf{I}$ & & 3 & 6 & 2 \\
\hline 196 & very small. $\ldots \ldots \ldots \ldots \ldots \ldots \ldots$ & 3 & & & & & \\
\hline 197 & very small........................ & 3 & & & & & \\
\hline 198 & small $\ldots \ldots \ldots \ldots \ldots \ldots \ldots \ldots \ldots \ldots$ & 14 & $\mathbf{I}$ & & I & 9 & 3 \\
\hline 199 & medium........................ & . & 2 & & 2 & $3^{2}$ & 7 \\
\hline 200 & 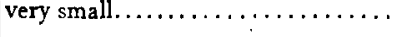 & StM & & & & & \\
\hline
\end{tabular}


Table III, June $\mathrm{I} 7(20 \mathrm{I}-240)$ brings out not much that is new but confirms some of the findings of the preceding data. Despite the fact that male and sexual females have now begun to hatch (in some of the later cases these are reckoned in with male and female eggs) the number of dwarfs has not materially increased. Male eggs preponderate somewhat, the sum total being 342 female eggs to 454 male eggs.

\section{THE IDENTIFICATION OF THE SPECIES OF P. FALLAX}

Confusion has arisen as to the identity of this species owing to the variations in its life-cycle. Walsh, who first described the species, states that he never found a winged individual in the galls, although he has opened hundreds of them. Pergande's observations on this gall extending over several years "run counter to those of Walsh, for I have found this particular gall swarming with the winged female." Pergande accounts for this discrepancy on the ground that his own observations were made from early May until June, and those of Walsh from June I 7 th to the end of the month "when the winged forms had already forsaken the galls." Pergande continues: "If the galls be opened early in May, or before the nipple has opened, they will be found filled with winged insects, pupæ, numerous eggs and what appear to be larvæ. These supposed larvæ, however, upon careful examination are not larvæ hatched from eggs deposited by the stem-mother, but the true sexual individuals, both males and females, produced from eggs deposited freely by the winged females."

My own observations furnish results that harmonize in part the observations of Walsh and of Pergande. They show that many galls do not ever produce winged individuals and that their place is taken by apterous forms; also that in some galls both types are present but as yet I have found none containing only winged individuals. The history of the galls was so closely followed that it is quite certain that the winged forms did not first appear and then leave the galls. On the other hand when winged forms occur their number is not large and the galls could not be said to be filled with them. It follows, in all probability, that in different 
Sex Determination in Phylloxerans and Aphids

TABL E III.

\begin{tabular}{|c|c|c|c|c|c|c|c|c|c|}
\hline $\begin{array}{c}\text { No. } \\
\text { or } \\
\text { GAL.Z }\end{array}$ & size & TOTAL & $\begin{array}{c}\text { LARGE } \\
\text { WING- } \\
\text { IEss }\end{array}$ & WINGED & DWARFS & $\begin{array}{l}\text { MALE } \\
\text { EGGS }\end{array}$ & $\begin{array}{c}\text { FEMALE } \\
\text { EGGS }\end{array}$ & $\begin{array}{c}\text { SEX } \\
9\end{array}$ & $\begin{array}{c}\operatorname{six} \\
\delta\end{array}$ \\
\hline 201 & small........... & 13 & 2 & & 1 & 5 & 5 & & \\
\hline 202 & small........... & 16 & $\mathbf{I}$ & & 4 & 5 & 4 & & \\
\hline 203 & small........... & 22 & 2 & & 6 & 7 & 7 & & \\
\hline 204 & small.......... & 44 & 4 & & 4 & 30 & 6 & & \\
\hline 205 & small........... & 6 & 2 & 2 & & & & & \\
\hline 206 & small........... & 17 & 3 & 2 & & & & & \\
\hline 207 & small........... & 8 & 4 & & 4 & & & & \\
\hline 208 & very small........ & (egg) & & & & & & & \\
\hline 209 & very small........ & 6 & & & & 2 & 2 & & \\
\hline 210 & very small....... & 9 & $\mathbf{I}$ & & I & 6 & I & & \\
\hline 211 & very small........ & 23 & 2 & & & 14 & 6 & I & \\
\hline 212 & very small....... & 18 & 2 & & I & 15 & & & \\
\hline 213 & large...$\ldots \ldots$ & $3^{\circ}$ & 。 & 6 & $\mathrm{I}$ ? & 23 & & I & \\
\hline 214 & medium $-\ldots$ & 18 & 2 & & & 9 & 5 & 2 & \\
\hline 215 & medium- & II & I & & 2 & I & 4 & 2 & 1 \\
\hline 216 & small $+\ldots \ldots$ & 22 & 7 & & & 4 & 7 & & 4 \\
\hline 217 & small $+\ldots \ldots$ & $5^{\circ}$ & 3 & & & 14 & 28 & I & 2 \\
\hline 218 & small $+\ldots \ldots$ & 16 & 2 & & & 15 & 9 & & \\
\hline 219 & small $+\ldots \ldots$ & 24 & 3 & & & 13 & 3 & & 5 \\
\hline 220 & small........... & 13 & 3 & & & & & & \\
\hline 221 & small.......... & 16 & 3 & & I & 6 & 6 & & \\
\hline 222 & small........... & $3^{8}$ & 3 & & & 27 & 8 & & \\
\hline 223 & medium........ & $3^{I}$ & 2 & & I & 16 & 9 & 2 & I \\
\hline 224 & medium........ & 27 & 10 & 2 & 4 & & 10 & & $\mathbf{I}$ \\
\hline 225 & small.......... & 15 & $\mathbf{I}$ & & & 6 & 5 & 2 & I \\
\hline 226 & small.......... & 25 & 2 & & & 10 & 13 & & \\
\hline 227 & n........... & 7 & $x$ & & & 2 & 2 & & 2 \\
\hline 228 & big ............ & 126 & 12 & & & 44 & 70 & & \\
\hline 229 & big ............. & 105 & II & & & 32 & 19 & 35 & 8 \\
\hline $23^{\circ}$ & big.............. & 100 & 6 & & & 55 & 39 & & \\
\hline $23 I$ & big............ & III & 17 & & & 80 & 89 & & \\
\hline 232 & & 172 & 3 & & & 9 & I & & \\
\hline 233 & & 9 & & 6 & & & & & \\
\hline 234 & & 9 & & 4 & & & & & \\
\hline $\begin{array}{l}235 \\
236\end{array}$ & & 3 & I & & & $\begin{array}{l}12 \\
23\end{array}$ & $\begin{array}{r}4 \\
27\end{array}$ & I & 3 \\
\hline 2.37 & & 5 & & & & 39 & iI & & \\
\hline 238 & & 6 & & & & 35 & II & & \\
\hline 239 & & 4 & & & & 12 & 27 & & \\
\hline 240 & & 3 & & & & 22 & 24 & & \\
\hline
\end{tabular}


localities the proportion of wingless and winged forms varies widely. Local races or local conditions may be the cause of this variation, and near New York and near Stamford, Conn., the cycle is intermediate between that described by Walsh and that given by Pergande.

\section{LIFE-CYCLE IN PHYLLOXERA CARY ECAUIIS}

As stated on a preceding page the life-cycle of this species is typical. When the gall is mature it cracks open and allows the winged individuals to escape. These fly out and those that alight on the leaves deposit their eggs on the under surface of the leaves along the midrib, especially near the base. Hundreds of eggs, large and small, may be found on the same leaf. A count of eggs from the leaves showed large female eggs and small male eggs approximately in the proportion of one to five. The data obtained in this way are open to some objection, because if the male layers should escape from the galls first, there would be at first a disproportionately high male rate. Or if the male layers were more active fliers, they might scatter more widely and more of them fail to reach the leaves of the trees from which they came. Again if the males hatch sooner than the females, proportionately ton few male eggs would be left on the leaves. For perfectly accurate data the counts should be made throughout the migration period and this I have been unable to do. Nevertheless I think the proportions given above represent an approximately true estimate.

Of far greater importance are the counts of the male producing and female producing inhabitants of each gall, as these are all the offspring of the same stem-mother, herself the product of a winter egg, fertilized by a "female producing" spermatozoon. The galls had been placed in Carnoy solution ${ }^{10}$ and preserved in 95 per cent alcohol. They were opened and their inmates placed in absolute alcohol and then in xylol, and examined under the microscope.

\footnotetext{
${ }^{10}$ Equal parts of absolute alcohol, glacial acetic acid and chloroform, saturated with corrosive sublimate.
} 
The abdomen and its eggs become so transparent in the xylol that the size of the contained eggs is readily made out.

Most of the galls were closed except a few at the beginning and end of the series, as indicated by the small number of migrants present. Even in these open galls a few immature individuals still remain. In the galls in which a large number of winged forms are recorded the number of immature individuals is small.

The 34 galls recorded in Table IV contained 4824 male producers and 1704 female producers (migrants) or 2.8 to $\mathrm{I}$. There is much variation as to the number of eggs contained in each individual; the female-producers as a group containing fewer than the male-producers. If we estimate the male producers as averaging 16 eggs and the female producers 8 eggs, the proportion will be 77,184 male eggs to 13,632 female eggs, or 5.6 to 1 . The excess of males is therefore again shown both by the presence of more male producers containing more eggs, as well as by the less exact estimate based on the supposed average number of eggs.

TABLE IV.

\begin{tabular}{|c|c|c|c|c|c|c|c|}
\hline $\begin{array}{l}\text { MALE } \\
\text { PRO- } \\
\text { DUCERS }\end{array}$ & $\begin{array}{c}\text { FEMALE } \\
\text { 'RODUCER }\end{array}$ & [MMATUR] & & $\begin{array}{c}\text { MALE } \\
\text { PRO- } \\
\text { DUCERS }\end{array}$ & $\begin{array}{l}\text { FEMALE } \\
\text { RODUCERS }\end{array}$ & MMATURE & \\
\hline 9 & $\mathbf{I}$ & 9 & open & 32 & 1 & many & \\
\hline 8 & 24 & 54 & open & 106 & 2 & - & \\
\hline 8 & II & 8 & open & 23 & 8 & & \\
\hline 120 & I & - & closed & 41 & 13 & 13 & open \\
\hline 13 & 331 & - & & 16 & 5 & Io & open \\
\hline 152 & 177 & $\rightarrow$ & & 7 & 0 & 3 & open \\
\hline 240 & 0 & - & & $3^{8}$ & 5 & 90 & open \\
\hline 229 & 0 & 295 & & $3^{6}$ & 3 & 63 & open \\
\hline 185 & 0 & 92 & & 209 & II & 53 & opening \\
\hline 219 & 29 & - & & 278 & 0 & $5^{6}$ & closed \\
\hline 87 & 209 & - & & II & 106 & 199 & opening \\
\hline $3^{61}$ & $\circ$ & I & & 3 & $3^{86}$ & 24 & \\
\hline 127 & 0 & - & & 383 & 4 & $3^{I}$ & closed \\
\hline 390 & 14 & - & & 0 & 328 & II & closed \\
\hline $3^{23}$ & 3 & - & & 40 & 0 & 197 & closed \\
\hline 240 & 0 & - & & 335 & 27 & 27 & closed \\
\hline 291 & $\circ$ & - & & 293 & 8 & $2 I$ & closed \\
\hline
\end{tabular}


The more important facts brought out by a study of the inhabitants of these galls remains to be discussed. Some few galls contain only male producers, and there is one record at least where all the migrants were female producers. The great majority of the galls contained both sorts of migrants, with a preponderance of male producers. The results have a rather unique bearing on the question of sex-determination as will be pointed out later.

Two additional facts of prime importance must be also noted here. I kept a record of the size of the galls. No relation between the proportion of male to female producers and the size of the gall was observed. In nearly all of the galls a few or even many very small individuals may be found. These carry a very few eggs, but the eggs are full size of their kind. I have observed cases where only a single female egg wes present. There can be little doubt that lack of food is the cause of the small size of these individuals. Their greater abundance amongst the later hatched individuals supports this interpretation as well as other facts observed. It follows, therefore, that food conditions do not determine whether a migrant becomes a male or a female producer. It is probable, therefore, that internal factors have already determined the result. Whether these internal factors can be traced to internal or to external conditions in the preceding generation is not evident from the facts given, but there is another point that would seem to indicate that the factors are internal in the first generation also. The stem-mother continues to lay her eggs up to the time when the gall opens. Before this event when the gall is swarming with larvæ and the walls completely lined by them, the conditions for obtaining food must be less favorable than during the early stages of the gall. Yet both amongst the first eggs laid, and amongst the last laid, male and female producers occur. It is difficult to see how food conditions determine the result; for even if the eggs should be affected only at a certain period on which the momentary condition of nourishment might act still we should expect a greater preponderance of one or of the other sex, according to whether the general conditions are favorable or the reverse.

The data furnish strong evidence in favor of some sort of 
internal factor, that preponderates especially in those cases where a large number of eggs of one kind are produced. These numbers are so large that the results cannot be due to chance. The nature of the factor involved will be discussed later.

THE SEXUAL FORMS OF OTHER SPECIES

The sexual forms of only a few of our Phylloxerans have ever been seen. Pergande describes 4 out of a total of 33 species. The minute size of the sexual individuals, as well as the fact that the eggs from which they come are often deposited on the limbs or trunk of the tree where they are difficult to detect accounts in part for this lack in our knowledge. By the following simple method, however, it is very easy to obtain the third generation. The galls should be collected when the winged migrants are ready to emerge and placed in a glass dish covered with fine cloth. The water from the galls may collect on the glass and drown the migrants unless special precautions are taken. I use large flat dishes and turn them upside down so that the galls lie in the middle of the cloth. At other times I have put the winged individuals into paste-board boxes, covered with cloth. The eggs are deposited on the glass, cloth, galls or paste-board, as the case may be. In the course of about a week they hatch; the small, numerous males will be found running rapidly about, while the females move more slowly.

Having found that the sexual forms in P. fallax and P. caryxcaulis are mature on hatching, I was led to hope that mature sexual forms of all the other species might also be obtained, by the method given above. To my surprise it was found that in three other species studied all the eggs laid by the migrants were the same sizenot of two sizes as in the other two species. Thinking that I might have obtained eggs of only one sex, I opened large numbers of individuals and still found eggs of only one size. I then made sections of the individuals hatched in my dishes and found that the sexual organs were entirely immature. Furthermore, careful study of the individuals showed that they are all alike, or so similar that I detected no differences by means of which they could be separated into males and females. 
A microscopic study of the reproductive organs showed that these were so immature that I was unable to tell whether the individual would be male, sexual female, or parthenogenetic.

In only a few cases as stated above have the sexual forms of the American species of Phylloxerans been described. This is to be regretted because it leaves our knowledge of the life-cycle incomplete at a critical point, and also because the sexual forms are more different in different species than are the parthenogenetic individuals, and therefore are of the utmost importance in the classification and identification of this difficult group. By means of the method here described one may obtain an abundance of material that would be in some cases very difficult to find under natural conditions.

I have given figures in Plate I of the sexual forms male and female of the two species dealt with at length in this paper, and also of the sexual (?) forms of three other species found in the vicinity of Woods Hole, Mass. In the latter only one form exists, as I have stated. Sections show that the reproductive organs are in a rudimentary stage and while I have not made very careful study of them, still I have not been able to distinguish the male from the female organ at this time. This fact is all the more striking when it is recalled that in the other species the male organ forms a conspicuous feature even of the early development and the large testes of the just hatched male contain ripe sperm. In the female, too, the egg at the time of hatching almost completely fills the body and is so conspicuous that it can be seen through the transparent wall of the body.

It remains for the future to discover the fate of these sexual (?) forms of the other species. The long proboscis may indicate that they live on the bark of the trees. If so their small size would make it difficult to detect them. I enclosed in a cloth bag a branch of a tree and placed within it many ripe galls. A subsequent examination of the branches failed to reveal any Phylloxerans, but the conditions were not very favorable.

The idea suggests itself to any one familiar with the facts here recorded that the third generation of these species is not a sexual generation at all, but one destined to continue the race by partheno- 
genesis another year. It is not inconceivable that they produce a different gall another year, but as yet there are no facts to support this view.

The sexual males and females of P. fallax are shown in Plate I, Figs. I-4, the first two drawn from life, the second two from preserved specimens. The male shown in Fig. I was probably slightly flattened, while held under the cover slip, so that the preserved specimen, Fig. 3, gives a truer idea of the form.

The sexual male and female of $P$. caryacaulis are shown in Figs. 5 and 6. The difference in size is less marked than in the last case.

The remaining three figures $7,8,9$, of the Plate, represent the single type of individual that emerges from the eggs of the winged migrant of three species. The first of these comes from a large, elongated stem-gall, quite abundant in Woods Hole. The gall, closed at first, cracks open to set free its migrants from whose eggs this form hatches. The species appears to be $P$. subelliptica, Shriner; but Shriner's description is very incomplete. Pergande who has seen only the gall questions whether it may not be a form of $P$. caryrecaulis. I had in fact at first confused these two at Woods Hole, but an examination of P. caryæcaulis from Woods Hole showed migrants with two kinds of eggs as in the New Bedford type, while the migrants of the present gall contain only one kind of egg. Obviously they are different species, or else different phases of the same cycle. The form shown in Fig. 7 is entirely different from the sexual forms of $P$. caryæcaulis. It is not uninteresting to find that the polar plates of the eggs of the migrants of this form show six chromosomes, (Figs. XIX, $A-F$ ) as in $\mathrm{P}$. carvæcaulis, but these are not of different sizes.

In Plate I, Fig. 8, is shown the individual that emerges from the egg of the migrant of a species which I provisionally identify as P. caryæglobuli, Walsh. Pergande cites the descriptions of Walsh and of Shriner, but questions whether Shriner's account does not apply to another species. Walsh's description is too brief for accurate identification. The sexual (?) form here described is so specifically marked that in future there should be no difficulty in settling the status of this species, if the plan of hatching the eggs of the winged migrant, here proposed, is followed. 
The last figure, Plate I, Fig. 9, is from a small leaf gall with a short nipple opening beneath. When open, four or five short bracts border the margin. The galls seem to corresp ond to $P$. depressa, but again the description is too imperfect to make identification certain.

These figures show, I hope, the value of this stage in the life cycle for systematic identification. Until this stage has been further studied in more species, and until their relation to the sexual forms is known, our knowledge of the genus must remain, as at present, most fragmentary.

In connection with the study of the sexual (?) forms of these species I have also studied the chromosomes of the equatorial plates of the migrants in the hope that a knowledge of the chromosome number might help in disentangling the systematic identification of the species, but also and primarily in the hope of discovering whether two types of chromosome groups exist where only one sexual (?) form has been discovered. The first question can be answered decisively; the second, with less certainty. The chromosome groups are sufficiently different to aid materially in identification. Within these species I have not been able to distinguish two types of polar spindle plates as in $\mathrm{P}$. caryæcaulis and occasionally in $P$. fallax, but the number of individuals found with perfectly distinct groups of chromosomes has not been large (despite the great amount of labor expended in finding the polar spindles) so that I should not like to speak positively on this point.

Polar plates of the polar spindle of the eggs of $P$. caryæglobulare shown in Fig. XIX, $G, H$. Twenty-two rounded chromosomes of very different sizes have been counted in several plates. As I pointed out in 1906 , it is interesting to find so large a number of chromosomes within the genus in which the winged individuals are so closely similar. Evidently the number, as such, is of no significance.

In P. depressa there are six chromosomes (Fig. XIX, $I, \mathcal{F}$ ) four large and two small, as determined by a polar spindle of the stemmother's egg and by a late nuclear stage of the same sort of egg. In a species whose sexual form I have not yet obtained, P. caryæfoliæ, the polar plates show eight chromosomes of different sizes 
(Fig. XIX, $Q, R, S$ ). Whether the size differences that appear are significant I cannot state as yet. The somatic cells of embryos from these eggs (artificially obtained) show also eight chromosomes.

In P. globosum, the polar plates contain six chromosomes (Fig. $\mathrm{XIX}, K-N$ ) but in this case they are not rounded but elongated. Their bent form renders a study of their size relations difficult.

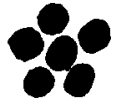

$A$

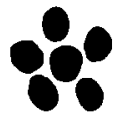

$B$

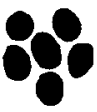

C

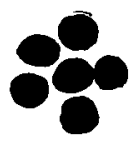

$D$

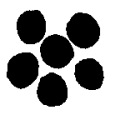

E

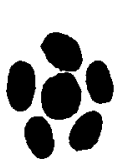

F

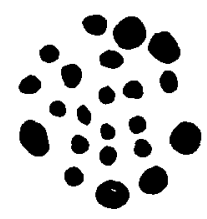

$G$

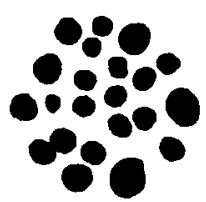

$H$

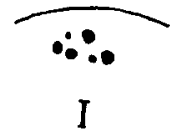

I

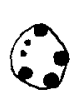

f

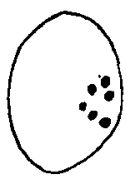

o

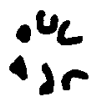

$K$

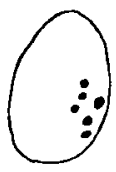

$P$

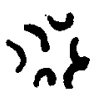

$L$

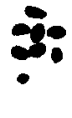

2
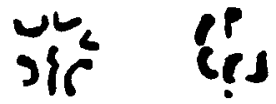

$M$

$N$

Fig. XIX $A-F$, equatorial plates of polar spindles of egg of migrant of P. subelliptica; $G, H$, ditto of caryæglobuli; 1 , equatorial plate of polar spindle of egg of stem-mother of P. depressa; $\mathcal{F}$, late egg-nucleus of same; $K, L, M$, equatorial plate of polar spindles of egg of migrant of P. globosum; $N$, equatorial plates of polar spindle of stem-mother's egg of same; $O, P$, late egg-nucleus of same; $2, R$, $S$, equatorial plate of polar spindle of egg of migrant of $P$. caryxefolix. None of the figures drawn to scale. 
Six chromosomes are found in polar spindles of $\mathrm{P}$. subelliptica much like the female group of $\mathrm{P}$. caryæcaulis (Fig. XIX A-F).

The preceding facts and figures show that identification of species may be materially assisted by a knowledge of the chromosomes. It may turn out that the failure to discover two kinds of groups of chromosomes in the eggs of the migrants has a real meaning in connection with the presence of only one form in these galls.

\section{SPERMATOGENESIS IN APHIDS}

Stevens described in 1904, in the first spermatocyte division in aphids, a lagging (accessory) chromosome, which, instead of passing to one pole, divides equally so that each of the first spermatocytes receives a half. All of the chromosomes were found to divide again equally in the second division to produce, in all, four spermatozoa. The result stood in the way of any attempt to bring the aphids into line with other insects possessing an accessory and made difficult any conclusion regarding the relation of the accessory to sex production. Stevens overlooked two essential facts in the spermatogenesis, namely, the fact that the lagging chromosome does not divide, as she had supposed, in the first division; and second, the fact that one of the products of the first spermatocyte division is much smaller than the other and subsequently degenerates.

During the winter of 1907-1908 I discovered in the phylloxerans the two points just noted. These facts I communicated to Miss Stevens, and she most generously gave me some of her former preparations of aphids to study. These with others of my own, that I had made some years before, convinced me that while the failure of the lagging chromosome to divide is more difficult to make out, the aphids show in all essential respects the same relations as do the phylloxerans. I urged this conclusion on Miss Stevens, who, after renewed investigation of her material, came to the same conclusion. Her results were sent to me in May, 1908, for publication in the Journal of Experimental Zoölogy, but owing to delay in publication did not appear until January, 1909. Meanwhile von Baehr, who had been working on aphids, published conclusions in 1908 similar to those found by Stevens and myself. 
It is not my wish to enter here into a detailed account of the spermatogenesis in aphids, since Stevens has already gone over the ground, but I should like to state a few of the results of my own observations that will serve to form the basis of comparison between the spermatogenesis of the aphids and that of the phylloxerans. In one not unimportant point I get a somewhat different impression of the facts from that given by Stevens in her last paper, namely, that the process, by which the division of the lagging chromosome takes place, while variable, is more regular than Stevens" account might lead one to infer. That irregularities occur, that whole cysts may "go wrong," as in other insects, is not to be denied; but in the great majority of cases the lagging chromosome moves into the large cell from which the two spermatozoa are ultimately formed (after the second division).

I have chosen of the several species of aphids examined three species from the Willow, for description. Presumably the first of these is the same species studied by Stevens who did not identify the species she used. Mine were obtained abundantly at Woods Hole, Mass.; those of Stevens, at Harpswell, Maine.

In Aphis salicola the spermatogonia contain 5 chromosomes beyond any doubt (Fig. XX, $A-C$ ). These can best be counted at a stage just before the equatorial plate is produced.

Three nearly equal chromosomes appear in the equatorial plates of the first spermatocyte (Fig. $X X, D-F$ ). At the first spermatocyte division two of the chromosomes divide, the third is drawn out (Fig. XX, $G-M$ ). Later stages in the division are shown in Fig. XX, $M-X$. Here, as in the phylloxerans, the lagging chromosome is not withdrawn into the larger cell until the very last moment, when in fact the nuclear sac has begun to appear around the chromosomes. The final stages in the process seem to involve a flowing or contraction of the chromosome, whose end in the large cell gradually increases in size as the chromosome shortens In the final stages the lagging chromosome is often surrounded by only a thin film of protoplasm, so that the two cells - the larger and the smaller - appear to be connected by a very delicate bridge. This bridge is found at times when the end of the lagging chromosome, still within the small cell, is slightly enlarged. The bridge 

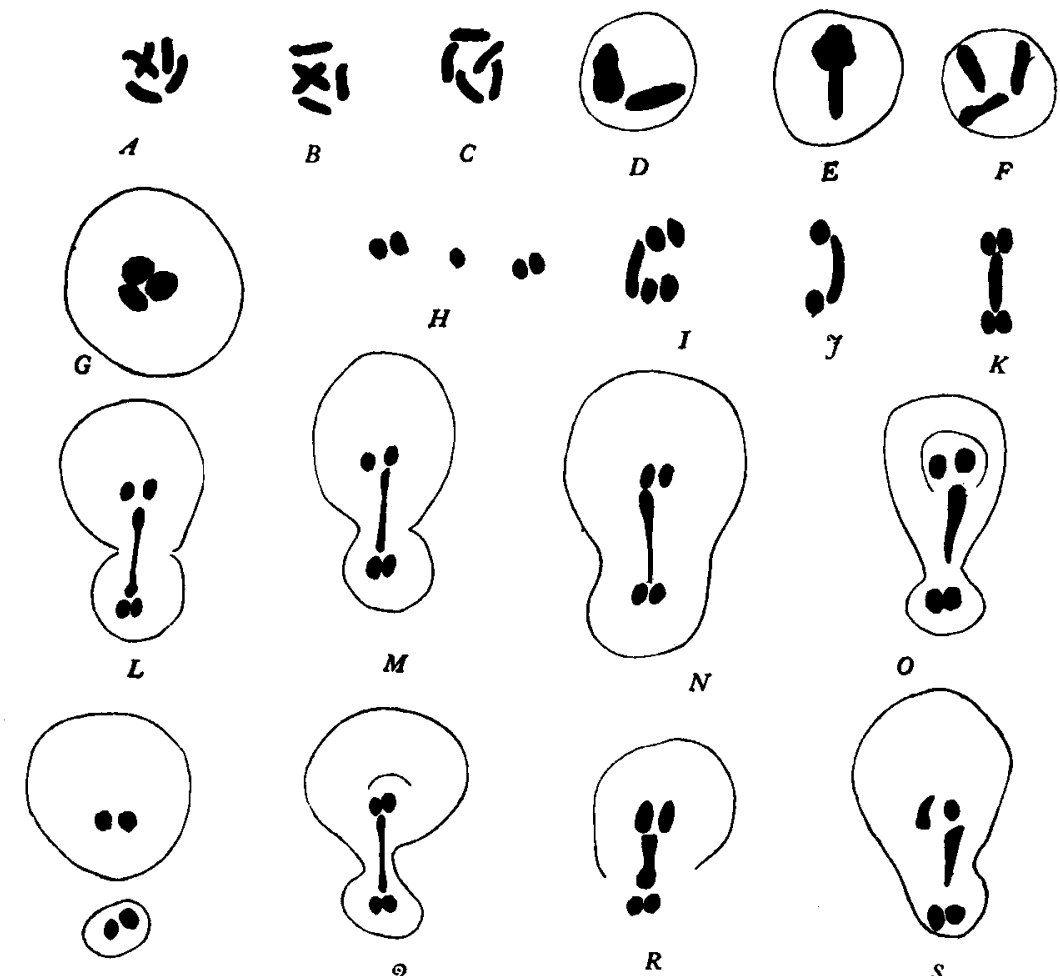

$P$
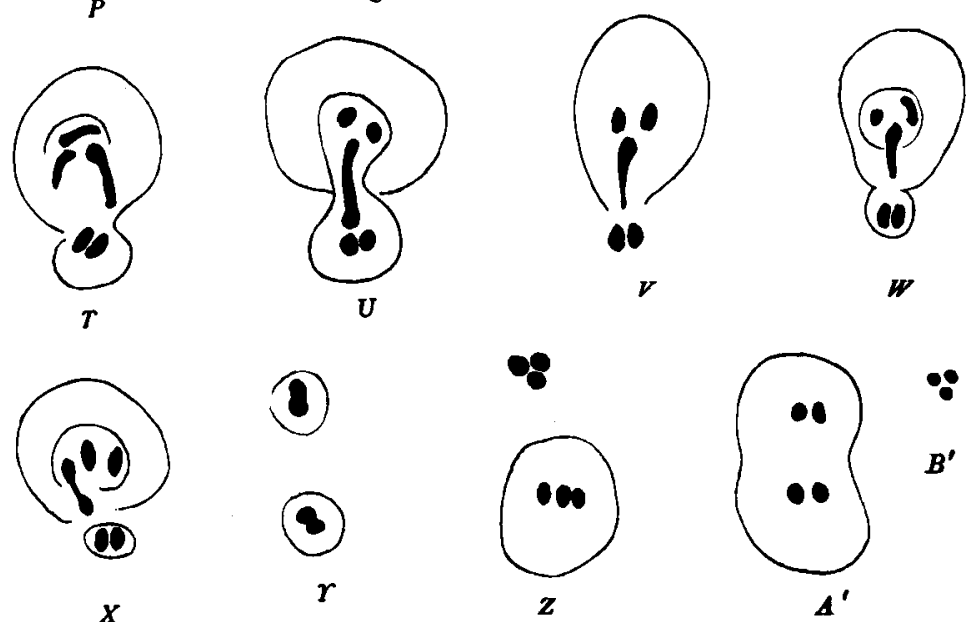

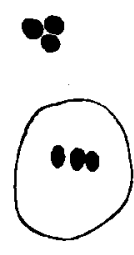

$\boldsymbol{Z}$

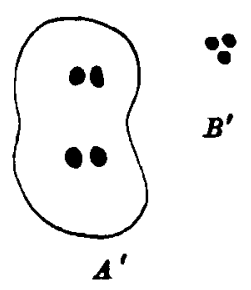

Fig. XX Aphis salicola. $A-C$, spermatogonial nuclei; $D-F$, stages just prior to first spermatocytes; $G$, equatorial plate of first spermatocyte; $H-X$, stages in division of first spermatocytes; $r$, rudimentary cells; $Z$, equatorial plates of second division; $A^{\prime}$, second spermatocyte division, $B^{\prime}$, after division. 
bulges sometimes to one side. That artificial conditions, such as handling or osmosis, might break such a delicate connection at this time is not at all improbable, and such an artificial result might give the impression that the accessory is actually divided. Moreover if the bridge arches toward or away from the observer, the effect may be produced at certain focal levels of discontinuity between the ends of the lagging chromosome, when none such exists. The arch containing the connecting thread of the accessory might also be cut off by the knife, and lie in another section, where its extreme tenuity might defy discovery. Such considerations make me sceptical as to whether the lagging chromosome in this species of aphid ever normally divides into two. Figures like that of Plate I, Fig. 3, in Stevens' paper in which two nearly equal cells contain each one end of the accessory do not seem to me to represent accurately the conditions that I have seen, if on no other ground than in the absence of a bridge of cytoplasm around the connecting thread of the accessory.

In the willow aphid the rudimentary cell is extremely small and contains very little cytoplasm. It does not subsequently divide and slowly degenerates.

The equatorial plate of the second spermatocyte division of the large cells shows three chromosomes (Fig. XX, Z). These divide equally to produce each two spermatids (Fig. XX, $A^{\prime}$ ). In all essential respects the results agree with those that $I$ have found in the phylloxerans.

Von Baehr's facts on a willow aphid A. saliceti with the same number of chromosomes agree with those given here. He also determined that while the female parthenogenetic egg contains six chromosomes, the male egg, after extrusion of its polar bodies, contains only five. He leaves open, of course, as I had done also, the question as to how the number becomes reduced to five. The most plausible inference was obviously that one was lost in the polar body. Stevens' earlier statement (I905) that "there is no evidence in my material of any difference between the maturation of the female parthenogenetic egg and that of the male" is probably incorrect, and her count of the same number of chromosomes in the somatic cells of the male and female embryo must have been an error. 

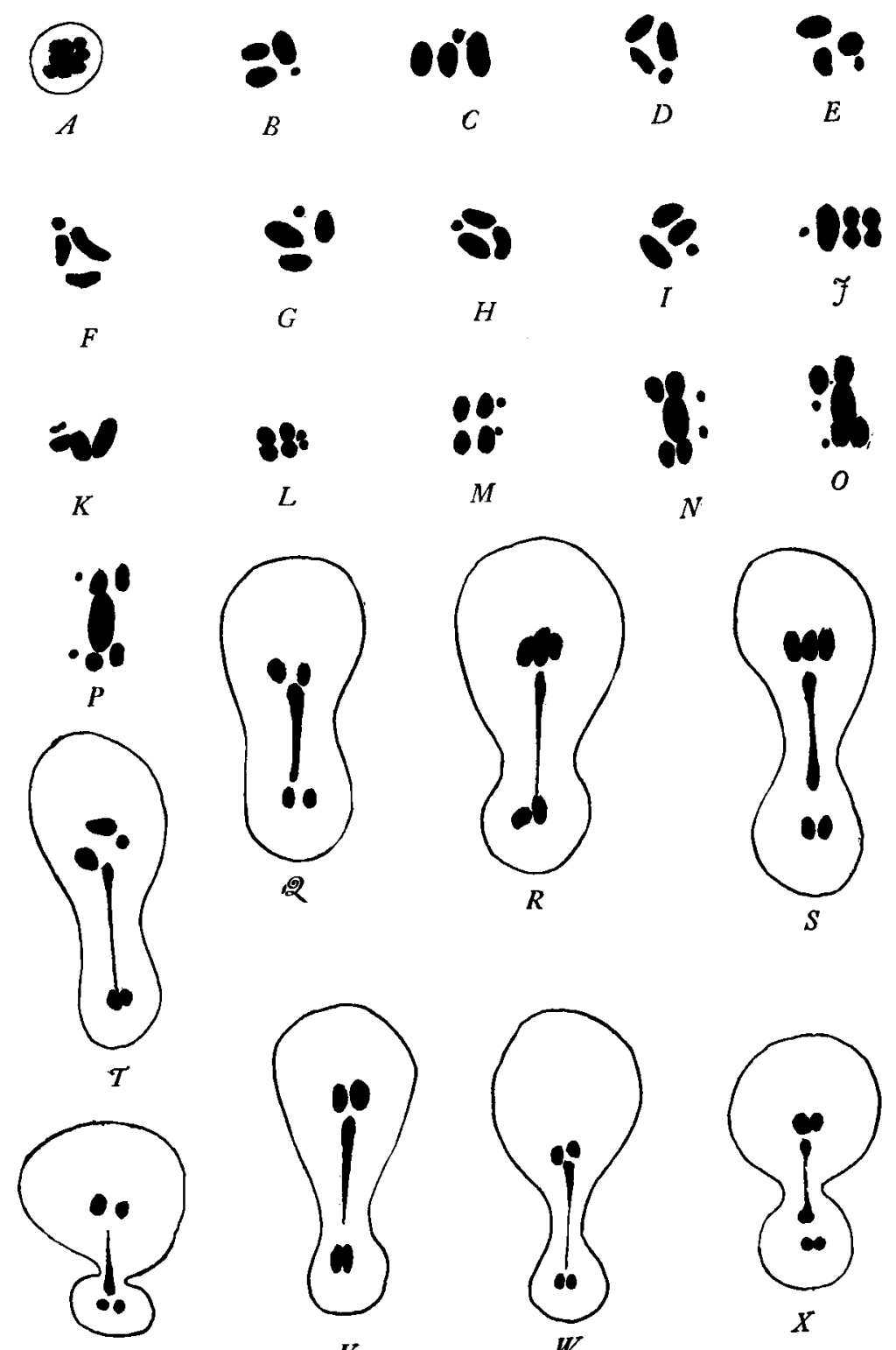

$U$
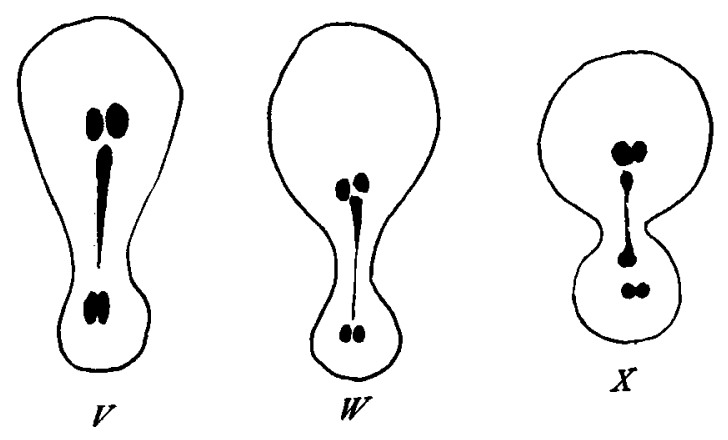

Fig. XXI Lachnus dentatus. $A$, stage prior to first spermatocyte; $B-I$, equatorial plates of first spermatocytes; $J-X$, division stages of same. 
In 1907 Tannreuther published an account of the germ cells of an aphid, Melanoxanthus salicis. He has confused the sequence of the stages to such an extent, and has overlooked so many of the essential facts, that a detailed criticism of his statements would be unprofitable. I suspect furthermore that his account of intranuclear polar body formation is entirely erroneous.

Another species of aphid, Lachnus dentatus, gives rise to sexual forms late in the autumn. It contains a large accessory and another
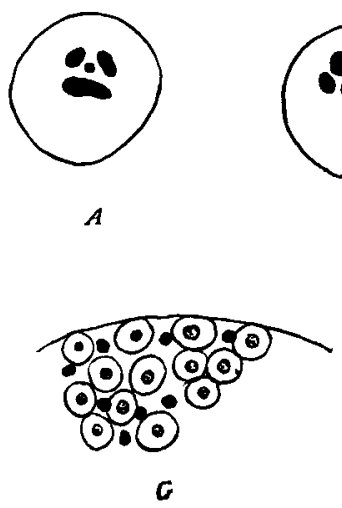
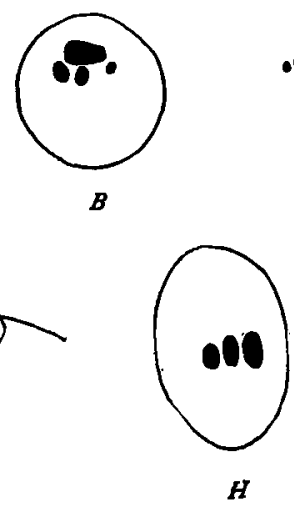

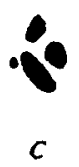

$c$

$H$

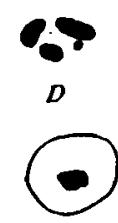

E
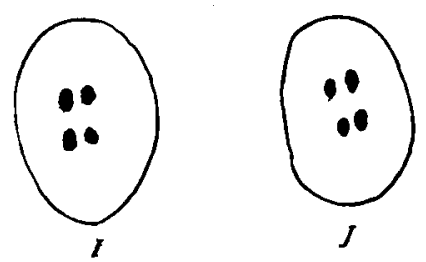

Fig. XXII Lachnus dentatus. $A-D, F$, second spermatocyte, equatorial plates; $E, F$ (lower half), rudimentary cells; $G$, part of ovary showing rudimentary cells (black); $H$ - $\boldsymbol{f}$, second spermatocyte divisoin.

very small chromosome, besides two others in the reduced number. I was not without hope that this might prove an analogous case to that of Phylloxera caryæcaulis and that the smallest chromosome might be a small accessory in addition to the large one. This is, however, not the case as the following facts show.

Equatorial plates of the first spermatocyte division are drawn in Fig. XXI, $B-I$; side views of the dividing plate in Fig. XXI, $L-P$; and later stages in Fig. XXI, $Q-X$; Fig. XXII, $F$. In Fig. $\mathrm{XXI}, K-P$, the division of the smallest chromosomes is clearly seen. The unequal division of the cell is shown in Fig. XXI, $R-W$. 
Equatorial plates of the second division are shown in Fig. XXII, $A-D$. Here again the four chromosomes are seen. The lagging chromosome is now, proportionately to the other chromosomes, much larger. In two cases (Fig. XXII, $E, F$ ), the rudimentary spermatocytes are also shown, and a section (Fig. XXII, $G$,) through a follicle containing the second spermatocyte shows how conspicuous these rudimntary cells are at this time. In fact

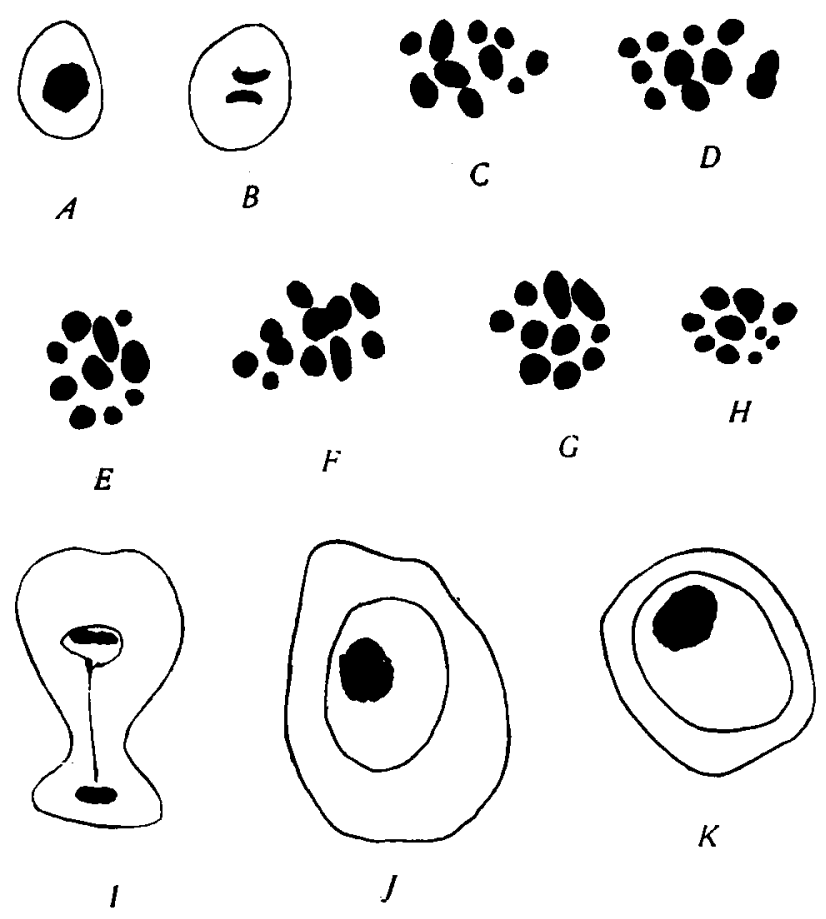

Fig. XXIII Chaetophorus viminalis؛ $A$, spermatogonial equatorial plate; $B$, division of same; $C-H$, equatorial plates of first spermatocytes; $J$, division of first spermatocyte; $\mathcal{F} . K$, synapsis of chromosomes of egg.

they form one of the most conspicuous and easily seen features of such cysts.

Another species, Chaitophorus viminalis, produces sexual forms in the late summer. It is not favorable for study since the chromosomes are numerous, crowded, and one, or more, irregular 
or possibly double. I count 9, Io and II, but the clearest cases (Fig. XXIII) give ro chromosomes and this I believe to be the typical number. A late stage in the division of the first spermatocyte is figured in Fig. XXIII, $I$.

This species shows clearly, however, in the oögenesis a stage that resembles the synapsis stage of other insects. It is shown in Fig. XXIII, $\boldsymbol{F}-K$. These ova are found in the bottom of the ovary, and probably become the sexual eggs. If this were not the case, a synapsis stage would be passed through even in eggs that retain the full number of chromosomes. It has been stated in fact that this process occurs in the parthenogenetic eggs of aphids, but this requires confirmation.

CYTOLOGICAL PARALLEL BETWEEN PHYLLOXERA CARYACAULIS AND SYROMASTES MARGINATUS

Wilson has pointed out recently the striking resemblances in the chromosomal cycle between these two species, and the comparison removes what might otherwise have proved to be a very anomaluus condition in one of the two forms here described. The diagram which Professor Wilson has constructed (1909) will show at a glance the points of comparison.

The comparison depends primarily on the behavior of the two accessories and is independent of the interpretation as to their origin. Wilson adopts the view that in this case two chromosomes are the product of division of one accessory, rather than an original pair that now move to the same pole. In support of this interpretation he points to the series of species described by Payne in which one, two, three or four chromosomes form one group, with which a single chromosome still forms "a pair."

In Syromastes there are two accessory chromosomes of unequal size $a+b$ as in $P$. caryæcaulis and these unite when they pass into the "female producing" sperm. In the female there are two pairs of homologous chromosomes, $a+a, b+b$. Presumably these pair with each other during synapsis and subsequently separate when the polar bodies are formed giving $a+b$ for the egg and $a+b$ for the polar body. The female sperm brings in 
another $a+b$ to produce the female; since male sperm lacks both $a$ and $b$ the male has only one $a+b$ derived from the egg. This interpretation is exactly the same as that for P. caryæcaulis, except, of course, the male sperm being rudimentary only one kind of individual results from the fertilized eggs.

PART II

\section{Critical Review of the Recent Literature}

\section{INTRODUCTION}

Two contrasting views appear in an examination of the recent theories of sex determination, one qualitative, the other quantitative. On several former occasions (1903, I905, I906, 1907) I have urged the advantages of the latter interpretation as explanatory of the facts. By a quantitative interpretation, however, I do not mean that the female is simply male plus something else a view recently advanced by Castle, but that male and female are two alternative possibilities of the living material, which possibility is realized depending on quantitative factors. When these quantitative factors are internal there are produced in the germ cells those conditions that turn the scale one way or the other. The gametes are not, therefore, male and female, but contain certain factors which, when combined, give rise, in an epigenetic fashion, to one or the other alternative. By a qualitative interpretation I understand that there may exist in the gametes certain bodies or substances containing the materials either for a male or for a female. These bodies or substances are usually thought of as separated, "segregated" in different gametes at some period, and are then recombined in fertilization in such ways as to insure two kinds of individuals.

The qualitative and the quantitative hypotheses look at the problem of sex from different points of view.

In order to bring out the contrast of these alternatives I have attempted to give in the following pages an analysis of the results from both points of view without attempting to disguise my preference for the quantitative interpretation with important modifications of that view. 


\section{THE CYTOLOGICAL EVIDENCE}

The recent cytological discoveries may be said to have revolutionized our ideas concerning the possibilities of sex determination particularly within the group of insects, and more particularly within the hemiptera, to which group the phylloxerans belong. The discovery of the accessory by Henking in 1890 , the further studies by Montgomery in 1898 , by Paulmier in 1899 , and by McClung in I 899 and 1900 laid the foundation for the remarkable discoveries made later. In $1902 \mathrm{McCl}$ ung suggested that the two kinds of spermatozoa might be connected with sex determination and inasmuch as he observed that the number in the male was unequal he inferred that therefore the sperm containing the accessorv produced the male while the sperm without the accessory produced a female. On this assumption the female group should contain one less chromosome than the male. The facts published in I 905 by Stevens and by Wilson showed, on the contrary, that the female contains one more, not one less chromosome than the male."1 Thus while McClung's general inference proved true, when the necessary facts were obtained, the further question raised by him as to the relation of sex to the accessory proved to be the reverse of his assumption.

The literature of the rôle of the accessory in spermatogenesis has been so often reviewed in recent years that there is no need to review it again.

In regard to the phylloxerans, two conclusions of importance are deducible from the evidence. In one species, P. caryæcaulis, there occurs an early union of two pairs of chromosomes and it is probable that these are the accessories. Second, the evidence that two whole chromosomes are eliminated in the male rests on the observation of the number of chromosomes in the polar body, as well as the absence of two chromosomes in the egg after the extrusion of the polar body, and lastly on the inference that two chromosomes must have been eliminated in the male line in order that the behavior of the accessories in the spermatogenesis can be made to conform with their behavior in the rest of the insects.

\footnotetext{
II When a pair of idiochromosomes is present the female contains the larger.
} 
In regard to the last point, it should be noted that the only other alternative ${ }^{12}$ would be to assume that the accessories unite in the male to produce one, or two, chromosomes less than in the female. If this were true, however, there would be a heaping up of chromosomes in every generation unless all of the accessories were ejected from the sexual egg.

The discovery of Meves that in the spermatogenesis of the bee functional and rudimentary sperm are produced invites direct comparison with the somewhat similar facts in the phylloxerans. Meves has shown that at the first spermatocyte division the centrosomes move to opposite sides of the cell, a somewhat irregular spindle figure appears and the chromatin mass assumes the form of granules (chromosomes). There is no subsequent separation of the chromosomes into two plates. In fact, all present remain in the cell, which pinches off nevertheless at one pole a small nonnucleated mass of cytoplasm. At the second spermatocyte division the centrosomes move apart, the granular chromosomes appear again, and this time divide, but the cytoplasmic division that follows is very unequal. One of the resulting nucleated cells contains only a small amount of cytoplasm-the other large cell alone differentiates into a functional spermatozoön. Thus in the bee only one of the possible four spermatozoa found in other animals is produced. Mark and Copeland have also later obtained closely similar results for the honey bee. A somewhat similar series of changes takes place in the egg of Vespa germanica, according to Meves, and his main points have been confirmed by Mark and Copeland for Vespa maculata. Here also the first spermatocyte division is abortive, but at the second division there is an equal division of the cytoplasm (as well as of the nucleus) and two functional spermatozoa result.

Concerning the interpretation of these results Meves points out that, since the male bee develops from an unfertilized egg that has extruded its two polar bodies, it must contain the reduced number of chromosomes; hence one division of the spermatocytes suffices,

\footnotetext{
19 The fact that one rejects as not worth considering the view that chromosomes may be absorbed and disappear in this way shows how strong a hold has the idea of the continuity of the chromosomematerial.
} 
from Meves' point of view, to reduce the chromatin by one-half, and thus prevent its quantitative accumulation through fertilization.

In regard to the production in the bee of only one-fourth as many spermatozoa in proportion to its spermatogonia as other animals produce, Meves states that according to Leuckart the bee produces nevertheless from twenty-five to thirty millions of spermatozoa. If even half that number be assumed and if only a few (six to eight) be set free for each fertilization the contents of the seminal receptacle will suffice for three or four years at the rate of 1 50,000 to 200,000 eggs a year. "Eine doppelt so gosse Anzahl von Spermien wie sie resultieren wurde, wenn die zweite Reifungsteilung bei der Honigbiene ebenso wie bei der Wespe die Entstehung von zwei gleichgrossen Tochterzellen zur Folge hätte, wäre dem nach offenbar unnütz; es hat den Zwecken der Art besser entsprochen weniger Spermien zu bilden und diese besser aüszurusten."

The quotation shows that Meves looks upon the peculiar change in the bee as a sort of adaptation to produce fewer but better spermatozoa, but it must, I think, appear rather extraordinary that such a method of producing better results should have been evolved, especially, in the light of the fact that in all the animal kingdom, with the rarest exceptions here mentioned, no such betterment has taken place. ${ }^{13}$ On the contrary, I think one cannot but suspect that the results are connected with the peculiarities of reproduction and parthenogenesis in the bee, and when we find an analogous series of events in the phylloxerans associated in somewhat the same way with these peculiarities of reproduction, the suspicion grows almost to a conviction that the interpretation is to be sought in this connection.

Let us therefore look a little more critically into the case of the honey bee.

Starting with Meves' discovery that in the male bee the chromosomes are in the reduced number-the result not of a union or synapsis of chromosomes, but to the half number of single elements

\footnotetext{
13 Especially when the enormous number of eggs produced by the bee in comparison with the few in many other forms is taken into consideration.
} 
being present-we can see how the first division should be abortive if we admit that at this division in many forms the separation of the paired chromosomes occurs. To Meves this interpretation would be meaningless since he does not accept the current view regarding the nature of the reduced chromosomes, but to those who think the evidence at hand points to such an interpretation of the reduction division, the assumption here admitted may make an appeal. The interpretation would mean that while the ordinary process of division is attempted it becomes abortive owing to the absence of the ordinary chromosomal behavior. ${ }^{14}$ Whether the result may not also have a real significance so far as the cytoplasm is concerned must be left an open question.

What meaning then would the second divison have? If the first had been, as assumed, the reduction division, the second would be an equational were all the chromosomes present. If, owing to the failure to separate the sex chromosomes in the first the process should take place in the second division, there might theoretically be produced two kinds of sperm, "male- and femaleproducing." If the former degenerates, all that become functional would produce females. Objections to this argument are evident. The fact that in Vespa both products of the second division become functional sperm is fatal to such a view-provided, as seems more than probable, the fertilized eggs of Vespa also all produce females.

The difficulties are not lessened by reversing the first assumption regarding the nature of the first spermatocyte division in the bee and wasp. In some groups of insects the first and in others the second division is supposed to be the reduction division. Now if we assume for the bee that the second is the reduction division we may appear to account for the production of a functional "female-producing sperm" (the "male-producing" being the rudimentary one); and if we assume for the wasp that the first division is the reducing one that separates male from femaleproducing cells-the latter alone dividing in the second-we might appear to account for the facts. In reality such an interpretation meets with more difficulties than it explains; it leaves unac-

\footnotetext{
14 There is no evidence from Meves' observations that an accessory passes out in the first spermatocyte division.
} 
counted for the failure of the division of the chromosomes in the first division of the bee, and, worse still, it fails completely to show how in the wasp the first division is a reducing division since all the chromosomes are retained. Whatever evidence the future has in store for us concerning the second division of the spermatocytes, the failure of the first division seems in all probability to be connected with the presence in the male of the reduced number of chromosomes.

Schleip finds for the ant, Formica sanguinea, that two polar bodies are given off from the egg as Henking had previously determined for another species, Lasius. The reduced number, 24, of chromosomes, appears in all eggs. Two polar bodies are formed, and into each 24 chromosomes are ejected. The female pronucleus contains still 24 chromosomes. After fertilization about 48 chromosomes can be counted, and the inference is plain that the reduced number, 24, is brought in by the sperm. These facts fit in with the results for the bee and go to show, taken in connection with the recent results on spermatogenesis, that the male contains the reduced number of chromosomes, the female the double number.

Lams has also found in another ant, Campodinotus herculaneus, that the first spermatocyte division is abortive and the second normal. No evidence of a lagging chromosome is to be found in the admirable side view of spindles given by Lams.

It has been generally taken for granted that in the ant as in the bee unfertilized eggs produce only males and this view has the support of observations by Forel, Lubbock and Field. On the other hand Wheeler ${ }^{15}$ has recently drawn attention to other observations showing conclusively that the unferrilized egg in certain species may produce females. Tanner obtained workers of Atta cephotes from an artificial nest composed of workers. The same nest produced numerous males also. Reichenbach obtained large numbers of workers of Lasius niger from the eggs of workers laid in an artificial nest. Males, too, appeared synchronously with their appearance in nature. Mrs. Comstock has also obtained

${ }^{15}$ Wheeler, W. M. The Origin of Female and Worker Ants from the Eggs of Parthenogenetic Workers, Science, xviii, December, r 903. 
workers from workers' eggs in the American variety of Lasius niger.

These observations make not improbable the view that the unfertilized eggs in certain species of ants can produce females, but unfortunately we do not know whether two polar bodies are extruded in such cases. Whether this happens or not, the facts indicate that before the extrusion of polar bodies the eggs have the dual potency of producing males or females. Such a conclusion makes it probable that the bee's egg too may have the same possibilities, only here the results are more one-sided, since after extrusion of the polar bodies the resulting egg is male determined. It would therefore be erroneous to conclude that the eggs of the bee are male before the polar bodies are extruded.

This case of the honey bee has been one of the greatest stumbling-blocks that modern theories of sex have met. One course in avoiding the contradictions here found has been to deny the facts, yet the facts seem to me to be as clearly determined as any other in this field, and while none of them may be final, yet it is unfortunate to reject one body of evidence because it does not fit in with conclusions derived from the other.

The unfertilized eggs all develop into males. It is assumed that all the eggs are therefore male producing, and that thesperm brings in the female determinant. But there is another theoretical possibility. The sex of the egg may not be determined at first. If it is not fertilized, it becomes a male; if fertilized, a female. The absence of fertilization or the act of fertilization may be the determining factor; or if the result is attributed to something lost or retained by the egg, such a result might be referred to the polar body formation which responds to the presence or absence of the sperm. Such are the difficulties met with on the assumption that the sex determinants exist in the egg or sperm or in both. None of these are necessary if we account for the results on the simple assumption that one nucleus means male, two mean female, which is the view that I adopted in 1903 .

In another hymenopteron, Nematus ribesii, the facts described by Doncaster are so anomalous that at present it is quite impossible to bring them into harmony with what takes place in the bee, 
wasp and ant. It is true that two polar bodies are given off from all eggs as in the bee, according to Doncaster, but he describes two types of eggs, those in which reduction occurs and those in which it does not occur. His suggestion that only those eggs are capable of fertilization in which reduction occurs may appear to account for the sexual eggs, but it still leaves unexplained how two polar bodies can be extruded from the egg that produces a male without a reduction of the chromosomes.

In an earlier paper Doncaster called attention to certain facts, that appear to be well established, showing that in thesaw-flies (Tenthredinidæ) virgin eggs produce males in some species, females in others. In Crœsus varus "the male is not certainly known, one observer only having described it, and all agree that females alone arise from virgin eggs." It should be recalled in this connection that Doncaster finds two polar bodies given off from this egg. He is driven to assume, in consequence, that both divisions are equational, but this is obviously an argument ad hoc and out of harmony with the general trend of modern cytology. His observation, that two of the three polar bodies fuse, might be brought into harmony with the similar observation made by Petrunkewitch, and if, as the latter believes, the fused product makes the reproductive organ, the germ cells would then have the double number of chromosomes and reduction be possible in the egg. But there is serious doubt in regard to Petrunkewitsch's conclusion and Silvestri's observations on certain Chalcidx show, in fact, that the polar bodies take no part in the development of the reproductive organs of these hymenoptera; yet the facts of development are identical with those in the bee. There is obviously something that is still lacking in these observations on the saw-flies, that makes it impossible to harmonize the results with the facts in other forms.

Doncaster points out that in Pœcilosoma luteolum the male is extremely rare, "and Miss Chawber of Lyndhurst tells me that she has bred thousands of this species for several years in succession without obtaining a male and without finding any diminution in the fertility of the females."

Hemichroa rufa produces "chiefly females from virgin eggs but occasionally males are produced." 
According to Cameron, Nematus pavidus gives rise only to males from virgin eggs, and Miss Chawber ${ }^{18}$ has reared males only from virgin eggs of Nematus lacteus.

Von Siebold found only I 3 females among 1700 males from the virgin eggs of Nematus ribesii. Doncaster finds that many virgin eggs do not develop, the percentage being lower than that for fertilized eggs.

The fact that virgin eggs in several species of saw-flies produce males and females, or either males or females proves conclusively that the egg of these hymenoptera may produce both or either sex. This result seems to me to indicate with some probability that in general the eggs in this group have the double possibility and that some mechanism exists by means of which the virgin egg is thrown, as it were, in one or the other direction towards the female side in Poecilosoma luteolum, towards the male side in other members of the group and in the bee. What turns the balance in these cases is still unknown, but it is evident that a closer scrutiny of the polar body formation and the events that immediately follow is needed. In the "gall-flies" (Cynpidæ) there are several species known in which two generations alternate. One generation is composed exclusively of females that lay parthenogenetic eggs from which males and females hatch. Here once more we find eggs which without being fertilized produce both sexes. In the generation composed of males and females the fertilized eggs-presumably all are fertilized-produce only females that are parthenogenetic as we have just seen.

\section{THE INFLUENCE OF THE ENVIRONMENT ON PARTHENOGENETIC REPRODUCTION}

It is in connection with parthenogenesis that the results here recorded for phylloxera and aphids have particular interest, for it is in the parthenogenetic egg that sex is determined. In two other groups of animals the relation between sex and parthenogenesis is so similar to that in phylloxerans and aphids that comparisons must inevitably be made.

${ }^{16}$ See Doncaster, footnote, p. $5^{63}$. 
In the phyllopods, Daphnia and its related genera, that we may for the sake of brevity refer to as daphnians - it has long been known that the fertilized eggs produce only females, while, from parthenogenetic eggs males or sexual females are produced. Weismann's classical and important observations on this group led him to the general conclusion that the life-cycle-its extent and phases -is the result of an internal mechanism that has become adapted, so to speak, to those conditions that each species is most likely to meet with. On the other hand the observations of Issakowitsch go to show that external conditions affect materially the phases of the life-cycle in the species Simocephalus vetulus. On Weismann's view the parallel between the daphnians and the phylloxerans is obvious, but in how far they are the outcome of similar internal factors we do not know. On Issakowitsch's view the internal mechanism is largely affected by the environment, but whether the effect is "sex-determining" or only determines when the parthenogenetic cycle gives place to the sexual phases remains to be examined. In daphnians one and the same individual may produce eggs that become parthenogenetic individuals, or eggs that become covered with a thick coat and require fertilization in order to develop, i. e., sexual female eggs; or eggs that become males. In the first case, the mother produces by means of parthenogenesis, parthenogenetic young; i.e., she may be said to be a parthenogenetic individual; in the second place, the same mother produces a sexual egg, she may therefore be said at the time to function as a sexual female; in the third place, she produces parthenogenetically a male, she may at this time be looked upon as a parthenogenetic female that produces males - she herself, of course, not being a male, but a male-producer. The point that I wish to make in this connection is this; that whatever the mother brings forth, she cannot be said to change her sex, nor if the conditions determine that she ceases to bring forth parthenogenetic individuals and produce sexual eggs or males can those conditions be strictly said to be sex-determining provided they lead equally to the production of males and sexual eggs. The change is from parthenogenesis to sexual reproduction and the factors might be said to be sex-producing, not sex-determining; since by 
common usage sex-determining means to call forth a male or a female.

Issakowitsch found that by keeping the daphnian (Simocephalus vetulus) at a temperature of $24^{\circ} \mathrm{C}$. he obtained during six generations a succession of parthenogenetic forms, about 500 individuals in all. At the end of three and one-half months the culture died out. In another culture carried through six generations composed of 85 broods of about 500 animals in all, the great percentage of individuals were parthenogenetic, but here and there males and winter eggs appeared. The longer the culture was kept at $24^{\circ} \mathrm{C}$. the stronger was the tendency to produce only parthenogenetic females. An examination of Issakowitsch's table brings out a point not mentioned by him, namely, that along certain lines of descent there appears to be a stronger tendency to produce males than along other lines.

At room temperature the results are strikingly different, for even in the first generation males and winter eggs appear so frequently that the cultures disappeared in one or two generations.

In the cold the cultures were shorter owing to a stronger tendency to produce males and winter eggs.

The results seem to show that sex-production is determined in these animals by temperature. Food was equally supplied in all cultures yet Issakowitsch thinks that in the final analysis food conditions bring about the result in connection with temperature which only acts indirectly: In order to examine this question he kept two sets of animals under the same temperature conditions viz: $24^{\circ} \mathrm{C}$. One was starved, the other fed. The former produced males and sexual females at once. Issakowitsch concludes that food rather than temperature per se is the sex-determining (sexproducing) factor. He believes that the following facts strengthen his view. If the winter egg is not fertilized its contents are absorbed, the empty shell being thrown off. Issakowitsch thinks that this winter egg supplies the ovary with nourishment. In consequence the next brood is parthenogenetic. After this the conditions between temperature and food are again established, and a sexual brood results at a low temperature.

A correlation is found to exist between the kind of egg pro- 
duced and the condition of the oviduct. In the young female the lining cells are all filled with fluid which is lost when the parthenogenetic eggs enter the tube-presumably supplying them with nourishment. After the eggs are set free in the brood chamber the lining cells again enlarge, etc. But if a winter egg is forming the cells remain flat and inactive. The winter egg grows at the expense of the surrounding cells in the ovary. Issakowitsch's interpretation is that when the nourishment is good the oviductal the cells enlarge; when poor, the egg must get its nourishment from immature cells of its ovary and the lining cells remain undeveloped.

His general conclusion is "that since at a low temperature the assimilatory activity of the cells is lessened, and since the activity of a growing egg is more intense than that of any other cell, we must conclude that at a low temperature the conditions are unfavorable for nourishment of the egg in the ovary. We expect therefore to develop a winter egg or a small male egg."

However doubtful it may appear that Issakowitsch has given a complete account of the methods by which the results are affected, his experiments seem to show that external conditions are instrumental in affecting the transition from one mode of reproduction to another. There is nothing in his results that throws any light as to how in one case a male is produced, and in the other a sexual egg. In fact we do not know as yet whether all the ovarian eggs are alike or whether two (or three) sorts of eggs exist corresponding to the two or three kinds of individuals that are produced. If there are such eggs, external conditions might determine which egg develops. Or if there are only two kinds, sexual (male and female) and parthenogenetic, the conditions might determine which one at a given moment developed ("accident" alone determining whether if a sexual germ is set free, it be male or female). On the other hand since in the end all three types would be traced to the parthenogenetic egg that gave rise to the mother, no fundamental distinction can exist for them, since we should still have to explain how from the parthenogenetic egg the three hypothetical types arose during development.

There are certain facts in connection with the life-cycle of the aphids that appear to be similar to those here described for daph- 
nians. When the sexual forms appear the leaves have in many cases begun to dry up, or at least to harden so that nourishment may be more difficult to obtain. In the rose aphid the sexual forms are found on the lower, older leaves, while the parthenogenetic individuals are on the terminal young buds and younger leaves. If these are brought into the green-house they continue to produce parthenogenetically; the leaves of plants grown under such conditions remain soft, many young leaves are present and the terminal buds continue to grow. It seems very probable that temperature has no direct influence on the life-cycle in the aphids, and the facts here given suggest that the change may be connected with conditions of nutrition.

The life-cycle of the rotifer, Hydatina senta, is similar in many ways to that of the aphids and phylloxerans. Here, too, all fertilized eggs become females, and these females produce by parthenogenesis a succession of parthenogenetic individuals. Some of these may produce males, others sexual eggs, but the same female never produces more than one kind of egg. Maupas's work on Hydatina senta seemed to show that a high temperature increases enormously the proportion of male-laying females ( 97 per cent) not by changing the character of the females so that a different kind of egg is produced, but by affecting the character of the laid egg, or its method of development, so that it becomes a male-laying individual. Conversely Maupas believed that a low temperature greatly increases the output of female-laying individuals ( 95 per cent). Nussbaum, Punnett and Whitney, who have repeated the experiment, find no evidence that supports Maupas's view. Whitney points out how Maupas's facts may be correct, but his conclusions wrong. At a high temperature the male-laying females are not so much affected as to their output of eggs as are the femalelaying individuals, hence the percentage of the male eggs will be proportionately increased. Furthermore while the average proportion of male-laying females is about 22 per cent some individuals produce fifty per cent of these individuals, others only two to five per cent. That these individuals are not fixed in respect to sexproduction was also shown, for a low male-producing strain may later become a high one. It is difficult to understand how such 
variations are brought about unless in some way the conditions under which the animals live produce an influence on the results. It should be repeated here again that if such an influence exists its effects may be to cause a change from a parthenogenetic to a sexual method of reproduction, i. e., it would be sex-producing, not sex-determining. In Hydatina, in fact, "the cause" of sex-determination is fortunately fairly well made out. If a young individual destined to lay male eggs is fertilized, she lays henceforth winter eggs and nothing but winter eggs. It is clear that the presence of the spermatozoon within the developing egg determines its fate. The conclusion is rendered more probable from the fact that Lenssen observed in Asplanchna that male young and winter eggs occur in the same individual. Whitney's observations show that the spermatozoon that has entered an egg is present throughout part of the growth and all of the maturation period. It may produce its effect either during growth, or maturation, or its effects may be due to the presence of a double number of chromosomes in the embryo causing it to develop into a female. There is a point here of capital importance that has not as far as I know been noticed, viz: that the influence of the sperm must occur while the germinal vesicle is still intact. This is shown by the size relations of the egg; the male egg is smaller than the winter egg, hence the latter must enlarge further if it is to become a sexual egg. The presence in it of an additional nucleus might on first thought be assigned as the cause of its special enlargement, but when we recall the fact that the sperm nucleus remains in a condensed condition up to the maturation period, this mode of explaining the result will not appear in so favorable a light. It seems probable that in Hydatina the presence of the sperm in the egg acts in some unknown way so that a sexual egg results; and that the result need not be connected with the functional activity of the sperm in the sense that it assists the processes of assimilation in the egg. The fact, however, that the egg becomes larger is of theoretical importance, since this probably means that at the same time (but not in consequence of the enlargement) it is determined as $a^{\text {. }}$ sexual egg. Even if some corresponding regulation should occur later in the chromosomes to complete the chain of events, the im- 
portant conclusion would remain, that the preliminaries of sexdetermination-and possibly therefore its cause in the sense of inaugurating a sequence of events-takes place in the egg of Hydatina before the maturation of the eggs. These preliminaries involve moreover the question of sex-determination and not simply sex-production.

Lenssen's observations on the maturation of the egg do not seem to be entirely correct, although his general conclusions that the same number of chromosomes are present in the male egg and in sexual eggs, and that double that number are found in the parthenogenetic eggs, is sound. The recent results of Whitney place this conclusion on a surer basis. Whitney points out that the parthenogenetic egg extrudes one polar body, the male egg two; that the sizes of the individual chromosomes in the male egg and in the sexual egg are twice that of the chromosomes in the parthenogenetic egg. These facts leave little room to doubt that a reduction in the number of the chromosomes of the male egg takes place preparatory to the formation of a male. Hence the possibility of fertilization of such an egg becomes intelligible, since the reduction is a preparatory step to fertilization in the sexual egg. The fact too that the reduction occurs in the male egg (that develops parthenogenetically) shows that the entrance of the sperm in the sexual egg has nothing whatever to do with the determination of reduction in that egg, and this substantiates the conclusion reached above that the preliminaries for sex determination go on irrespective of the presence of the sperm. In this instance, however, the process only involves reduction that is common to both male and sexual female eggs.

Another fact emerges from Whitney's observations-the male egg, as well as the parthenogenetic egg, is produced in the presence of all of the chromosomes - as in the phylloxerans. So, too, is the sexual egg, plus, however, the chromosomes of the male-which proves too much for the chromosome view, unless the compact sperm be assumed to have already become functional. But this assumption cannot be made for the phylloxerans.

If, after reduction and the extrusion of two polar bodies, in the male rotifer, we suppose that the male has half the total number of 
chromosomes, the case is strictly comparable to that of the bee. Theoretically there should not be two spermatocyte divisions but only one true division. It remains to be seen whether this prediction prove true.

The male rotifer develops in the presence of half the full number of chromosomes; in the phylloxeran the male develops with the full number minus the accessories. The sexual eggs in both forms and the parthenogenetic eggs contain alike the full number during development, but preparatory to development the sexual egg reduces its number of chromosomes which is made good by the addition from the male.

For the bee it has long been disputed that all the unfertilized eggs are male producing (fertilization turning them femalewards). Certain authors maintain that there must be two kinds of eggs and that only the male eggs can not be fertilized. The case of Hydatina shows that an egg destined to produce a male may, if fertilized, become a female, which is a case analogous to that of the bee except that the determination by fertilization seems to come earlier in Hydatina.

The third type in which large female-producing eggs exist and small male-producing ones, is that of Dinophilus apatris, as Korschelt has made known. In one important respect the form differs from the other two, viz: both eggs are fertilized (presumptively) and both give off two polar bodies. This shows that the result is independent of the sperm unless selective fertilization occurs. If selective fertilization does not occur, it is evident that sex is determined in the egg when all the chromosomes are present, for the two sizes of eggs exist when the eggs are laid. Whether subsequently changes take place that reduce the amount of chromatin in the small egg we do not know. A series of experiments were carried out by von Malsen that show that more female eggs are laid at a low temperature than at a high temperature. In the cold the proportion is about I male to 3.5 females; in the warmth, about I male to $\mathrm{I} .7$ females. These results are interpreted by von Malsen to mean that sex is uetermined by external conditions. The effects are produced, he believes, not directly by the temperature but by the influence of nutrition-the relation between the 
metabolism and the temperature determining the result. In support of this conclusion he cites some experiments in which the animals were starved when the percentage of males was increased. This conclusion is open to one serious criticism. If the condition of nourishment determines the number of large eggs that can develop, the proportion of the two kinds of eggs that matureif two kinds really exist at an earlier stage-will be altered. This would mean not that sex is determined by the nutrition of the parent but only that a well-nourished parent can produce more female eggs than one that is starved. This is precisely the state of affairs shown by the phylloxerans. Poorly nourished females produce only one egg, but this is of normal size, while well-nourished females may produce eight to ten or more. Such differences would seriously affect the sex ratio if the males are somewhat less affected, owing to the small size of the egg. We have no means of knowing at present whether the large egg of Dinophilus apatris formed by the fusion of several ovarial cells is large on account of the number of cells that unite to produce it, or whether, being already a female egg, it absorbs a larger number of cells than does the male. One fact speaks strongly in favor of the view that the result is not due simply to the number of cells absorbed but to the determination of the egg before or at the time of absorption, namely, the great difference in size of male and female eggs. If the result were due to the factor of absorption alone, we should expect to find a graded series, not a dimorphic condition. The evidence, while as yet not decisive on this point, indicates, nevertheless, that there must be already in the ovary two kinds of eggs prior to the absorption period, and that the nature of the egg determines how much of the surrounding material it will absorb. If this view prove correct, sex in Dinophilus apatris must be determined in the egg long before the maturation stage is reached. The conclusion is in harmony with the facts here described for Phylloxerans.

THE PROBLEM OF THE THREE CHROMOSOMES

In those insects where the spermatogonium of the male has one accessory, the oögonium of the female has two chromosomes, 
homologous with the accessory of the male. These three chromosomes form pairs whenever they meet (in the female only). To all external appearances they are identical. We have no evidence to show that they are functionally different, but the qualitative interpretation demands that they must be different if sex is determined by them; if not sex is a purely quantitative result. If one of these three is female determining and the other two male determining, the results, so far as sex goes, can be explained only on the theory of selective fertilization. This hypothesis rests, therefore, on two assumptions, neither as yet verifiable.

On the assumption, that the three chromosomes consist of two male chromosomes and one female (despite their external identity) we can work out the problem with the help of selective fertilization as follows for those cases where an accessory chromosome is present in the male.

We may represent the male determining chromosome by $M$, the female determining chromosome by $F$. Hence,

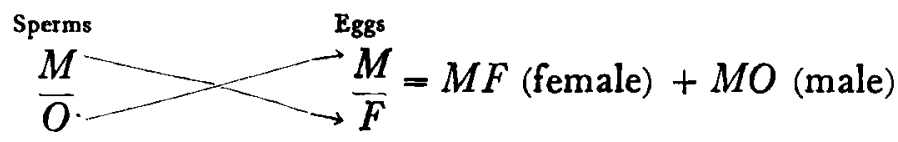

For the case where there is a fourth smaller chromosome $(f)$, this appears only in the male line, and the formulæ would be

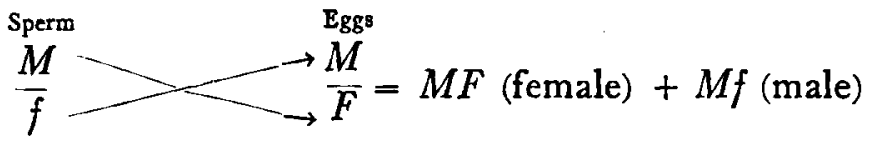

In the majority of cases where the fourth chromosome is equal in size to the other three, the formulæ are

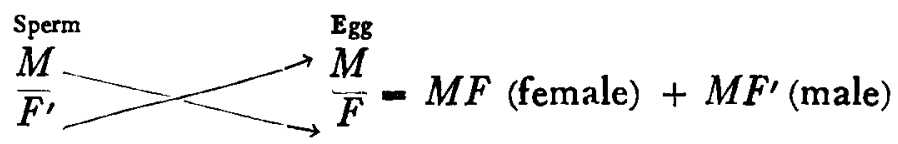

Unless $F^{\prime}$ is different from $F$ both results would be the same and only one sex, the female, would arise; but if $F^{\prime}$, while the potential 
bearer of the female character, is weaker than $F$, or in modern terminology, the dominant $F$ has become a recessive $F^{\prime}$ (with respect to $M$ ), the results can be accounted for. Expressed in phylogenetic terms, originally only one kind of individual developed as a result of union of $F$ and $M$. Gradually two kinds of individuals arose owing to one of the $F$ determinants becoming weaker than its opponent, $M$. In time this $F$ became smaller or vanished, because it lost all real function except as the bearer of latent female characters in the male. In other words whenever four sex chromosomes exist the male carries potentially (recessive) the female characters, wherever the fourth chromosome has dis appeared, as in certain insects and spiders, the male is a homozygous male. This scheme is advanced merely in order to show how, on the chromosome theory, the graded series shown by the fourth chromosome might be consistently worked out. The view assumes both reciprocal fertilization and sex primordia that "segregate" in the gametes. It ignores the fact that no differences between $F^{\prime}$ and $F$ have been seen. It assumes that sex primordia exist both in males and females and that there are two classes of males in different species, some pure males, others mixed. It encounters the objections that may be raised against the view that the egg determines in all cases the sex, because it contains the dominant male and female primordia.

The problem is simplified if we assume that the three chromosomes are identical, in which case the result is quantitative. Femaleness is only twice maleness in the sense that when one of the three bodies is present a male develops, when two a female. It may be urged in opposition to this conclusion (I) that the female may develop male characters; (2) that the difference between the male and the female characters may depend on qualitative differences as shown by injecting sperm extracts into the female that call forth male characters; (3) that in mosses the male and the female may develop with half of the chromosomes present; (4) that in the phylloxerans the producers of male eggs and female eggs appear with the full number of chromosomes present; (5) that the function of the mate of the accessory when it is present is ignored. These objections may possibly be met by the following considerations: 
I The female develops male characters (by which is meant secondary sexual characters not spermatozoa) in old age or after castration. This may mean that these secondary characters owe their suppression in the female to materials manufactured in the ovaries. In insects, however, it has been found that the secondary characters of the male do not appear in the female after castration. Gynandromorphism, that occurs in this group, may depend on a different relation and will be considered later.

2 The primary qualitative differences between the sexes have never been changed by injection, They represent the fundamental alternatives of the protoplasm and quantitative factors only determine which alternative is realized. The secondary characters of the male that arise in the female by injecting male extracts can be explained if the injected substance overcomes the inhibiting effects produced by the products of the ovary.

3 In mosses only one kind of sporogonium exists, hence as pointed out, the case is not parallel. Waiving this distinction, the problem in the mosses is concerned with the development of two kinds of gametes which may depend on some unknown quantitative relation existing in the reduced groups of chromosomes-if chromosomes here represent the material factor of sex determination.

4 In the phylloxerans all the chromosomes are present when the male and the female egg develop, yet a change in their grouping has been demonstrated in one case at least. Whether this in itself will account for the result is not evident, but the change is concerned with the production of two kinds of eggs not necessarily with the production of male and female. The male develops only after two chromosomes are extruded.

5 When the mate of the accessory is the same size as the accessory-in other words when no accessory exists--we have no obvious difference in the chromosomes by which to explain sex. Yet differences may exist that have not yet been found, as Boveri has shown, in the case of the sea urchin. Until such facts become known, however, this is a real objection to the quantitative interpretation, and unless such facts are discovered it is fatal. The absence of data on this point is not due to lack of observations, 
for, in several insects where the number of chromosomes is small the pairs have been closely studied by Wilson and no differences discovered.

In 1906, on the basis of his own observations relating to the number of chromosomes in the male and female and of the similar results of Stevens, Wilson discussed very fully two alternative views of sex determination. The first rested on the assumption of male-determining and female-determining chromosomes. He pointed out that this hypothesis involves the idea of selective fertilization, in favor of which Cuénot's hypothesis for yellow mice is cited. As a second, "alternative hypothesis" Wilson suggested that the "differential chromosomes may perform a definite and special function in sex production without being themselves specifically male-determining and female-determining, or even qualitatively different save in the degree of their special activity (whatever be its nature). The kind of activity that produces a male will, if reënforced or intensified, produce a female."

In the case of the bee he points out the difference may depend on fertilization or its absence. Where an unpaired accessory exists, as in Anasa tristis, the presence of this one, and of another of the same kind (in the egg) produces a female, while in the male one of these alone is the cause of that sex developing. But when, as in other cases, there is no unpaired accessory, but a corresponding pair of equal sizes, the quantitative result no longer holds. Therefore Wilson suggests that one member of the pair in the male may show less activity than its mate. In consequence the egg fertilized by such a sperm becomes a male, and the weakened chromosome is confined to the male line. This suggestion is somewhat similar to the one discussed above in which the weaker chromosome is represented as the female determiner $\left(\mathbf{F}^{\prime}\right)$. In a later paper, to be referred to in another section, Wilson suggests a third view differing from both of these, but more nearly akin to the second one here described.

THE BOTANICAL EXPERIMENTAL EVIDENCE

The important experiments of Blakeslee, of the Marchals and of Correns on plants have an important bearing on the problem of 
sex in animals, since many points of resemblance appear in the two great divisions of the living world.

Blakeslee recognizes two groups of moulds; viz: homothallic in which the thalli are all equivalent, conjugation taking place between parts of the same thallus or between any two thalli; and heterothallic in which the thalli are of two sorts, designated by the symbols $(+)$ and $(-)$. If spores are taken from the $(+)$ or $(-)$ strain they produce a strain exactly like the parent. Phycomyces has been cultivated in this way through 107 generations, and Mucor mucedo through 106 generations without change in their sexual behavior. It appears that the $(+)$ and the $(-)$ strains perpetuate themselves indefinitely as such. If a $(+)$ and a $(-)$ strain are brought together zygospores are produced by the union of equivalent parts from each thallus. If two $(-)$ strains meet, or two $(+)$ strains no sexual process occurs. From the zygospore a sporangium is formed containing many spores. It is here that the discoveries are extremely important, for the spores in the same sporangium are some male, others female.

Another mould Sporodinia is homothallic, the mycelium (gametophyte), the germ tube (sporophyte), and the sporangia are all alike. In other words from the zygospore a sporangium arises containing only one kind of spore which produces a homothallic mycelium. There is no visible separation here into $(+)$ and $(-)$ elements, even although the conjugation phase of the mycelium be so interpreted. Such a form suggests the conditions found in an hermaphroditic animal, although the two kinds of germ cells in the latter present an external difference.

A third type, Mucor mucedo, has separate $(+)$ and $(-)$ mycelia. By their union a zygospore results which gives rise to a sporangium containing in some cases only ( - ) spores (to judge from their mycelial product) and in other sporangia only $(+)$ spores. Both sorts of spores do not appear in the same sporangium despite the fact that the zygospore has been produced by the union of a $(+)$ with a (-) strain. This remarkable discovery presents a quite different phase of the sex question. The case is paralleled, as Blakeslee points out, among the flowering plants by such a form as the Lombardy poplar, where the fertilized egg produces in some cases a 
male tree, i. e., one producing only pollen, in other cases a female tree, i. e., one producing only ovaries. On this view any pollen grain could fertilize any egg, for all the eggs are of one sign and all the sperm of the opposite.

What determines whether the fertilized product gives rise in one case to a female and in another to a male is quite unknown. The three types of sexual reproduction represented by these three moulds, Phycomycetes, Sporodinia and Mucor, illustrate three important phases of sexual reproduction; the first shows that male and female strains develop in the same sporangium; the second shows that no dissociation occurs in the sporangium; and the third that one sporangium contains spores only of one sign and another of the other sign. Either the first or the third types might be made the basis for comparison with unisexual animals; if the first, there would be $(-)$ and $(+)$ sperm, $(-)$ and $(+)$ eggs, with reciprocal fertilization; if the third, all the sperm would be of one sign, all the eggs of the other sign; any sperm could fertilize any egg. Unfortunately we lack evidence for animals that show to which type they belong. Both alternatives will be considered later. It will also be noted that the $(+)$ and $(-)$ signs are used with respect to fertilization, not with respect to the kinds of "sporophyte" that arise from the zygospore. Externally these sporophytes in moulds are alike whatever their physiological possibilities. Sex is used in animals and plants with regard to the kind of sporophyte that results from fertilization; these are of two kinds, male or female. If the third type of reproduction represents the transition to the higher type, two facts of much importance will be noticed; first that the male gametes all have one conjugation sign, and the female gametes the other. Hence every sperm can fertilize every egg. Sex therefore relates to the character of the sporophyte, rather than to the sign of the gametes; yet one sign is associated with one sex and the other with the opposite. The second fact is this; since opposite signs must unite the product is hybrid $(+$ and - ) yet only one sign comes to development in the male, and the other in the female. Whatever determines the sex, therefore, must also determine the sign of its gametes. If the former is a quantitative relation, the latter must be also. 
In the dioecious mosses the important experiments of Elie and Emile Marchal show interesting sex relations. In Ceratodon purpureus, Barbula unguiculata and Bryum argenteum each protonema gives rise to male or to female "flowers," i. e., the sexes are separate. When the oöspore is fertilized by an antherozoöid the resulting sporophyte produces spores which produce again the male or the female protonema. The Marchals found by sowing spores from single capsules that some of the spores produce male protonema, others female. In current phraseology this means that the fertilized oöspore contains both sexes combined and these are "separated" again, in the spores or, put in another way, the factors that produce the male and the female sex cells are both present in the oöspore generation and are separated when the spores are formd.

The experiments prove that the spores are not hermaphroditic, i. e., capable of giving rise to male and female buds on the same protonema; they leave open the question whether the sex is predetermined in the spore or whether the protonema gradually develops one or the other sex during its life in response to external conditions.

This possibility was tested by cutting off pieces from a protonema of known sex and raising them under very diverse conditions. Such pieces regenerate a new protonema. These secondary protonemata are always of the same sex as that of the original protonema. The evidence is still not final for it might be claimed that sex once determined at a critical stage by external conditions is irreversible in later stages, until the critical stage is again reached.

In a second paper the Marchals give some further experiments. It has long been known that the tissues of the sporophyte will produce a protonema if separated from the parent plant, and put under favorable conditions. Since these tissues result directly from the fertilized egg, they contain the full number of chromosomes, and, theoretically at least, also the double sex potentiality. The results show in fact that the same protonema produces both male and female flowers. The details are worth careful scrutiny. The first formed flowers were male in large excess, $1: 25.8$. Later I: 8.7 and finally $\mathrm{I}: 7.8$. This predominance of male elements 
was very marked. It was equally well seen in the rare hermaphroditic flowers that contained both antheridia and anthegonia. In a very small number of cases the flowers were exclusively female.

Experiments were tried with the sporophytes of purely male flowers, mixed flowers and purely female flowers Protonemata were obtained from each and the sex of their flowers recorded. In all cases the result was the same as in the first generation, irrespective of the kind of sporophyte utilized. Flowers of the three kinds appeared in all, the males in excess, even when a purely female flower had been used. Evidently the factors that determine male and female flowers are not decisive for the kind of gametes they produce. The results show clearly that the tissues of the sporophyte carry the conditions for both sexes, and that these become "separated" when the spores are formed.

It is perhaps not without significance to observe that the male flowers appear some time before the female ones, although the protonema is bisexual as subsequent results show. If this early suppression should continue throughout life the result would be difficult to distinguish from a male plant.

The Marchals point out that since the diploid or double number of chromosomes is present in all the cells of the sporophyte and the reduction occurs when the spores are formed, the "separation" of the sexes must occur also at this time. When we recall that in animals the "separation" of the sexes also occurs according to some current theories at the reduction period it becomes a matter of extraordinary interest to determine the meaning of this phenomenon. No less striking is the fact that with half the number of chromosomes some of the spores are male producing, others female producing. The product of the sexual union of the germ cells derived from these spores is a hermaphrodite. If we are justified in extending to animals the general point of view here reached, we might conclude that at the reduction period in the egg as well as in the sperm a "separation" of the male and the female factors takes place. If we assume that it is a matter of "chance" whether the egg or its polar body become a male or a female, then selective fertilization follows, but even with this assumpion it would still remain a puzzle what determines the sex of the resulting hybrid. 
We might conclude on the other hand that the egg always "retains" one sex factor and the polar body the other (while there are two kinds of functional sperm); the egg would then be homozygous but if two kinds of sperm are produced one must be functionless unless like can fertilize like. The third possibility shown by the moulds does not seem to appear in these dioecious mosses; viz: where one sporophyte produces only male spores and another female spores. Moreover in mosses all sporophytes are alike, while in animals and in some dioecious plants two types of sporophytes exist, males and females. If in these all the sperm are males $(+)$ and all the eggs female $(-)$ direct comparison with the mosses cannot be made. For the sake of clearness it may be well to keep these contrasts in mind.

The chromosomal cycle in ferns shows apparently that there is no necessary connection between the reduced number of chromosomes and the segregation of sex. ${ }^{18}$ Each spore produces a prothallium-homologous with the protonema of mosses-with the reduced number of chromosomes in all of the cells. Such a prothallium may produce both archegonia and antheridia, the former containing each an ovum, the latter spermatozoöids. This fact shows that the gametes of one or the other sex are produced long after the reduction has occurred, and on one and the same plant. If it can be shown that the spermatozoöids of a prothallium can fertilize the egg-cell of the same prothallium, then they must be of opposite signs. The fact that in certain ferns it has been possible to suppress the development of the archegonia or of the antheridia by changing the external conditions-a result that Hertwig and Whitney have also obtained in Hydra - obviously 'does not show that the sex has been changed, but that in a hermaphrodite form certain conditions are more favorable for the production of one or the other gamete.

Previous to the recent agitation concerning the sex of the gametes and their reciprocal fertilization, it was generally taken for granted by zoölogists and botanists that any sperm may fertilize any egg.

\footnotetext{
${ }^{18}$ In hermaphroditic prothallia the reduced group of chromosomes might be supposed to contain both elements that are separated only at the time of formation of the reproductive organs or of their germ cells.
} 
In other words, the sex of the gametes as applied to conjugation has been merged into the sex problem of the sporophyte. At the present time, in fact, several recent theories of sex, as in Castle's latest view, do not hesitate to make a male gamete (sperm) fertilize a male gamete (egg). We meet here with an apparent contradiction in terms by using the same words, male and female, for the higher and the lower forms. The results can be harmonized if we admit that by sex in higher animals and plants we refer to a different condition from the sign of the gametes concerned in the act of fertilization. All sperm must then be of one sign ( + or - ), all eggs of the opposite sign (unless reciprocal fertilization be assumed). But on the view that the female (or the male) is heterozygous in regard to its gametes, i. e., a + (or a-) gamete may carry either a male or female sporophore-determinant, what then determines the sign of the gametes? This question is left unanswered or ignored. Evidently the result cannot depend on its association with the male or the female since no such relation is recognized on this view.

\section{MENDELIAN TREATMENT OF THE SEX PROBLEM}

The presence in animals and plants of two kinds of individuals, males and females, has led to several attempts to explain their presence according to Mendel's Law. Sex is treated as a unit character not different from other unit characters in its heredity. Correns' experiments give the best basis for an explanation along these lines. The more speculative writings of others will be considered later.

Bryonia alba is monœcious; Bryonia dioica is diøcious.

I When the female plants of dioica were fertilized with pollen from alba all the plants were female. Correns concludes from this result that the diocious condition (with only one sex on one plant) dominates the monœcious condition; and since the resulting plants are always of the same sex, the eggs through which the diœcious condition was introduced must have been all of one kind -female producing.

2 The normal combination of $\mathrm{B}$. dioica $+\times$ dioica or produces females and males in equal numbers. The result shows 
that the egg cell of dioica fertilized by pollen from a male plant of the same species produces two kinds of offspring. Combining this result with the first experiment ( $\mathrm{I}$ ) it is certain that the egg cells have a definite sex-tendency, but that the product of their fertilization is not necessarily of the same sex; otherwise all the offspring in both experiments must have been female.

3 When Bryonia alba $\&$ was crossed with $B$. dioica $\sigma^{7}$ half of the offspring were male and half female. Again it is evident that the monocious condition (males and females on the same individual) is recessive to the diøcious condition. It follows that the decision in regard to sex rests with the male cells. The male germ cells of B. dioica cannot be all of the same sex, for the offspring would then be of one sex only, because it is certain that the female germ cells of $B$. alba are all alike.

Correns' scheme may be summed up by saying that the male is heterozygous, i. e., it contains both the male and the female tendencies; when the spermatozoa are produced there is a separation of the sex characters and spermatozoa with male and female tendencies result; the female is homozygous and all of her eggs have the female tendency; when a female egg is fertilized by a female sperm a homozygous female results; when a female egg is fertilized by a male sperm a heterozygous male results owing to the dominance of the male character.

Correns' conclusion agrees with that in the insects in so far as two kinds of sperm are assumed that determine the sex of the offspring, but the results are not in harmony with the facts for the phylloxerans, aphids, hydatina, daphnians and some other parthenogenetic forms, because here the fertilized egg produces a female which must therefore be dominant since from it both males and females are produced later. Appreciating the difficulty in the case of the bee, Correns tried to escape from the position to which his view leads him if applied here by assuming that there are two kinds of eggs-male (parthenogenetic) and female (sexual) eggs. Even if it be granted that Dzierzon's theory for the bee is not conclusively proven, yet the facts seem almost overwhelmingly in favor of that interpretation.

In connection with Mendelism and sex, Bateson, Punnett, 
Doncaster, Raynor and Durham have brought forward some astonishing facts connected with the assumption of certain characteristics by one or the other sex and their transmission. The evidence is too complicated to go into here but the assumptions necessary to account for these results throw important light on sex as determined by one or by the other parent. Experiments along these lines bid fair to give a further insight into the problem.

Doncaster based his first interpretation of the facts for Abraxas on the assumption that each sex gives off male and female bearing gametes, and on the further assumption that in the first generation there is a coupling so that the male ova bear the A. grossulariata character and the female ova the A. lacticular character; further that in the gametes of the male there is no coupling, that after fertilization dominance attaches to the sex brought in by the ovum.

Bateson and Punnett have simplified this hypothesis and explained the facts by two (three) assumptions; ( 1 ) that the female is heterozygous for sex, the male homozygous; (2) that femaleness is dominant to maleness; (3) that in the first generation whenever the two dominants, femaleness and the grossulariata coexist there is a repulsion between them so that each cell gets one or the other of these factors, not both. Here the assumption made for the insects on the basis of primordia determining sex is reversed, the female is heterozygous in the moth according to Punnett and Bateson, and the male, according to the McClung-Stevens-Wilson hypothesis. Wilson asks, apropos of Bateson's and Punnett's view, if the male is homozygous what is the meanig of the formation of two kinds of spermatozoa in many insects? In the case of the bee the contradiction is even more inexplicable without a further assumption. One escape would be to deny that the accessory chromosome, which alone gives a difference in the two kinds of sperm, has anything to do with sex determination, yet a definite relation between that chromosome and sex has been demonstrated and it is difficult to believe that this constancy has no relation to sex determination. Another way out of the dilemma would be to assume that in some cases the discriminating factor lies in the male and in other cases in the female. Here the facts for Phylloxerans furnish the data to support such a view. The parthenogenetic egg contains the possi- 
bilities of producing both sexes. In Mendelian language the $\mathrm{cgg}$ is heterozygous. In the male on the other hand we also find two kinds of sperm, one of which becomes functional. This functional sperm is that which corresponds obviously to the female-producing sperm of other insects, since it carries the accessories. It is significant therefore to find the corresponding male-producing sperm nonfunctional. The case shows how either the egg or the sperm may contain the discriminating factors. It is interesting to note that neither Stevens nor Dederer has found an accessory present in the spermatogenesis of Lepidoptera. It must exist in the female, if an unpaired chromosome occurs in this group.

On a quantitative interpretation, the male or the female is "heterozygous" in a sense different from that in which this term is generally used in Mendelian parlance. Heterozygous does not mean that the female contains the male and female "unit characters" that are separated in the eggs, but that a differential factor exists - an extra chromosome that is neither a male nor a female "unit character." If it is present two possibilities may be realized, if absent only one, but in either case the material of the egg has always a dual potentiality that is realized in sex; therefore all eggs and all sperm are capable of producing both sexes if the proper conditions for their realization are supplied. It is especially this conception of the problem that seems to me very important and which is liable to become obscured when the Mendelian term heterozygous is applied to sex. How far this same conception may be applied wherever alternative conditions exist in Mendelian inheritance remains for the future to decide. It is not, I think, without advantages, even when applied to this broader aspect of the problem of discontinuous inheritance.

One of the first attempts to apply Mendel's Law to sex was that of Castle in I903. ${ }^{19^{\prime}}$ He assumed two kinds of spermatozoa, male and female, and two kinds of eggs, male and female: The male sperm can only fertilize a female egg, and a female sperm can only fertilize a male egg. The separation of male from female qualities was supposed to take place at the second reduction divi-

\footnotetext{
${ }^{19}$ Strasburger and Bateson had previously suggested the possibility of such an application, and in fact Mendel's letters shows that he had considered also this view as a possibility.
} 
sion, in both cases. On the Mendelian scheme any sperm may fertilize any egg, but if this applied to sex, as Castle points out, there would be three, not two sorts of individuals, but selective fertilization while avoiding this difficulty runs foul of another one, because all the fertilized eggs will be sex hybrids, i.e., all alike each having resulted from the combination of male and female. In other words, while the theory accounts for the combination of male and female characters in every individual, it fails to account for those factors that determine sex, i. e., the sex of the individual that arises from the egg. It is this problem that is the primary requirement of a theory of sex determination. It was obviously impossible at that time to account for the sex of the individual by referring the results to the egg alone or to the sperm alone, for, besides being inconsistent with some of the views adopted for special cases, this assumption would be directly opposed to the Mendelian theory of heredity which assumes that the dominance or recessiveness is due to the intrinsic properties of each character and does not depend on whether it is at the time carried by the sperm or the egg.

Castle argues that "the strongest evidence of the latency of each sex in the other is afforded by the transmission through one sex of the characters of the other. Thus, as Darwin states when the domestic cock is crossed with the hen pheasant, the male offspring have the secondary sexual characters of the male pheasant; these, manifestly, must have been inherited through the female pheasant." There is possibly a fallacy in this argument. The facts only show however that the secondary sexual characters of plumage, etc., of the pheasant are transmitted as dominant characters to the hybrids both male and female.

SEX DETERMINATION AS THE RESULT OF A QUANTITATIVE RELATION

In attempting to sum up in 1903 the evidence, then recent, as to the factors of sex determination, I pointed out that while the newer facts showed that sex was early determined in the germ cells, they did not warrant the conclusion that "the male and female primordia" in the germ cells are separated, but that at first 
neither sex alternative is realized, and that the conditions internal or external to which the germ cells are exposed determine which one comes to the front. Later in 1905-1906 I argued that the determinative conditions are found within rather than without the germ cells, and in the case of the bee the determinative factor seemed to depend on whether one or two nuclei made up the segmentation nucleus. If the egg was fertilized the presence of two nuclei determined that the female condition evolved; if the egg was unfertilized, the single egg nuclei determined that the male condition developed. In the case of the hybrid gynandromorphs described by Toyama an analysis of the results (1907) seemed to show very clearly that a single nucleus derived from a male sperm likewise produced male parts. This case furnished strong evidence in favor of the view that the results are purely quantitative, and are not the outcome of maleness or femaleness, as such, attached to the egg or sperm.

This same point of view advanced for a special case was expanded two years later (1907) in my Experimental Zoölogy into a general theory of sex determination for those forms in which the two sexes had been found to contain more or less chromatin, especially for insects with an accessory, and for cases like the bee in which one nucleus stands for the male, two for the female. At that time I tried to lay special emphasis on the point that the male and the female condition represent alternative possibilities of the protoplasm, which one being realized depending on a quantitative factor in the cases under discussion. In other words that there is not a "segregation" of male from female in the gametes, but some orher process which leads to the development of one or the other sex. This point of view looks upon maleness and femaleness as inherent properties of the protoplasm, alternative as to the nature of their development. Special factors condition sex in the sense that they determine sex, but are not sex "determinants" in the Weissmannian sense.

In the light of the most recent results we face the further question as to whether these quantitative factors are only more or less chromatin or more or less of a particular kind of chromatin residing in special chromosomes. An answer to this question 
involves the whole problem of the nature of the chromosomes themselves - a question about which we know at present almost nothing. If the size differences of the chromosomes means that they are qualitatively different, then the probable answer is that the quantitative difference depends on more of a particular kind of chromatin. But if the size differences of the chromosomes has only a genetic meaning and they are qualitatively identical or very similar, the probable answer is that the result is merely more chromatin.

The case of Acholla multispinosa described by Payne, in which the single $\mathrm{Y}$-element is quantitatively greater than the five chromosomes that form the $X$ group (the mates of $Y$ ), may seem to be demonstrative in favor of the view that the result is not quantitative but qualitative. But even here we do not know whether five separate chromosomes might not be more active than the same material contained in one chromosome. Tempting as it is to assume that the quantitative effects are due to the number of the sex chromosomes qualitatively different from the others, the evidence is still too imperfect to decide so important a question. We can safely leave the solution to the future, nevertheless this case of Acholla is extremely important. The single large chromosome is confined to the male line. It seems arbitrary to ignore its function as a male-producing factor in development. The evidence in favor of this view is at least as great as that for the accessory chromosome in other insects, and the main argument for ignoring it is that it does not fit in well with theories based on the accessories alone.

In a recent analysis of the problem Castle proposes a view that has certain points of resemblance to a quantitative hypothesis, and at the same time attempts to make sex inheritance a phase of Mendelism. "The female is the male condition plus a distinct unit character Mendelian in heredity." In support of this view Castle points out how the case of Abraxas can be accounted for on the basis of the special assumptions made by Bateson and Punnett. The essence of Castle's position is that maleness and femaleness are not allelomorphic, but there exists a unit character whose presence produces a female, its absence a male. A further analysis of the 
Abraxas case along these lines shows that Wilson's assumption, based on the chromosomal evidence, that two $X$ 's produce the conditions leading to femaleness, one $\mathrm{X}$ produces the conditions leading to maleness will not explain the results, while the assumption of one $X$ for femaleness and no $X$ for maleness fits in with the observed relations. This interpretation has the advantage of giving a simple explanation for Abraxas. In fact it is little more than the hypothesis of Bateson and Punnett made more general in the sense that it assumes a unit character that determines femaleness, but for this very reason it introduces an interpretation of sex that is extremely hypothetical. For, the unit character is no longer simply a quantitative factor but a special element that has the power of turning maleness into femaleness. It is an entirely imaginary factor and lacks observational evidence in its support. It leads to further assumptions in regard to the secondary sexual characters in the male, supposed to be absent in the female. These are referred to another unit character and it is suggested that this is the Y-element of Wilson. If so, such characters should be absent when $\mathrm{Y}$ is absent, which appears not to be the case. In so far as the view rests on a quantitative conception of sex determination it contains elements that are in harmony with the views here discussed, but in so far as it calls for a Mendelian element whose presence turns maleness into femaleness it meets with serious difficulties and must make further hypothetical assumptions for its support. One of its more serious drawbacks we have already referred to, namely that postulating male and female gametes it assumes that they conjugate without regard to their condition as sex-bearers, male fertilizing male at times, etc. This difficulty might be met by assuming that the unit character for sex (sporophyte) has nothing to do with the conjugation properties of the gametes and the signs male and female are used only as symbols for the presence and absence of this differential character. But such a view ignores the conjugating element itself whose signs cannot be explained on the assumption, here adopted, of their determination by their association with the sex element.

We owe to Wilson the most complete analysis of the present evidence relating to sex determination. His conclusion is based 
on the evidence that "half the spermatozoa are characterized by the presence of a special nuclear element which I shall call the 'X-element' while the other half fail to receive this element." In the simplest case the $\mathrm{X}$-element is a single chromosome. In other cases the $\mathrm{X}$-element is the larger of a pair of chromosomes -the smaller called the Y-element. In still other cases the X-element may be represented by two or more chromosomes. Comparison of the somatic number of chromosomes in male and female shows that the X-element (whether a single chromosome or more than one) "is present as a single unit in the male while in the female it is doubled."

Wilson provisionally formulates the following theory. "Males are produced from zygotes that contain but a single $\mathrm{X}$-element; females from those that contain two such elements." In ordinary sexual reproduction all the fertilized eggs should after maturation bear the male tendency because one X-element is left in the egg after reduction. If capable of parthenogenesis with the reduced or haploid number of chromosomes, such eggs should produce males, as appears to be actually the case in the bees and ants. If fertilized by a spermatozoon that lacks the $\mathrm{X}$-element, the egg still produces a male for the same reason. If fertilized by a spermatozoon that contains the $\mathrm{X}$-element, the egg produces a female because of the introduction not of a dominant "female tendency" but of a second X-element.

Wilson points out that there may exist also other factors still unknown and calls attention to the formation of the asexual spores in mosses where there occurs an "apparent disjunction of the sexual tendencies" since these spores contain the reduced number of chromosomes. Nevertheless "we are led to suspect.

from the facts known in animals that the male-producing spores may be characterized by the absence of some element that is present in the female-producing ones." This difficulty is now considerably lightened by the discovery of Baltzer (see below) that in the sea urchin there may exist a pair of chromosomes of unequal sizes associated with sex. If such exist in the mosses their separation at reduction might lead to the formation of two kinds of spores, even if both have the same number of chromosomes. The question, 
after all, is one of relation, and not one of absolute numbers. In any cycle there may appear a stage when the separation of the factors that determine sex is brought about and in each species this relation may have become adapted to the presence or absence of certain quantitative or qualitative factors. It is not, therefore, for all cases a question of the haploid or the diploid numbers, or of one or two X's, or of one X or no X, but in each particular case certain factors turn the scale one way or the other.

Boveri has recently described some observations of one of his students, Baltzer, on the egg of the sea urchin showing that two kinds of eggs exist. Half of the eggs have two hook-shaped chromosomes the other eggs have one hook and a homologous rod-shaped chromosome. All the sperm contain a hook and a rod-shaped chromosome. Sex is determined by the egg; in the sense that the egg with the particular hook-shaped chromosome, fertilized by a sperm, gives a female with the rod and the hook-shaped chromosomes as a pair; the egg with the rod-shaped chromosome fertilized by a sperm gives a male with a pair of rods. The result is due in Boveri's opinion to the greater activity of that fertilized egg and its derivatives that contains the rod and the hook-shaped chromosomes, owing to the greater volume of this combination, as compared with the activity of an egg containing the two hook-shaped chromosomes. To the "sex chromosomes" is ascribed no different sex tendencies, but the result is due to greater activation.

\section{GYNANDROMORPHISM}

The appearance of male and female parts in the same individual has been frequently described especially for the insects. I have offered elsewhere a suggestion as to how this condition may arise. It remains only to bring this suggestion in line with the present points of view.

If sex-determination be looked upon as a quantitative factor only, gynandromorphism in such forms as the bee may be accounted for as follows: Two (or more) sperms entering the egg one only fuses with the female pronucleus. Their combined 
product gives rise to female parts; the other sperm (or sperms) also developing, give rise to male parts. If in the bee, as in the phylloxerans, the sperms are all of one class, no such complications arise in these cases as might theoretically arise if gynandromorphism should appear in a species having two kinds of sperm, one with, the other without, an accessory. Here two categories of cases appear. If any egg can be fertilized by any sperm, i. e., no selective fertilization occurs, then, should the female-producing sperm enter and fuse with the egg pronucleus, the resulting parts would be female -if another such sperm also entered at the same time, but did not fuse, it would give rise to male parts. Should this other sperm be a "male-producing sperm," so called, it might either produce male parts for all we know to the contrary, although it has no accessory, or else it might not produce normal development of any kind.

On the theory of selective fertilization the following scheme would give the results:

If a female egg carrying the female determinant be entered by more than one sperm carrying the male determinant and one combines with the nucleus, the parts that result from this combination will become female (since the female determinant dominates) the other sperms can produce male parts, hence an hermaphrodite results. But if a male egg (carrying the male determinant) be entered by more than one female sperm carrying no sex determinant, the derivatives of the combined nucleus will produce a female and that derived from the male sperm will produce male parts.

There is still another way in which gynandromorphism may be regarded. If one sex is heterozygous the simultaneous but independent development of dominant and recessive characters would produce gynandromorphism; which could occur only in that sex that is heterozygous. Should both sexes produce gynandromorphs, the result would mean either that both sexes are heterozygous; or that abnormal fertilization, as explained above, is responsible for the effects.

The following evidence on the effects of castration have a bearing on the problem of sex.

It has been shown for the mammals and birds especially that 
removal of the ovaries at an early age causes the development of "male" characters (somatic). The result shows unmistakably that the female in these groups has the capacity to produce both secondary sexual characters. It is also sometimes claimed that castration causes the male to develop the characters of the female, and in favor of this view the retention of the high voice by eunuchs and the absence of a beard have been supposed to indicate an approach to the female. It is, however, evident that these are juvenile characters, and that castration has only suppressed the complete development of the male. Other cases have been cited that seem to their authors to show an approach to the female type, but the evidence is not as convincing as that in the case of the female. In the insects there seems to be no correlation between the development of the secondary sexual characters and the sexual organs, so that we cannot test the nature of the individuals in this way.

In the crabs the evidence is as follows:

In the crustacea (Carcinus, Inachus, Stenorynchus) there are certain facts according to Geoffrey Smith connected with parasitic castration that have been interpreted to mean, that the male assumes the secondary characters of the female when the testes are destroyed. Instead of the narrow abdomen of the male, the infected males have a broad abdomen more like that of the female، and the copulatory abdominal appendages of the male are wanting. Instead the corresponding parts are biramous like those of the female. It may appear, therefore, that the male is heterozygous and produces the female character when the male organ is suppressed. But the facts might possibly be interpreted in another way. The broad abdomen of the castrated male might be considered to correspond to the juvenile state. The only external structure cited by Smith that might seem to indicate that the characters of the castrated males are female rather than juvenile ones is the presence of hairs on the abdominal appendages of Inachus, absent in the young crab, but present in the adult female. Such evidence would not in itself be conclusive, since the presence of hairs may be due to increase in size or to a later moult rather than to latent female characters. The claws of the male of Inachus also differ from those of the female, but here again the 
claws of the castrated male seem to be in most respects as like the juvenile claws as they are like those of the female.

A number of infected crabs showed a condition of hermaphroditism, having, for example, the broad abdomen but with copulatory styles on it. Smith concludes "that the male sex and probably the male sex alone can be so radically modified in its sexual nature as to assume a perfect external hermaphroditism." If, on the contrary, we assumed that we have here not hermaphroditism but an imperfect development of male characters combined with the juvenile condition, we might offer a plausible explanation of the facts.

On the other hand two considerations of great weight point in the opposite direction. Smith found several cases in which the parasite had left the host and the latter had recovered. In such cases a perfect hermaphroditic gland regenerated that produced both spermatozoa and ova. One individual had developed both oviducts and vasa deferentia. This fact alone would demonstrate that the male crab is in reality heterozygous.

Infected females never show the male characters, as is the case in castrated vertebrates, even when the ovary is completely removed. This might seem to show that in the crabs the female is homozygous, at least if the evidence for the vertebrates is logically applied to the crabs. There is, however a curious point here, seldom, if ever, noticed. Why should one expect, if both sexes have dual possibilities, that the destruction of the ovary causes the male characters to appear and the destruction of the testes the female? I see no logical grounds for such an expectation.

THEORETICAL DISCUSSION

In the unsettled condition of the evidence it is obvious that the problem of sex-determination has by no means reached a satisfactory solution. It is equally clear that a large amount of data is rapidly accumulating that promises to furnish an insight into the conditions that regulate sex. The evidence furnished by the phylloxerans shows that the parthenogenetic egg of the female has the dual capacity of producing either males or females. There 
is little to show that these parthenogenetic females, prior to the reduction divisions, differ essentially from ordinary females. It is a fair inference perhaps, that in some cases at least the sexual female may contain dual possibilities.

The spermatogenesis of the phylloxerans shows that two classes of sperms are produced and it is significant, I think, to find that the class of functional sperm corresponds to that class in other insects that is "female-producing." This means only that this combination gives rise to a female, not necessarily that the sperm carry female determinants.

In fact the analysis of the results if based on the assumption of male and female determinants demands that the "female-producing sperm" carry the male determinant. Such sperm would introduce into the sexual egg those elements which, after being carried through one or more parthenogenetic generations, make possible the production of males. The only clue as to what these elements might be is found in the accessory chromosomes. The following situation then develops: The accessories left in the sexual egg must be the female accessories; the functional sperm brings in the male accessories. It follows that the male-producing parthenogenetic egg must have eliminated its female accessories in order to produce a male. There are then two (pairs of) female-producing chromosomes and one (pair of) male-producing. At the time of extrusion of the polar bodies in the male egg of the phylloxerans, the two female accessories must always be thrown out and the two male accessories retained. Conversely for the sexual egg. Extending the same reasoning to other insects with accessories it follows that the "female-producing" sperm contain the male accessories. Such sperm must fertilize eggs containing the female accessories and produce the heterozygous female. The sperm without the accessory must fertilize an egg containing the male accessories and produce the homozygous males. This means selective fertilization.

Such seems to me to be at present the logical outcome of the assumption that the accessories are sex-determinants if their determination is a qualitative process.

Several objections to this view have been already urged and 
need not be repeated here in extenso. The most serious one is that although the hypothesis is ostensibly based on the presence of certain chromosomes which are assumed to be male and female determining respectively, yet to these chromosomes, which are to all appearances identical are ascribed exactly opposite functions; and in order to make the scheme workable it must further be assumed that selective fertilization occurs - a process still unproven.

For these and other reasons, sufficiently discussed in the preceding pages, it seems more probable that the relation of these chromosomes to sex may be a quantitative one. This interpretation I urged especially two years ago in my general treatment of the problem of sex in my Experimental Zoölogy. The same view I had previously argued in the special case of the bee, and in the case of gynandromorphism in the bee and silk-worm moth. I shall repeat here, therefore, in conclusion, the essential part of the general argument advanced in the Experimental Zoölogy. It was pointed out that we can explain the cases in which an accessory is present on the assumption that the sperm with the accessory brings more chromatin into the egg than does the sperm without that chromosome. In the bee the result is due to two nuclei leading to the formation of a female, one to the formation of a male. I pointed out that on this view sex is not laid down in the egg or sperm but is determined later by quantitative relations that appear as a result of certain combinations. The objection to this view is found in those cases where no accessories exist, but even here the recent results of Baltzer show that differences between the pair of sex chromosomes may still be present. It remains to be discovered whether this relation holds in general or not. It would obviously go beyond the evidence to assign the determination of sex to differences in the chromosomes in those cases where no difference has been observed. The remarkable cases here described for Phylloxera fallax show that the determination of male and female lines may take place in the presence of all the chromosomes. We have in this case strong evidence in favor of the view that other processes than the number of chromosomes may initiate changes that ultimately lead to the production of one or the other kind of individuals. For obviously it is as important to discover what 
factors determine that one winged migrant produces only female eggs and another only male eggs, as it is to determine maleness and femaleness itself.

"The average equality of males and females indicates, I think, that external conditions do not regulate the results but that some internal physiological mechanism exists that determines the sex. Of course this statement does not exclude the possibility that external influences may determine that the internal mechanism shall become active in one way or another, as seen in the cyclical modes of reproduction. This physiological mechanism does not involve the separation of male and female elements or units in the egg and sperm but only involves the production of those conditions that determine whether one or the other sex will develop." In the group of insects these conditions seem to be connected with the accessory chromosomes as quantitative factors. Their separation does not involve in itself the separation of maleness from femaleness, but the separation of one special chromosome in such a way that two classes of individuals result after fertilization. Possibly the same conditions may be brought about in other ways in other animals.

"It seems not improbable that this regulation is different in different species, and that therefore it is futile to search for any principle of sex determination that is universal for all species with separate sexes; for while the fundamental internal change that stands for the male or the female condition may be the same in all uni-sexual forms, the factor that determines which of the alternative states is realized may be very different in different species." If this point of view justifies itself, the problem of sex determination resolves itself into a search for those factors that turn the balance towards one or the other of the two possible alternatives. Let us not forget that while approximate equality of male and female is for many species the general result, it is not true for the output of special individuals, and also not true for certain species in which an excess of one or the other sex exists. Nowhere is this better seen than in the offspring of the same stem-mother of $P$. caryxcaulis where all may be male producers or all female producers. 
The quantitative interpretation of sex-determination is only the first rough approximation, I think, to a solution. It is valuable because it is supported by a large number of observations in which such a quantitative difference is apparent. But there is nothing in these facts that shows that the effects are directly quantitative rather than that observable quantitative differences accompany, or follow in some cases, more profound changes. It should not be forgotten, moreover, that the quantitative differences have been found in only a relatively small number of cases; that they are absent in others, and that in such cases as the male and female eggs of phylloxerans where size differences exist in the egg as a whole-differences that appear directly associated with the formation of the male and the female-the differences originate in the presence of the entire number of chromosomes. The loss of certain chromosomes from the male egg appears to follow, not to precede the size relation. These considerations may arouse a suspicion at least that it is not chance that determines to which pole the accessory chromosome moves when it is present, but that its pole is predetermined. At least the facts here described for the phylloxerans and aphids may be urged in support of this view. If such differences already exists between the two daughter sperms these differences may subsequently be as intimately connected with the sex of the embryo as the accessory itself. The accessory may follow sex or be associated with other differences that determine sex rather than be its sole cause.

\section{LITERATURE CITED.}

Beard, F.-The Germ Cells. Zoöl.Jahr., xvi, Igo2.

Von BAEHR, W. B.-Ueber die Bildung der Sexualzellen bei Aphididæ. Zoöl. Anz., xxxiii, 1908 .

Baltzer, F.-Ueber die Grösse und Form der Chromosomen bei Seeigeleiern. Verhand. Deut. Zoöl. Gesell., rgo8.

Benda, C.-Das Problem der geschlechtsbestimmenden Ursachen. Deutsch. med. Wochenschrift, 1903. 
Blakeslee, A. R.-Sexual Reproduction in the Mucorina. Proc. Am. Acad. Arts and Sciences, $\mathrm{xl}, \mathrm{1904}$.

Differentiation of Sex in Thallus, Gametophyte and Sporophyte. Botal. Gaz.., xlii, 1906.

Blochmann, F.-Ueber die Richtungskörper bei unbefruchtet sich entweckelnden Insekteneiern. Verl. Natur. med. Ver. Heidelberg, iv, I889.

Boveri, Th.-Ueber die Beziehung des Chromatins zur Geschlechts-Bestimmung. Sitz. Phys. med. Gesell. Würzburg, December, I908.

Brewster, E. T.-Note on the Determination of Sex in Man. Amer. Anthropologist, viii, Igo6.

Castre, W. E.-The Heredity of Sex. Bull. Mus. Comp. Zoöl., xl, 1903.

A Mendelian View of Sex Heredity. Science, March 5, 1909.

Correns, C.-Die Vererbung der Geschlechtsform bei den gynodiöcischen Pflanzen. Ber. Deutsch. Botan. Gesell., xxiv, Igo6.

Die Bestimmung und Vererbung des Geschlechtes. Berlin, 1907.

Cú́not, L.-Sur la Détermination du Sexe chez les Animaux. Bull. Sci. France et Belg., xxxii, r899.

Doncaster, L.-On the Maturation of the Unfertilized Egg and the Fate of the Polar Bodies in Tenthredinidæ. Q. J. Mic. Sc., xlix, 1906.

Gametogenesis and Fertilization in Nematus Ribesii. Q. J. Mic. Sc., li, r9o7.

Hertwig, R.-Ueber das Problem dez sexuellen Differenierung. Verh. Deutsch. Zool. Gesell., I905.

Weitere Untersuchungen ueber das Sexualitätsproblem. Verhandl. Deutsch. Zool. Gesell., rgo6.

Ueber Knospung und Geschlechtsentwickelung von Hydra fusca. Biol. Centrlbl., xxvi, 1906.

Henking, H.-Untersuchungen über die ersten Entwickelungsvorgänge in den Eiern der Insecten. Zect. wiss Zool., li, I8go.

Issakowirsch, A.--Geschlechtsbestimmende Ursachen bei den Daphniden. Biol. Centrlbl., xxv, Ig05.

KING, H. D.-Studies on Sex Determination in Amphibians. II. Biol. Bull., xvi, I9og.

Lams, H.-Les Divisions des Spermatocytes chez la Fourmi. Arch. f. Zellfor., i, 1908.

LaUterborn-Ueber die cyclische Fortpflanzung limnetischer Rotatorien. Biol. Centrlbl., xviii, ı898.

Lenssen-Contribution à l'étude du developpement et de la maturation des eufs chez Hydatina senta. La Cellule, xiv, I898.

McClung, C. E.-The Spermatocyte Divisions of the Acridida. Kan. Univ. Quart., ix, rgoo. 
McClung, C. E.-The Accessory Chromosome-Sex Determinant ? Biol. Bull., iii, 1902.

Von Marsen.-Geschlechtsbestimmende Einflüsse und Eibildung des Dinophilus apatris. Arch. f. mikr. Anat., lxix, 1907.

Marchar, Elie et Emile-Recherches expérimentales sur la sexualité des spores chez les mousses dioïgnes. Acad. Roy. de Belgique, Deuxieme Series, Tome I, 1906.

Mark, E. L., and Copeland, U.-Maturation Stages in the Spermatogenesis of Vespa maculata. Proc. Am. Acad. Arts and Sci., xliii, 1907.

Meves, Fr.-Ueber Richtungskörperbildung im Hoden von Hymenopteren. Anat. Anz., xxiv, I903-I904.

Die Spermatozytenteilung bei der Honigbeine. Arch. f. mikr. Anat., Ixx, I907.

Meves, Fr., und J. Duesberg-Die Spermatozytenteilungen bei der Hornisse. Arch. f. mikr. Anat., lxxi, rgo8.

Montgomery, T. H.-The Spermatogenesis in Pentatoma up to the Formation of the Spermatid. Zoöl. Jahrb., xii, 1898 .

Morgan, T. H.-Recent Theories in Regard to the Determination of Sex. Pop. Sci. Mon., December, I903.

An Alternative Interpretation of the Origin of Gynandromorphous Insects. Science, xxi, rgo5.

Ziegler's Theory of Sex Determination and an Alternative Point of View. Science, xxii, 1905.

The Male and Female Eggs of Phylloxerans of the Hickories. Biol. Bull., x, 1906.

The Biological Significance and Control of Sex: Sex Determining Factors in Animals. Science, xxv, 1907.

The Cause of Gynandromorphism in Insects. Amer. Naturalist., xli, 1907 .

Experimental Zoölogy. I9o7.

The Production of Two Kinds of Spermatozoa in Phylloxerans-Functional "Female Producing" and Rudimentary Spermatozoa. Proc. Soc. Exp. Biol. and Med., v, 1908.

Sex Determination and Parthenogenesis in Phylloxerans and Aphids. Science, February 5, I908.

Musson, J. P.-Spermatogenesis of the Butterfly, Papilio Rutulus. Proc. Bost. Soc. Nat. Hist., xxxiii, 1 go6.

Newcoms, S.-The Probability of Causes of the Production of Sex in Human Offspring. Carnegie Institution, 1904.

Nussbaum, M.-Die Geschlechtsentwickelung bei Polypen. Sitz. Niederrhein. Gesell., I 892 . 
Nussbaum, M.-Die Entstehung des Geschlechts bei Hydatina senta. Arch. mikros. Anat., xlix, 1897 .

Pergande, T.-North American Phylloxerinæ Affecting Hicoria (Caraya) and other Trees. Proc. Davenport Acad. Sci., ix, I904.

Petrunkewitsch, A.-Die Richtungskörper und hr Schicksal im befruchteten und unbefruchteten Bienevei. Zool. Jahr., xiv, I901.

Punnett, R. C.-Sex Determination in Hydatina with some Remarks on Parthenogenesis. Proc. Roy. Soc., lxxviii, 1906.

Punnetr, R. C., and W. Bateson-The Heredity of Sex. Science, xxvii, 1908.

Quajat, T.-Nuove ricerche dirette a constature il sesso delle uove e considerazioni sul metodo Ichiwata per la separazione delle larve.

SchleIP, W.-Die Richtungskörperbildung im Ei von Formica sanguinea. Zoöl. Jahrbuch, xxvi, I908.

Silvestri, F.-Contribuzioni alla Conoscenza Biologica degli Imenotteri Parassiti. Bull. Zoöl. agrar Portici, iii, rgo8.

Smrth, G.-Rhizocephala. Fauna und Flora. Neapel., Igo6.

Stevens, N. M.-A Study of the Germ Cells of Aphis rosa and Aphis oenotheræ. Jour. Exp. Zoöl., ii, 1904.

Studies on the Germ Cells of Aphids. Carnegie Institute, Igo6.

An Unpaired Chromosome in the Aphids. Jour. Exp. Zoöl, vi, 1909.

Strasburger-Chromosomezahlen, Plasmastructuren, Vererbungsträger und Reductionsteilung. Tahrb. wiss. Botanik, xlv, 1908.

Surton, W. S.-The Spermatogonial Divisions of Brachystola magna. Kan. Univ. Quart., ix, 1900.

Tanneeuthrr, G. W.-History of the Germ Cells and Early Embryology of Certain Aphids. Zool. Jahr. xviv, I907.

Wheeler, W. M.-The Origin of Female and Worker Ants from the Eggs of Parthenogenetic Workers. Science, December, r9o3.

Whrtney, D. D.-The Influence of External Factors in Causing the Development of Sexual Organs in Hydra viridis. Arch. Entwick, Mech., xxiv, 1907 .

Determination of Sex in Hydatina senta. Jour. Exp. Zoöl., v, 1907.

Observations on the Maturation Stages of the Parthenogenetic and Sexual Eggs of Hydatina senta. Jour. Exp. Zoöl., vi.

Wirson, E. B.-Studies on Chromosomes, I-V. Jour. Exp. Zoöl., ii-vii, 1905-1909.

Recent Researches on the Determination and Heredity of Sex. Science, xxix, Igog.

The Female Chromosome Groups in Syromastes and Pyrrhocoris. Biol. Bull., xvi, rgog. 
Fig. I Male of P. fallax (somewhat compressed).

Fig. 2 Female of P. fallax.

Fig. 3 Male of P. fallax (preserved specimen).

Fig. 4 Female of P. fallax (preserved specimen).

Fig. 5 Male of P. caryacaulis.

Fig. 6 Female of P. caryæacalis.

Fig. 7 Sexual (?) form of P. subelliptica.

Fig. 8 Sexual (?) form of P. caryæglobuli.

Fig. 9 Serual (?) form of $P$. depressa. 


\section{T. H. Morgan}

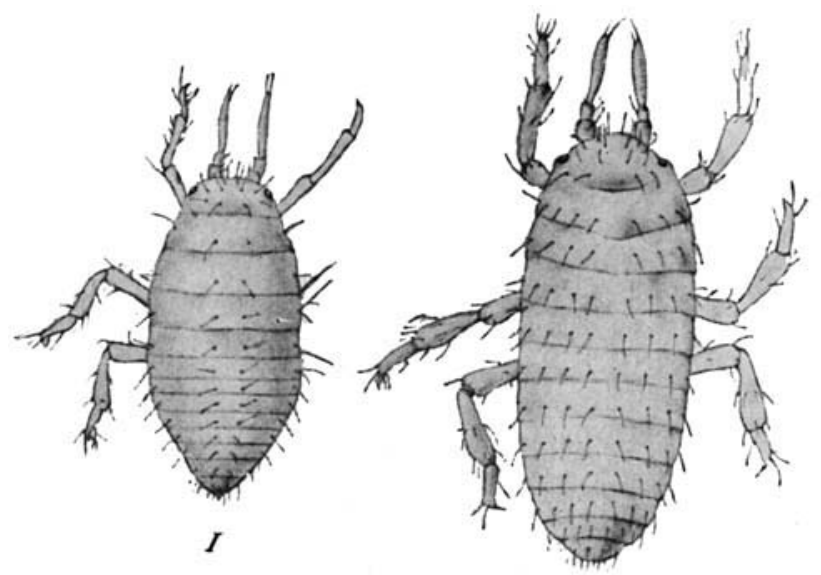

2
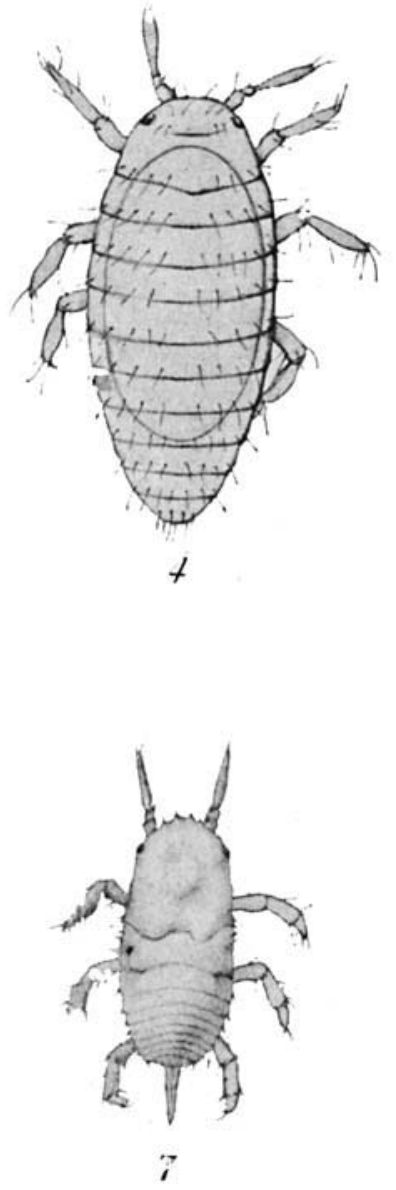

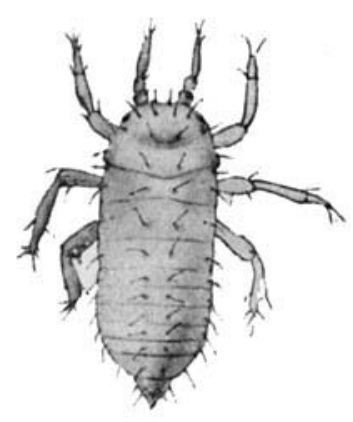

5

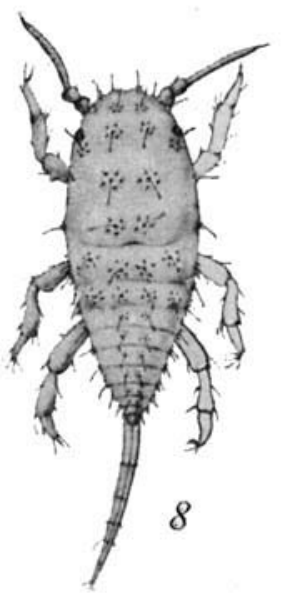

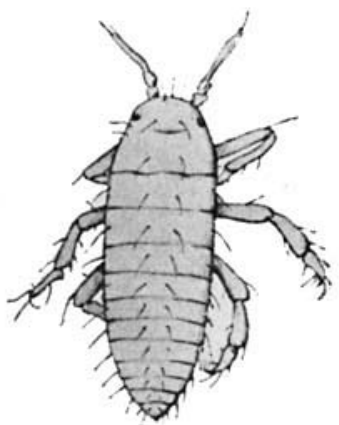

3

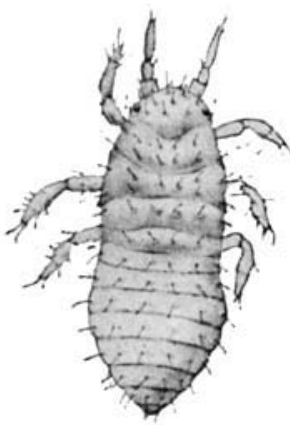

6

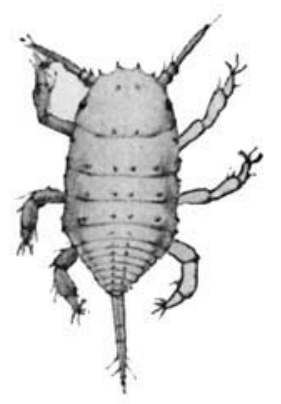

9 